\title{
Ludolf Kuchenbuch
}

\section{Ordnungsverhalten im grundherrlichen Schriftgut vom 9. zum 12. Jahrhundert*}

Inhalt: Einleitung: retexere und intexere 175 - Vorbereitung: Zeugnisse aus dem 11.Jahrhundert (S. Lorenzo/Oulx, St.-Remi/Reims, St.-Dié, St.-Maximin/Trier, St.-Pieter/Gent, St.Père/Chartres) 181 - 9. Jahrhundert 193 - Die Statuta seu Brevia Abt Adalhards von Corbie (822) 195 - Die descriptio mancipiorum von St.-Victor/Marseille (813/814) 203 - Das Polyptychon von St.-Germain-des-Prés (825/828) 206 - Die Brevium Exempla und das Capitulare de villis im Codex Helmstadensis 254 (825/850) 215 - Die Dispositionen und Ordinationen der Reimser Bischöfe (7.-9. Jahrhundert) 218 - Das Prümer Urbar (893) 222 - Der urbariale Mischcodex der Abtei Werden (Ende 9.-11.Jahrhundert) 229 - Zwischenergebnisse 235 12. Jahrhundert 237 - Deskriptive Konkretion (Marchiennes, Münchweier, Muri, Deutz) 239 - Begriffliche und ordinative Systematik (Marmoutier, Werden, Fulda, Lorsch) 246 - Domaniale Rechenhaftigkeit (Suger v. St.-Denis, Heinrich v. Winchester für Cluny) 253 - Schlußbemerkungen 262

\section{Einleitung: retexere und intexere}

Als Bischof Adalbero von Laon gegen 1025 in seinem Carmen ad Robertum regem daran ging, Platz und Leistung des genus afflictum der servi im tripartiten ordines-Gefüge zu charakterisieren, stellte er die folgende Frage: Quis abaci signis numerando retexere possit servorum studium, cursus, tantosque labores? ${ }^{1}$ Gut ein halbes Jahrhundert später (1088) leitete der Mönch Paulus, edituus und notarius

* Ich habe zu danken: den Mitgliedern des Hagener Historikerkolloquiums für gemeinsame ,Arbeit am Begriff', Johannes Fried und den Diskutanten der Tagung im Historischen Kolleg für Weitungen der Perspektive, vielen, am jeweiligen Ort der Untersuchung genannten Kolleginnen und Kollegen für freundliche Beschaffungen und Einsichten, schließlich Jochen Schäfer für Korrektur und Formatierung.

1 Ich gebe den Wortlaut nach der jüngsten, nicht eben besten Edition: Adalbéron de Laon, Poème au roi Robert. Introduction, édition et traduction par Claude Carozzi (Les classiques de l'histoire de France au moyen âge 3, Paris 1979) V.287-8, S.22. Otto Gerhard Oexle, Die funktionale Dreiteilung der, Gesellschaft' bei Adalbero von Laon. Deutungsschemata der sozialen Wirklichkeit im früheren Mittelalter, in: FmSt 12 (1978) 30 erstellt einen anderen Wortlaut für V.287, indem er emendiert und Überschriebenes einfügt. Dies berührt meine Interpretation nicht. Zur Kritik an obiger Edition vgl. Otto Gerhard Oexle, Adalbero von Laon und sein ,Carmen ad Rotbertum Regem'. Bemerkungen zu einer neuen Edition, in: FRANCIA 8 (1980) 629-638. 
der Abtei St.-Père in Chartres, einen Rückblick auf seinen Liber Hagani, den ersten Teil des aus diversen scripta gespeisten und ausführlich kommentierten Kartulars, mit der Bemerkung ein: Quae huc usque novis paginis curavi intexere... ${ }^{2}$

Adalbero und Paulus gehen beide vom Verb texere aus, um die Bewältigung ganz verschiedener geistiger Aufgaben auszudrücken. Adalbero fragt nach einer angemessenen Darstellung der vielen eifrigen, ermüdenden und mühseligen Unterhaltswerke der servi. Daß ihm dabei deren Zählung mit Hilfe von Rechensteinen auf dem Kolumnen-Abakus in den Sinn kommt, darf erstaunen. Denn über dieses Instrument wird erst seit der zweiten Hälfte des 10.Jahrhunderts in gebildeten monastischen Kreisen gehandelt, und man rechnete mit ihm wohl nur im Rahmen des Quadriviums, besonders in der Geometrie. ${ }^{3}$ Doch ist diese wohl neuartige Assoziation der Funktion der laboratores mit der des Abakus hier nicht das Entscheidende. Mir scheint die Affinität, die die Darstellung gerade der Unterhaltsstiftung mit dem Aufräufeln von Verflochtenem, Gewobenem hat, besonders aufschlußreich zu sein. Das vielfältige Gewebe der labores steht als Ausgangsbild vor Augen, wenn deren angemessene Beschreibung (und Abschätzung) zur Aufgabe wird. Paulus dagegen nennt den kompilatorischen Umgang mit den ihm aus den archiva zugänglichen privilegia, cartae und rotuli, für die er immer wieder das Passepartout scriptum zur Verfügung hat, in-texere, verflechten, hineinfügen. Solcher Verbgebrauch beim Erstellen und Benutzen von geschriebenem Wissen über Land und Leute, Rechte und Einkünfte legt die Vermutung nahe, ihre Autoren und Schreiber hätten das Nomen textus für derlei scripta zur Verfügung. Dies ist aber, soweit ich bislang sehen kann, für das frühere Mittelalter nicht der Fall. ${ }^{4} \mathrm{Ob}$ sich diese Vermutung bestätigt und welche Gründe es dafür gibt, bleibt zu untersuchen.

Die Hypothese, daß grundherrliche Schriftstücke im Verständnis der Zeitgenossen keine textus sein könnten - und heutige Forschung deshalb das Text-Etikett für derlei Schriftgut nicht ungeprüft übernehmen sollte -, ist nur ein Indiz für die Situation der Forschung zum Thema meiner Abhandlung. Zwar sind zum Rahmen der auf dieser Tagung nachgefragten ,Bedeutung trivialer Schulung für

2 Benjamin Guérard (Hg.), Cartulaire de l'Abbaye de Saint-Père de Chartres, Bd. 1 (Paris 1840) 43.

${ }^{3}$ Hierzu Werner Bergmann, Innovationen im Quadrivium des 10. und 11.Jahrhunderts. Studien zur Einführung von Astrolab und Abakus im lateinischen Mittelalter (Sudhoffs Archiv Beih. 26, Wiesbaden 1985) $176 \mathrm{ff}$. Mit der „Entwicklung vom praktischen Gebrauch zum wissenschaftlichen Traktat" rechnet Johannes Fried, Kunst und Kommerz. Über das Zusammenwirken von Wissenschaft und Wirtschaft im Mittelalter vornehmlich am Beispiel der Kaufleute und Handelsmessen, in: HZ 255 (1992) 281-316, hier: 283.

${ }_{4}$ Eine wort- und begriffsgeschichtliche Studie zum textus steht noch aus. Erste lexikalische Orientierung vermittelt den Eindruck, daß textus solchen scripta reserviert ist, die wortlautstabil sind und religiöse bzw. rechtliche Kanonisierung hinter sich haben. Das bestätigen auch die kurzen Bemerkungen bei Clemens Knobloch, Zum Status und zur Geschichte des Textbegriffs. Eine Skizze, in: Zs. f. Literaturwissenschaft und Linguistik 77 (1988) 36-65, hier $70 \mathrm{ff}$. Zum Textbegriff der Urkundenlehre (samt Hinweis auf einige textus-Belege in den fränkischen Formulae) vgl. Harry Bresslau, Handbuch der Urkundenlehre für Deutschland und Italien, Bd. 1 (Berlin ${ }^{4}$ 1969) 46. 
die geistige Orientierung und das gesellschaftliche Handeln' (Johannes Fried in seinem Einladungsschreiben) neuere Überblicke durchaus verfügbar. ${ }^{5}$ In Bezug auf engere Sachgebiete oder kleinere Fragen jedoch, gerade solchen zum Tagtäglichen neben Liturgie und Studium, müssen ihre Autoren oft noch kleinlaut bleiben. Dies gilt ganz besonders für die Beziehungen zwischen trivialem Denkstil und ruraler Einkommenssicherung, Wirtschaftsweise und Herrschaftsgestaltung im früheren Mittelalter. Wichtige Anstöße hat hier Johannes Fried gegeben. ${ }^{6}$ Aus den jüngsten orientierenden Überblicken Hagen Kellers zum Umfeld der ,pragmatischen Schriftlichkeit ${ }^{\prime}$ geht hervor, wie wenig die hier ins Auge gefaßten Fragen in der vergangenen und laufenden Forschung thematisiert sind. Untersuchungen, in denen von den Umbrüchen seit dem 12.Jahrhundert ausgegangen wird, heben vorwiegend auf die gegenseitigen Einflüsse zwischen technischen Innovationen, ständisch-partikularem Lebensstil, aktuellen Zeiterfahrungen sowie markt-, geld- und gewinnorientiertem Wirtschaftshandeln ab. ${ }^{8}$ Grundlegend für die Implikationen des sich ausweitenden Schriftbezugs ist M. Clanchys Buch über England. ${ }^{9}$ Neben ihm fehlen aber Parallelarbeiten zu anderen Regionen. Hier entsteht nun Abhilfe durch mehrere Themenschwerpunkte des Münsteraner Sonder-

${ }^{5}$ Alexander Murray, Reason and Society in the Middle Ages (Oxford 1978); Charles $M$. Radding, A World Made by Men. Cognition and Society, 400-1200 (Chapel Hill/London 1985); Brian Stock, The Implications of Literacy: Written Language and Models of Interpretation in the Eleventh and Twelfth Century (Princeton 1983); Johannes Fried, Die Formierung Europas: 840-1046 (Oldenbourg-Grundriß der Geschichte 6, München 1991) 29ff., $139 \mathrm{ff}$. Gesonderte Erwähnung verdient die Habilitationsschrift von Gerhard Otte, Dialektik und Jurisprudenz. Untersuchungen zur Methode der Glossatoren (IUS COMMUNE Sh.1, Frankfurt/M. 1971).

6 Johannes Fried, Vorbemerkungen, in: Akten des 26. Deutschen Rechtshistorikertages: Frankfurt am Main, 22. bis 26. September 1986, hg. v. Werner Simon (IUS COMMUNE Sh. 30, Frankfurt/M. 1987) 395 ff.; aus rechtsgeschichtlicher Sicht von Interesse: Wendy Davies/Paul Fouracre, Conclusion, in: dies. (Hg.), The Settlement of Disputes in Early Medieval Europe (Cambridge 1986) $207 \mathrm{ff}$; ; ein Einzelfall, auf den noch zurückzukommen sein wird: Dieter Hägermann, Der Abt als Grundherr. Kloster und Wirtschaft im frühen Mittelalter, in: Friedrich Prinz (Hg.), Herrschaft und Kirche. Beiträge zur Entstehung und Wirkungsweise episkopaler und monastischer Organisationsformen (Monographien zur Geschichte des Mittelalters 33, Stuttgart 1988) 345-385.

7 Hagen Keller, Die Entwicklung der europäischen Schriftkultur im Spiegel der mittelalterlichen Überlieferung, in: Geschichte und Geschichtsbewußtsein. Festschrift Karl-Ernst Jeismann zum 65. Geburtstag, hg. von Paul Leidinger/Dieter Metzler (Münster 1990) 171-204; ders., Vom ,heiligen Buch' zur ,Buchführung'. Lebensfunktionen der Schrift im Mittelalter, in: FmSt 26 (1992) 1-31; ders., Einführung zum Kolloquium in Münster, 17.-19. Mai 1989, in: Pragmatische Schriftlichkeit im Mittelalter. Erscheinungsformen und Entwicklungsstufen, hg. v. Hagen Keller, Klaus Grubmüller und Nikolaus Staubach (Münstersche Mittelalterschriften 65, München 1992) 1-7.

${ }^{8}$ Z. B. Georges Duby, Hommes et structures au moyen âge. Recueil d'articles (Le savoir historique 1, Paris 1973) $83 \mathrm{ff.}, 203 \mathrm{ff} ., 381 \mathrm{ff}$.; Lester K. Little, Religious Poverty and the Profit Economy in Medieval Europe (Ithaca 1978); Lynn White jr., Medieval Religion and Technology (Berkeley 1978) $217 \mathrm{ff}$.

9 Michael T. Clanchy, From Memory to Written Record. England 1066-1307 (London 1979,

21993). Ich zitiere nach der 2 . Auflage. 
forschungsbereichs, insbesondere die so wichtigen Verschriftlichungsprozesse in den italienischen Stadtkommunen. ${ }^{10}$

Die jüngsten Literalitäts-Studien zum Frühmittelalter sind betont auf die teilweise erstaunlich dicht anmutenden Schriftbezüge in ,law, government, and administration "(d.h. die Urkunden- und Gerichtspraxis) sowie in der Buch-Kultur abgestellt, zielen also mehr auf die politisch-soziale Reichweite des Schrift- und Schriftengebrauchs sowie die Beziehungen zu oral-auralen Lebensvollzügen $a b$, doch beginnt mittlerweile das interdisziplinäre Nachdenken über standes-, gattungs- und wissensspezifische Differenzierungsmöglichkeiten. ${ }^{11}$ Der Bezug der Memorialstile auf die überlieferten artes, besonders die grammatica, wird neuerdings von Janet Coleman herausgestellt. ${ }^{12}$

Neuere Forschungen - im Sinne Erwin Panofskys ${ }^{13}$ - über ,Analogien' von Denkstil und Schrift- bzw. Buchgestaltung, die ihren vielbeachteten Ausgang von frühscholastischen Handschriften genommen haben ${ }^{14}$, sind bislang noch wenig ins frühere Mittelalter zurückverlängert worden. ${ }^{15}$ Die erheblichen Fortschritte,

10 Pragmatische Schriftlichkeit (wie Anm.7) 21-36. Klaus Schreiner, Verschriftlichung als Faktor monastischer Reform. Funktionen von Schriftlichkeit im Ordenswesen des hohen und späten Mittelalters, a.a.O. 37-76, berührt das ökonomische Ordnungsverhalten aus intentionaler zeitgenössischer Sicht (Verschriftlichung der Wirtschaftsverwaltung, seit dem 13. Jahrhundert, 64-67).

11 Rosamund McKitterick, The Carolingians and the written word (Cambridge 1989); dies. (Hg.), The Uses of Literacy in Early Mediaeval Europe (Cambridge 1990); zuletzt dies., Zur Herstellung von Kapitularien: Die Arbeit des Leges-Skriptoriums, in: MIÖG 101 (1993) 316; zum Stand der orality-literacy-Debatte aus literaturwissenschaftlicher Sicht: Ursula Schaefer, Vokalität. Altenglische Dichtung zwischen Mündlichkeit und Schriftlichkeit (ScriptOralia 39, Tübingen 1992) 3-87. Ursula Schaefer $(\mathrm{Hg}$.), Schriftlichkeit im frühen Mittelalter (ScriptOralia 53, Tübingen 1993).

12 Janet Coleman, Ancient and Medieval Memories. Studies in the reconstruction of the past (Cambridge 1992) 113-154.

13 Erroin Panofsky, Gotische Architektur und Scholastik. Zur Analogie von Kunst, Philosophie und Theologie im Mittelalter, hg. u. mit einem Nachwort versehen von Thomas Frangenberg (Köln 1989); Jesse M. Gellrich, The Idea of the Book in the Middle Ages. Language Theory, Mythology, and Fiction (Ithaca/London 1985) 51-92.

$14 \mathrm{Vgl}$. die richtungsweisenden Studien von Malcolm Beckwith Parkes, The Influence of the Concepts of Ordinatio and Compilatio on the Development of the Book, in: Medieval Learning and Literature. Essays presented to Richard William Hunt, hg. v. J. J. G. Alexander und M. T. Gibson (London 1976) 115-141 (nachgedruckt in: ders., Scribes, Scripts and Readers. Studies in the Communication, Presentation and Dissemination of Medieval Texts (London 1991) 35-70 und Richard H. Rouse, Cistercian Aids to Study in the Thirteenth Century, in: John R. Sommerfeldt (Hg.), Studies in Medieval Cistercian History II (Cistercian Studies 24, Kalamazoo 1976) 123-134; ders., L'évolution des attitudes envers l'autorité écrite: le développement des instruments de travail au XIII ${ }^{\mathrm{e}}$ siècle, in: Culture et travail intellectuel dans l'occident médiéval, hg. v. Geneviève Hasenobr/Jean Longère (Centre régional de publication de Paris, Paris 1981) 115-144; Richard H. und Mary Rouse, Statim invenire: Schools, Preachers, and New Attitudes to the Page, in: Renaissance and Renewal in the Twelfth Century, hg. v. Robert L. Benson u. Giles Constable (Oxford 1982) 201-225. Ausgehend hiervon der weitgespannte Essay von Ivan Illich, Im Weinberg des Textes. Als das Schriftbild der Moderne entstand. Ein Kommentar zu Hugos „Didascalicon" (Frankfurt a. M. 1991).

${ }_{15}$ Eher schriftlichkeits- als denkgeschichtliche Ansätze bei: Nigel F. Palmer, Kapitel und 
die die quellenkritische Forschung nach Charles-Edmond Perrin und Wolfgang Metz zu allen für die Grundherrschaft bedeutsamen Zeugnissen aufweisen kann ${ }^{16}$, bleiben noch orientiert an Gattungskonzepten traditioneller Quellenkunde. Aber es mehren sich die Fragen nach den Verschränkungen von Verzeichnissen und Urkunden, nach den Formen von Erstschrift, Reinschrift und Abschrift, von Redaktion, Ergänzung und Überarbeitung für den jeweils vorliegenden Wortlaut, nach dem Gebrauchswert der Hefte, Rollen, Kodizes, die so häufig Mischcharakter haben. ${ }^{17}$ Auch die neuere Kartular-Forschung hat hier ihren Platz. ${ }^{18}$ Die Frage nach

Buch. Zu den Gliederungsprinzipien mittelalterlicher Bücher, in: FmSt 23 (1989) 43-88; Johann Peter Gumbert, Zur, Typographie' der geschriebenen Seite, in: Pragmatische Schriftlichkeit (wie Anm. 7) 283-292; Wolfgang Raible, Die Semiotik der Textgestalt. Erscheinungsformen und Folgen eines kulturellen Evolutionsprozesses; vorgelegt am 21. April 1990, Heidelberg 1991 (Abhandlungen der Heidelberger Akademie der Wissenschaften, Philosophisch-historische Klasse; Jg. 1991, Abh.1) 6f.; Malcolm Beckwith Parkes, Pause and Effect. An Introduction to the History of Punctuation in the West (Cambridge 1992) $20 \mathrm{ff}$., $72 \mathrm{ff}$.

16 Robert Fossier, Polyptyques et Censiers (Typologie des Sources du Moyen Age Occidental 28, Turnhout 1978). Fossier hat seine ganze Argumentation über die Entwicklung der Gattungen an die These gebunden, daß die karolingischen Güter- und Einkünfteverzeichnisse nahezu noch spätantiken, abstrakten Charakter hätten, und erst im 10. Jahrhundert der Durchbruch zum deksriptiven Realismus erfolgt sei. Diese These ist so nicht haltbar. Vgl. zur Karolingerzeit: Ludolf Kuchenbuch, Die Klostergrundherrschaft im Frühmittelalter. Eine Zwischenbilanz, in: Prinz (wie Anm.6) 299 ff.; Yoshiki Morimoto, Etat et perspectives de recherches sur les polyptyques carolingiens, in: Annales de l'Est 40 (1988) 99-149; Dieter Hägermann, Quellenkritische Bemerkungen zu den karolingerzeitlichen Urbaren und Güterverzeichnissen, in: Werner Rösener $(\mathrm{Hg}$.), Strukturen der Grundherrschaft im frühen Mittelalter (Veröff. d. Max-Planck-Instituts f. Geschichte 92, Göttingen 1989) 47-73. Der Stand der Überlieferungskritik für die nachkarolingischen Jahrhunderte ist bis heute noch nicht maßgeblich über Charles-Edmond Perrin, Recherches sur la Seigneurie Rurale en Lorraine. D’après les plus anciens censiers (IX ${ }^{e}-X I^{e}$ siècles) (Paris 1935) bes. 589-625 u. 660-690 hinausgekommen. Sachlich - um die königliche Versorgung - erweitert hat das Überlieferungsfeld Wolfgang Metz, Staufische Güterverzeichnisse. Untersuchungen zur Verfassungs- und Wirtschaftsgeschichte des 12. und 13. Jahrhunderts (Berlin 1964). Vor allem gattungstypologisch weiterführend ist Gregor Richter, Lagerbücher- oder Urbarlehre. Hilfswissenschaftliche Grundzüge nach württembergischen Quellen (Veröff. d. staatlichen Archivverwaltung Baden-Württemberg 36, Stuttgart 1979). Zur Ergänzung ist man auf die quellenkritischen Einleitungen zu Einzeleditionen bzw. Regionaluntersuchungen angewiesen. Auf sie rekurriere ich fallweise im Laufe der Untersuchung. Fragen nach den Beziehungen zwischen innerer und äußerer Form zum Denkstil werden dort in der Regel nicht gestellt. Vgl. aber die folgende Anm.

17 Dieter Hägermann, Eine Grundherrschaft des 13.Jh. im Spiegel des Frühmittelalters, in: RhVjbll 45 (1981) 1-34, hier: 2-8; Jean Durliat, Qu'est-ce qu'un polyptyque? A propos des documents de Tours (ChLA 659), in: Media in Francia. Recueil de mélanges offert à Karl Ferdinand Werner à l'occasion de son 65e anniversaire par ses amis et collègues français (Paris 1989) 129-138; Dieter Hägermann/Andreas Hedwig, Das Polyptychon und die Notitia de Areis von Saint-Maur-des-Fossées. Analyse und Edition (Beih. d. FRANCIA 23, Sigmaringen 1990) 10 ff.; Ludolf Kuchenbuch, Grundherrschaft im früheren Mittelalter (Historisches Seminar NF1, Idstein 1991) 26-30; Werner Rösener, Grundherrschaft im Wandel. Untersuchungen zur Entwicklung geistlicher Grundherrschaften im südwestdeutschen Raum vom 9. bis 14. Jahrhundert (Veröff. d. Max-Planck-Instituts f. Geschichte 102, Göttingen 1991) $66 \mathrm{f}$. Wichtig in editorischer Hinsicht: Bernd Stübing, Zur Textwiedergabe in Editionen am Beispiel der Ziegenhainer Urbare, in: Mabillons Spur. Zweiundzwanzig Miszellen aus dem 
dem Ordnungsverhalten kann sich all diesen Erwägungen entsprechend nicht nur auf inhaltliche Aspekte beziehen, sondern hat ebenso die Gestaltung des Überlieferten zu beachten und zielt schließlich auf Beziehungen beider zueinander ab. Dabei ist davon auszugehen, daß die für Grundherrschaft einschlägige Überlieferung im früheren Mittelalter noch keine spezifische, sich von anderen Schriftguttypen maßgeblich abhebende Gestalt hatte. $\mathrm{Da}$ also die Aufgabe, die ich mir hier stelle, die Frage nach den Beziehungen zwischen Denkstil und Schriftpraxis ausdrücklich einschließt, ist es unumgänglich, im betreffenden Schriftgut wenigstens in Auswahl auch den Gestaltungsdetails nachzugehen.

Woher nun einen heuristisch tragfähigen Ausgangspunkt für Vergleich und Trendermittlung für das 9. und 12.Jahrhundert beziehen, wenn die Forschung zur Frage, wie sich zunehmende Schulung im trivialen Denkstil auf Inhalte und Formen des grundherrlichen Schriftguts ausgewirkt haben könnte, nur so Disparates und Ansatzhaftes zu bieten hat?

Die Suche nach einem Faustpfand im 9.Jahrhundert, mit Hilfe dessen alle wesentlichen Aspekte des Themas hätten exponierend erörtert werden können, blieb unbefriedigend. Den Vergleich aber von späteren Erscheinungen her - etwa den so suggestiven Formulierungen Jordans von Sachsen (ca. 1220) zur Spiegelung der forma tractatus in der forma tractandi und Bonaventuras zur, Autorschaft ${ }^{19}$ aufzubauen, verbot sich methodisch. Es ist ja überhaupt nicht ausgemacht, welche Entwicklungen, Traditionsbrüche, Wiederentdeckungen etwa zwischen den ersten grundherrlichen Registern (7./8.Jahrhundert) und dem Domesday-Book

Fachgebiet für Historische Hilfswissenschaften der Philipps-Universität Marburg z. 80. Geburtstag von Walter Heinemeyer, hg. v. Peter Rück, (Marburg 1992) 77-89.

18 Richtungsweisend: David Walker, The Organization of Material in Medieval Chartularies, in: The Study of Medieval Records. Essays in honour of Kathleen Major, hg. v. D. $A$. Bullough/R. L. Storey (Oxford 1971) 132-150; vgl. auch Martin Schoebel, Archiv und Besitz der Abtei St. Viktor in Paris (Pariser Historische Studien 31, Bonn 1991); Frank M. Bischoff, Kodikologische Beiträge zum Lausanner Kartular, in: Mabillons Spur (wie Anm.17) 167191; der Tagungsband Olivier Gyotjeannin u. a. (Hg.), Les Cartulaires (Paris 1993) hat einen neuen Forschungsstand geschaffen. Das neue Buch von Patrick J. Geary, Phantoms of Remembrance: Memory and Oblivision at the End of the first Millenium, (Princeton 1994) enthält in Kapitel 3 (Archival memory and the destruction of the past) 81-144 wichtige neue Ergebnisse über regionale Unterschiede und langfristige Entwicklungstrends (8.-11.Jahrhundert). Ich danke P. G. für Einblicke in sein Manuskript.

19 Zitiert von Parkes, Influence (wie Anm. 14) 120: "Causa formalis huius scientie est forma tractandi et forma tractatus. Forma tractandi est modus agendi qui est principaliter diffinitivus, divisivus, probativus, improbativus et exemplorum suppositivus; forma tractatus est forma rei tradite que consistit in separatione librorum et capitulorum et ordine eorum.." Ebenso suggestiv ist (a.a.O. 127f.) Bonaventuras Abgrenzung von Schreiber, Kompilator, Kommentator und Autor: "... quadruplex est modus faciendo librum. Aliquis enim scribit aliena, nihil addendo vel mutando; et iste mere dicitur scriptor. Aliquis scribit aliena addendo, sed non de suo; et iste compilator dicitur. Aliquis scribit et aliena et sua, sed aliena tamquam principalia, et sua tamquam annexa ad evidentiam; et iste dicitur commentator non auctor. Aliquis scribit et sua et aliena, sed sua tamquam principalia, aliena tamquam annexa ad confirmationem et debet dici auctor." 
$(1086)^{20}$, oder den frühen Schenkungsbooms (z.B. für Echternach, Lorsch, Mondsee) und der zeitlich so verschiedenen Anlegung von Kartularen ${ }^{21}$ stattgefunden haben, wie die seit der Spätantike bekannten Gliederungsgewohnheiten von biblischen, exegetischen, liturgischen, erzählenden, Rechts- und Artes-Schriften fortlebten, was mit der graphischen Ordnung von Seite, Blatt, Heft, Rolle und Kodex geschah. ${ }^{22}$ Mehrere Referate der Tagung selbst galten ersten Erkundungen über das zeitlich so verschiedene Aufscheinen des divisionsgeleiteten Argumentierens: beim Glossieren von Isagoge und Kategorienlehre (J. Marenbon), beim kirchenrechtlichen Streit (W. Hartmann) oder im bildbezogenen Einzeltraktat (R. L. Benson), beim Auslegen des Corpus Iuris Civilis (G. Otte). Doch mußte - auch in den Diskussionen - noch offenbleiben, welche Bedeutung solche Exempla im epochalen Vorgang eines zunehmend trivial geschulten Orientierungs- und Handlungsstils in Lateineuropa vom 9. zum 12.Jahrhundert hatten.

\section{Vorbereitung: Zeugnisse aus dem 11.Jahrhundert}

In dieser Situation habe ich nach Zeugnissen zwischen den $\mathrm{zu}$ vergleichenden Zeiträumen mit Schwerpunkt im 11.Jahrhundert gesucht, die dazu dienen könnten, in mehrerlei Hinsicht sowohl zurück als auch voraus zu blicken.

$\mathrm{Zu}$ erinnern ist zunächst noch einmal an den Gedanken, die Leistungen der - im wesentlichen ja grundherrlich gebundenen - servi ließen sich durch Operationen mit dem Abakus numerisch fassen. Adalbero blickt aber nicht nur auf Verhältnisse praktischen Rechnens, für die das Nebeneinander des Einsatzes der Finger, des Kerbholzes und des Rechentuchs bzw. -tischs kennzeichnend ist, sondern er imaginiert den ersten Schritt, den labores denkend beizukommen, als Entflechtung, als Auflösung eines Gewebes, das doch wohl für die verschlungene ,Wirklichkeit steht. Vor das Rechnen gehört die Zählung, vor diese eine Aufgliederung und begriffliche Fassung des Vorhandenen, durch die das Zählbare begrifflich ermöglicht wird. Es geht um das Unterscheiden der insignia rerum und ihre Fassung in die signa von Wortlaut und Schriftbild, eine Fähigkeit, deren Erwerb Walther von

${ }^{20}$ R. H. C. Davis, Domesday Book: Continental Parallels, in: J. C. Holt (Hg.), Domesday studies: papers read at the Novocentenary conference of the Royal Historical Society and the Institute of British Geographers (Winchester 1986) 15-39; vgl. den Forschungsüberblick von Timothy Reuter, „Domesday Book and beyond": neue Literatur anläßlich der 900-JahresFeier, in: DA 48 (1992) 113-134, hier: 118.

21 Vgl. dazu Geary (wie Anm. 18). Beispielhaft bleibt die große Regionalstudie von Heinrich Fichtenau, Das Urkundenwesen in Österreich vom 8. bis zum frühen 13. Jahrhundert (MIÖG Ergbd. XXIII, Wien-Köln-Graz 1971); sowie Peter Johanek, Zur rechtlichen Funktion von Traditionsnotiz, Traditionsbuch und früher Siegelurkunde, in: Peter Classen ( $\mathrm{Hg}$.), Recht und Schrift im Mittelalter (VuF, Bd. XXIII, Sigmaringen 1977) 131-162.

${ }^{22}$ Hierzu das neue Überblickswerk: Henri-Jean Martin/Jean Vézin $(\mathrm{Hg}$.$) , Mise en page et$ mise en texte du livre manuscrit (Paris 1990); zu graphischen und diagrammatischen Traditionen: Jobn E. Murdoch, Album of Science. Antiquity and the Middle Ages (New York 1984). 
Speyer (ca. 981) anspielungsreich in die Grammatica-Jahre, die erste Phase monastischer Artes-Bildung nach dem Elementarunterricht, verwies. ${ }^{23}$

In drei grundherrlichen Verzeichnissen, einer Urkunde und zwei Kartularen des 11.Jahrhunderts möchte ich nun nach Ordnungselementen suchen, die den Blick in die früheren und die späteren Zeugnisse schärfen helfen könnten. Auf die nähere Situierung der einzelnen scripta, ihre Einbettung in den epochalen, regionalen und auch lokalen Zusammenhang (Skriptorium) kann ich hier nicht eingehen.

Auf die Jahre vor 1050 datiert Andrea Castagnetti eine Beschreibung der Güter und Einkunftsrechte der Taufkirche $S$. Lorenzo von Oulx (bei Turin ${ }^{24}$ : colonia und casa indominicata mit in über zehn verschiedenen Orten gelegenen Mühlen, Äckern, Wiesen und Hangweiden (alpes) werden als Habe angeführt, dazu diverse, wohl auf fiskalische Ansprüche zurückgehende Naturaleinkünfte aus vier, sowie Korn- und Geldzinse von namentlichen homines aus weiteren drei Orten. Es folgt die Reihe der neun als coloni ausgewiesenen provendarii. Es folgen weiter neunzehn Kleinbetriebe (coloniae ${ }^{25}$ ), verstreut über neun Orte. Sie werden bewirtschaftet von familienweise benannten coloni, die zu gleichen Abgaben (ein Drittel des Kornertrags) und Diensten (zwölf opera jährlich) verpflichtet sind. Schließlich folgt die Zuweisung des Zehnten der Umgebung an S. Lorenzo. Man hat ein typisch domaniales Breve des Frühmittelalters vor sich. Dies gilt sowohl für das Vokabular als auch für den Aufbau. Die die descriptio leitenden Termini signa im Waltherschen Sinne? - sind schnell aufgezählt: die Elemente des indominicatum (colonia - typisch für den Süden -, casa, terra arabilis (gemessen in Scheffel Saatgut), pratum (gemessen in Karren Ertrag), mol(end)inum; dann die (in Einzelstücken oder mittels Hohl- bzw. Gewichtsmaßen gezählten) Naturalabgaben, Münzzinse (denarius, solidus) und Fronden (opera); schließlich der Rechts- bzw. Funktionsstand der Pflichtigen (colonus, provendarius), ihr Gut (colonica, sonst meist mansus, östlich des Rheins oft huoba), ihre Frauen, Kinder und Verwandten. Auch der Aufbau entspricht dem vielfach Gewohnten: zuerst das Salland, dann die Zins- und Dienstleistungen, am Ende Zusätzliches (hier: der Zehnt). Dem Stil der Aufstellung ist noch manches Direkte, Unmittelbare der Erhebung vor Ort abzulesen: das Präsens regiert die Sätze, die meisten Aussagen schließen syndetisch an die vorigen mit et an, Namensnennungen werden demonstrativ eingeleitet (hii sunt; scilicet). Doch ist sie nicht mehr durchgehend verlaufsprotokollarisch gehalten: man spart sich Wiederholungen (similiter debet sicut ...), es wird

23 Peter Vossen, Der Libellus Scolasticus des Walther von Speyer. Ein Schulbericht aus dem Jahre 984 (Berlin 1962) 38, V. 18-21; vgl. auch die Erläuterungen v. Vf. 67 ff. Ich spiele hier auf V.20f. an: "Et mihi Romanam primum monstraverat aulam in signo signi vertentem insignia rei."

${ }^{24}$ Druck in: Andrea Castagnetti/Michele Luzzatti/Gianfranco Pasquali/Augusto Vasina (Hg.), Inventari Altomedievali di Terre, Coloni e Redditi (Fonti per la Storia d'Italia 104, Rom 1979) 1-9. Das Stück ist abschriftlich in einem Kartular des 13.Jahrhunderts erhalten. ${ }_{25}$ Castagnetti, a.a.O., 5/7 f. löst die Abkürzung col als colonus auf. Das ergibt im Zusammenhang aber kaum Sinn. 
auf vorher Ausgeführtes verwiesen (ut supra), auch in dem Sinne, daß dies geschrieben steht (de super scripto vico o. ä.). Die intitulatio (in einer Handschrift aus dem 13.Jahrhundert übrigens rubriziert) bezeugt jedoch distanzierte und funktionale Reflexion, denn über allem steht: carta de racione facienda. ${ }^{26}$ Der zeitgenössische Schreiber benennt das Schriftstück als carta, macht aus der descriptio, der Protokoll und Eschatokoll fehlen, eine Urkunde, und drückt abstrakt-begrifflich ihren Zweck aus. Sie soll, soweit darf man hier aus dem ungemein breiten Sinnfeld von ratio aussuchen, rechtsbezogene Rechenschaft ermöglichen.

Im Titel eines Verzeichnisses aus St.-Remi/Reims, das Jean-Pierre Devroey in die erste Hälfte des 11.Jahrhunderts datiert, wird mit sachlich aufgefächertem Bedacht eine deutliche Aussage gemacht: NOTITIA CENSUS DEBITI VILLARUM SANCTI REMIGII, quantum soluitur ab ipsis quibusve terminis. ${ }^{27}$ Ein wirklich exakter Titel, denn die Aufstellung bezieht ihre grundlegende Gliederung vom Ort; man geht von villa zu villa vor, und jeder Abschnitt wird eingeleitet (und durch Versalien abgesetzt) mit DE GENEREIO, DE PONTE, DE CERRONE, DE GERSONNE usf. So kommt man auf - allerdings nicht durchgezählte - 54 Abschnitte. Im elften wird der dominierende Sachgesichtspunkt des Verzeichnisses sogar im Abschnittstitel mitgeführt: CENSUS DE VEIO SANCTI REMIGII ${ }^{28}$. Eine Durchsicht bestätigt, daß es - mit wirklich wenigen Ausnahmen - um Geld- und Naturalzinse geht, und zwar um deren Anzahl sowie deren Abgabetermine: in der Regel die wichtigsten christlichen Festtage des Jahres und die der Patrone bzw. anderer Heiliger (ergänzend kommen Monatsangaben hinzu). Zwar wird der Ortsbezug immer wieder aufgefächert durch Radizierungen bestimmter Zinse auf Land (mansus, terra, pratum), Leute (kopfzinspflichtige Männer oder Frauen) und Einrichtungen (Mühle, Markt, Kirche u.a.), ebenso kommt es aber innerhalb von Abschnitten mehrfach zur Addition (summa), allerdings nur der Geldzinse. ${ }^{29}$ Der Schreiber der ,Aufzählung', so ist notitia hier zu

${ }^{26}$ Castagnetti weiß um die Problematik später eingefügter Überschriften. In diesem Fall vermutet er derlei nicht (A.a.O. 4).

${ }^{27}$ Le Polyptyque et les Listes de Cens de l'Abbaye de Saint-Remi de Reims (IX ${ }^{\mathrm{e}}-\mathrm{XI}^{\mathrm{e}}$ siècles). Edition critique par Jean-Pierre Devroey (Travaux de l'Académie Nationale de Reims, Bd. 163, Reims 1984) 105-119, hier: 105; Kommentare zu Überlieferung und Deutung: LIIf. LXXXIX ff. Das Verzeichnis, ursprünglich ein separates Stück, wurde einem vor 1774 verlorenen Codex aus dem 11.Jahrhundert, der mehrere Polyptycha (9./10.Jahrhundert) enthielt, zu unbekanntem Zeitpunkt hinzugefügt. In den Codex wurde noch eine Zinsliste aus der zweiten Hälfte des 12. Jahrhunderts hineingeschrieben.

${ }^{28}$ Devroey (wie Anm. 27) 108. Ich gebe hier zur Veranschaulichung den ganzen Abschnitt wieder: "In maio.XX. solidos et .XX. porcos. Sunt ibi .XX. mansi ingenui debentes singuli modium et dimidium frumenti et duas mensuras lignorum; et .CC. et dimidium de ascillis; et .II. boves ad mustum et .II. ad vetus (vinum) conducendum; debet adhuc unusquisque .IIII. or modios frumenti deducere ad locum monasterii et .I. carrum foeni cum .II. bobus; in festo sancti Martini.VI. denarios. Mansus et in festo sancti Remigii DE TUNIACO quinque solidos." Ein Ortsname (Braux-Saint-Remi) ist, seltener Einzelfall im so abkürzungsreichen Schriftgut dieser Art, sogar zu BRS kontrahiert: 114.

29 Devroey (wie Anm. 27) $116 \mathrm{ff}$. 
verstehen ${ }^{30}$, hat das für Inhalt und Form Bezeichnende seines Schriftstücks treffend formuliert.

Noch präziser ist dies in einer series descriptionis gelungen, die ein Schreiber zwischen 975 und 1092 für die Kollegiatstiftsbrüder von St.-Dié/Vogesen redigierte. ${ }^{31}$ Das Stück besteht aus sieben Abschnitten, die sich auf geschlossenen Ortsbesitz oder solchen in Streulage (cum appendiciis suis) beziehen. Sie sind in der Mehrzahl von einem den Inhalt ankündigenden Satz eingeleitet: Hae sunt rectitudines vel census de (folgt der Ortsname); dazu kommen mehrfach genaue inhaltliche Einschränkungen (exceptis ...) ${ }^{32}$. In jedem Abschnitt regieren die (insgesamt neun) Abgabetermine im Jahreslauf die Aufzählungsfolge, egal, wann das Zinsjahr jeweils beginnt (Martini, Johanni, Mitte März oder Mai), welcher Rechtsgrund für die Erhebung der einzelnen Zinse, vor allem Geld, besteht (Land bzw. mansus, Getreide- bzw. Weinfuhre, Ernteschnitt, Gewerbe, Gericht, Weinbann, Holzrecht, Altarabgaben u. a.) oder aus welchem Unter-Ort der curtis der Zins kommt. Summiert werden die Einzelposten weder pro Abschnitt noch im Ganzen. Entscheidend für die Ordnung und die Titulierung ist also die curtis-bezogene Zeitfolge der einzelnen Einkünfte. Über die Entstehung und den Geltungsmodus dieser Aufstellungen nun legt der Schreiber in seinem Vorwort präzise Rechenschaft ab: Quia res hujus aecclesiae, maxime tamen ex omnibus appendicia et fraterna stipendia dispersa atque nimis cuique licita videbantur, placuit ea que scilicet curtes vocamus, atque quoslibet census vel rectitudines communi decreto fratrum atque totius congregationis fidelium subscribi atque velut sub anathemate confirmari, ne praeposito vel ceteris praebende fratrum prelatis sibi usurpare vel distribuere liceret, nisi diffiniretur assensu communi. In cujus etiam descriptionis serie tantum ea computantur que communitati fraterne certis tempori-

30 Also nicht im Sinne der urkundenkritischen Unterscheidung von carta und notitia. Vgl. die Belege bei Jan Frederik Niermeyer, Media Latinitatis Lexicon Minus (Leiden 1976) 722. Ich habe hier bewußt den Terminus ,Liste ${ }^{\tau}$ vermieden. Es ist meines Erachtens noch nicht ausreichend geklärt, wie die sachbegrifflichen, syntaktischen, skripturalen und graphischen Umschläge von der Aufzählung in die Liste zu fassen sind. Die Bestimmungen von Jack Goody, The domestication of the savage mind (Cambridge 1977) 74-111, sind, ohnehin am ,listing' vorderasiatischer Kulturen demonstriert, zu stark am Prozeß einer ,decontextualisation' orientiert, für den die vorausgehende, inquiry', bestimmend für die hier untersuchten Verzeichnisse, nicht so wichtig ist. Peter Koch, Von Frater Semeno zum Bojaren Neascu. Listen als Domäne früh verschrifteter Volkssprache in der Romania, in: Wolfgang Raible $(\mathrm{Hg}$.), Erscheinungsformen kultureller Prozesse (ScriptOralia 13, Tübingen 1990) 121-165, legt seine linguistische Unterscheidung zwischen Aufzählung und Liste zu einseitig von einer Trias von "Linearisierungsprinzipien menschlicher Kommunikation" (140ff.) her an. Ich komme auf diese Fragen zurück in dem Aufsatz: Teilen, Aufzählen, Summieren. Zum Verfahren in ausgewählten Güter- und Einkünfteverzeichnissen des 9. Jahrhunderts, in: Ursula Schaefer (Hg.) (wie Anm. 11) 181-206.

31 Edition: Ch. Pfister, Les revenus de la Collégiale de Saint-Dié à la fin du $\mathrm{X}^{\mathrm{e}}$ siècle, in: Annales de l'Est II (1888) 514-42, Wortlaut: 515-517; Datierung und neuere Interpretation bei Perrin (wie Anm. 16) 269-320. Er nennt das als Einzelpergament aus dem 11.Jahrhundert erhaltene Stück, notice-censier'.

32 Es werden folgende Pflichten ausgeschlossen: Ackerfronden auf dem Herrenland (croadae), Getreidezinse zur Fütterung von Jagdhunden (brennae), Zehnte. 
bus referenda decernuntur, his praetermissis que praeposito vel ceteris ex providentia forensi haberi conceduntur. ${ }^{33}$ Eine klare Abgrenzung des Zwecks, die Versorgung allein der Kanoniker, ist also vorgenommen. Ebenso ist der Vorgang, wie dies erreicht wurde, beschrieben. Der Bezugsindex für die Versorgung, die curtis, wird herausgestellt. Auch das Einkommen selbst (und sein Rechtsrahmen) ist begrifflich gefaßt (census vel rectitudines). Schließlich wird das Verfahren der $\mathrm{Zu}$ rechnung (nicht das der Zusammenzählung) ausgedrückt (computare) und für das Kompositum, das gegliederte Ganze, ein treffendes Wortpaar eingeführt: series descriptionis.

Zwischen 1042 und 1047 hat Poppo, Abt des Klosters St. Maximin/Trier, einen Kompromiß mit den seit langem prestationsunwilligen Familiaren der Abtei in Wasserbillig, einem mit Marktrecht ausgestatteten Weindorf am Zusammenfluß von Sauer und Mosel, urkundlich verschriften lassen. ${ }^{34}$ Den Weinbauern, die sich durch Teilungen ihrer Anwesen (mansionilia/curtilia), Taktieren mit der Konvertierbarkeit ihrer (im Marktwert zudem noch variablen) Weinzinse und expliziten Abgabe-Verweigerungen die Einschätzung als homines rebelles et ... fere insuperabiles erworben hatten, rang Abt Poppo die Radizierung ihrer fixen Grund-Abgaben auf eine feste Zahl von mansionilia, eine präzise, auf Regionalmaß, Jahresernte und Preisbewegung achtende Weinzinsregelung sowie Fronden am Fischwehr, auf dem Salland und zum Burgerhalt ab. Das decretum wird als für die Bauern tollerabilis, für die Abtei utilis und in diesem Zusammenhang lex vel pactum genannt. Rückblickend gilt es als ratio redituum. ${ }^{35}$ Abt Poppo wird in der Narratio als pater fidelis in domo dei dispensator gelobt. Und in der Arenga ist das Gedeihen der res ecclesiasticae an das ehrliche Bemühen der rectores gebunden, (ut) eas gubernent vel ordinent. In diesem chartecensier ${ }^{36}$ sind Grundbegriffe grundherrlicher Ordnungsnormung und Ordnungspraxis versammelt, die man so in Privaturkunden früherer Jahrhunderte kaum findet. ${ }^{37}$ Der Kompromiß wird in

${ }^{33}$ A.a.O. 515; dazu Perrin (wie Anm. 16) $287 \mathrm{ff}$.

34 Edition (zuletzt): Camillus Wampach, Urkunden- und Quellenbuch zur Geschichte der altluxemburgischen Territorien (Bd.1, Luxemburg 1935) Nr. 268. Das Stück ist im Berliner Manuskript des Liber Aureus abbatiae s. Maximini (1. Hälfte des 13. Jahrhunderts) überliefert, der neben gut 80 Maximiner Urkundenabschriften auch die eines umfassenden Urbars enthält. Schöne Interpretation von Edith Ennen, Die Grundherrschaft St.-Maximin und die Bauern von Wasserbillig, in: dies., Gesammelte Abhandlungen zum europäischen Städtewesen und zur rheinischen Geschichte, hg. v. Georg Droege (Bonn 1977) 472-477; alles zur frühen Ortsgeschichte jetzt bei Thomas Gießmann, Besitzungen der Abtei St. Maximin vor Trier im Mittelalter. Überlieferung, Gesamtbesitz, Güterbesitz in ausgewählten Regionen (Trier 1990) 197-208.

35 Eine weitere Formulierung dieses Sachverhalts begegnet im gleichen Zusammenhang. Über die beurkundete ratio redituum wird, gewissermaßen in übergeordneter Abstraktionsstufe, als modus usibus nostris inservire gehandelt.

${ }^{36} \mathrm{Zu}$ dieser Verbindung von Urkunde und Verzeichnis vgl. Perrin, Recherches (wie Anm. 16) 660ff.; zum agrarverfassungsgeschichtlichen Hintergrund Fossier (wie Anm.17) $34 \mathrm{ff}$.

37 Diese Behauptung gilt natürlich nicht für andere soziale Ebenen und Überlieferungsbereiche, in denen Spannungen zwischen normativen Ansprüchen und situativer Praxis zu verein- 
die Aura guter Sachwaltung für die domus dei gezogen, ebenso der Abt als derjenige, dem diese Aufgabe übertragen ist. Der Kompromiß gilt weiter als spezifisch angemessen für beide beteiligten Seiten. Die Bezeichnung des Resultats als ratio liegt da nahe, deshalb auch sind decretum und lex/pactum sinnkongruent verwendet, dies im wohlweislichen Bezug auf die in der Arenga formulierte Devise, iure credimus ratum fixumque debere, quicquid huiusmodi hominum comprobatur assensu.

Ein namenloser Schreiber aus der Abtei St.-Pieter/Gent hat um die Mitte des 11.Jahrhunderts mit großer Sorgfalt ein Kartular der Abtei neu geschrieben, das wahrscheinlich im frühen 10.Jahrhundert entstanden war. Da beide Handschriften (letztere nur fragmentarisch) erhalten sind ${ }^{38}$, hat man die seltene Gelegenheit, einen alten Liber Traditionum mit seinem späteren Doppelgänger zu vergleichen. Dies soll hier nur anhand eines kurzen Auszuges geschehen, der deshalb von besonderem Interesse ist, weil zum einen der Schreiber des 10.Jahrhunderts offensichtlich nach Diktat schrieb ${ }^{39}$ und sein Nachfolger darauf reagierte, zum anderen es sich um die wohl früheste Doppelfassung urbarialer scripta des früheren Mittelalters handelt. ${ }^{40}$ Schon Henri Pirenne ist 1895 in seiner quellenkritischen Abhandlung zu diesen Manuskripten nicht entgangen, was der Abschreiber des 11.Jahrhunderts mit dem alten Liber in seiner Neuschrift machte: Er kürzte Schenkungsnotizen, regulierte die Graphie generell und aktualisierte die Schreibweise der Personen- und Ortsnamen. ${ }^{41}$ Es ist aber sinnvoll für den hier verfolgten Zweck, die Resultate des Abschreibens mit der Vorlage aus dem 10.Jahrhundert detaillierter vor Augen zu führen. Je drei Absätze aus Vorlage und Neuschrift ${ }^{42}$,

baren sind, der Ausgleich dieser Widersprüche aber einen jeweils eigenen Erfahrungs- und Artikulationseffekt haben kann. Beispielhaft hierzu Johannes Fried, Der karolingische Herrschaftsverband im 9. Jahrhundert zwischen „Kirche“ und „Königshaus“, in: HZ 235 (1982) 1-43; Otto Gerhard Oexle, Haus und Ökonomie im früheren Mittelalter, in: Gerhard Althoff u. a. (Hg.), Person und Gemeinschaft im Mittelalter. Karl Schmid zum 65. Geburtstag (Sigmaringen 1988) 101-120; Davies/Fouracre (wie Anm. 6).

38 Paralleler Druck bei Arnold Fayen (Hg.), Liber Traditionum Sancti Blandiniensis (Cartulaire de la Ville de Gand, 2e Série: Chartes et Documents, Bd.1, Gand 1906) 6-49; neue Edition des Fragments (10.Jh.): M. Gysseling/A. C. F. Koch (Hg.), Het „Fragment" van het tiende-eeuwse Liber Traditionum van de Sint-Pietersabdij te Gent (Koninklijke Belgische Academie. Handelingen van de Koninklijke Commissie voor Geschiedenis CXIII, Brussel 1948) 253-312, hier: 272-299; zur Datierung A. C. F. Koch, De dateringen in het Liber traditionum Sancti Petri Blandiniensis van ca. 1035, in: a.a.O. CXXIII (Brussel 1958) 137-190.

39 Gysseling/Koch, Fragment 259.

40 Fayen, Liber, $14 \mathrm{ff}$.; Gysseling/Koch, Fragment, $280 \mathrm{ff}$.

41 Zit. bei Fayen, Liber, VIII.

42 Mir waren zum Vergleich nur Faksimiles des Fragments aus dem 10. Jahrhundert zugänglich im Tafelband von M. Gysseling/A. C. F. Koch (Hg.), Diplomata Belgica ante annum millesimum centesimum scripta (Boustoffen en studien vor de geschiedenis en de lexicografie van het Nederlands, Bd.1, Brüssel 1950), Bd.2, Tafel VIIIff. Da auch Fayen (wie Anm.38) nach S.XIII je ein Faksimile beider Hss. beigegeben hat, ist schon auf einen ersten Blick der graphische Ordnungsgewinn erkennbar, den das Manuskript aus dem 11. Jahrhundert kennzeichnet. Der Schreiber hat nicht nur die Zeile korrekt waagerecht gehalten und die einzelnen Buchstaben standardisierter und formstabiler geschrieben, sondern er bewegt sich auch kon- 
die den Übergang von den Besitz- und Rentenverzeichnissen zu den Traditionsnotizen markieren, sollen dazu dienen.

10.Jahrhundert ${ }^{43}$ :

\section{RATIO DAE DULCIACO IN PAGO HANNAV.}

Abent hibi fratres de terra arabile (bonoaria) XXI. et de prato bonoario (.I.) et mansos.V., molendinum I. et decima de ecclesia, de frumento et de spelta adque legumine. Donet unusquisque de spelta modia XIII et de ligna carradas .III, pullos .II., oua .X., ad hoste(m) in uno anno sol(idos) .II., in alio ad uindemia(m) sol(idum) .I., et de molino donet modia de annona .LXIIII. et hagastald(os) s(unt) .II., puellas .III. censales.

Racio de rebus $q(u o) d$ franci homines tradiderunt $s($ anct)o Petro ad monasterio Blandinio; ipsis censis iussit Einhard(us) fr(atre)s habere, et post hobitu(m) eorum ipsos res recipere.

In primis de uilla Sumaringahem q(uo)d UUlsrid(us) tradidit, inde uenit de ceruisa sigl(a)s XX.; de remedio Norb(er)ti sol(idos) .II.; de remedio Sigeb(er)ti sol(idos) .V.; de Brunhardo ceruisa sigl(as) .XXIII.; de UUalachario sigl(as) XV.; Gondbald(us) sigl(as) .XX.; de lino libra dimidia.

11. Jahrhundert ${ }^{44}$ :

RATIO DE DULCIACO IN PAGO HAINAU. Habent ibi fratres de terra arabili LXX mansos et de prato bunaria XL, item mansos $\mathrm{V}$, molendinum unum et decimam de aecclesia, de frumento et de spelta atque legumine. Dat unusquisque de spelta modia XIII et de ligno carradas III, pullos II, ova X; ad hostem in uno anno solidos II, in alio ad vindemiam solidum I, ... Et hagastaldi sunt duo censales, puelle III.

RATIO DE REBUS QUAS FRANCI HOMINES DEDERUNT SANCTO PETRO. Censum domnus Ainardus jussit recipere fratribus et post obitum eorum ex toto res tenere.

In primis de villa Sumeringem quod Vulfridus dedit: inde veniunt cervise sigle XX, de remedio Norberti solidi II, de remedio Sigeberti solidi V, de Brunhardi cervise sigle XXIIII, de Walacharii sigle XV, Gumbaldi sigle XX, de lino libra dimidia.

Der genauere Vergleich von Vorlage und Neuschrift zeigt nicht allein die Fülle der skripturalen Änderungen (Versaliengebrauch, Zahlwort statt Ziffer) sowie der orthographischen und grammatischen Emendationen. Dazu kommen sinnvolle Kürzungen, stilistische Variationen, Umstellungen einzelner Wörter, Änderungen der Ausdrucksweise, Ergänzungen, sachliche Korrekturen. All das gipfelt in der

sequent im Fahrwasser des Worttrennungsprinzips. Vgl. dazu Paul Saenger, Coupure et séparation des mots sur le Continent au Moyen Age, in: Martin/Vezin (wie Anm. 22) 451-455. Ein Vergleich der Interpunktion sowie der Einrichtung der Seite ist nicht möglich.

${ }_{43}$ Gysseling/Koch, Fragment $282 \mathrm{ff}$.

${ }^{44}$ Fayen, Liber $19 \mathrm{f}$. 
weitgehenden Umformulierung des letzten Satzes im zweiten Absatz. Man sollte nicht übersehen, daß dem Neuschreiber auch Fehler unterliefen, daß ihm manches unklar war und ganze Zeilen leer bleiben mußten.

Der Vergleich beider Fassungen insgesamt ${ }^{45}$ zeigt darüberhinaus, daß der Genter Anonymus aus dem 11.Jahrhundert in seiner Neuschrift die Vorlage oft erheblich verändert hat. Er kürzt Sachaussagen und Ortsangaben auf das Nötigste hin, tilgt überflüssige Bezüge. Er läßt Aufzählungen namentlich genannter mancipia und Zusammenfassungen weg, ebenso ganze Abschnitte, die er teilweise an anderer Stelle einfügt - er greift also in die Reihenfolge ein. Auch sind ihm die Bezugnahmen auf die einzelnen Originalurkunden nicht mehr wichtig, die sein Vorgänger mit Bemerkungen wie: sicut carta docet, oder: si vis scire de precarias aut de terras censales, lege cartas; ibi invenies omnia ${ }^{46}$. Sein Liber gilt ihm also als weniger abhängig von Archiv oder Schrein. Zwei weitere Details scheinen mir wichtig zu sein. Einmal drängt es ihn zur Glosse. Das Wort frinsinga schreibt er nicht nur korrekt, sondern er fügt auch für seine Leser id est porcum hinzu. ${ }^{47}$ Und er distingiert an einer Stelle explizit das Vorige vom Folgenden: Suprascriptae donationes traditae sunt temporibus Ludowici imperatoris. Hae donationes traditae sunt temporibus Karoli calvi imperatoris. ${ }^{48}$ Was im 10. Jahrhundert faktisch getan worden war, wird ein Jahrhundert später also bewußt formuliert. Dies aber nur vereinzelt. Der Schreiber beginnt zu erklären, was unverständlich geworden sein könnte, und bezeichnet bzw. betitelt Teile des Manuskripts im Licht sachlicher und zeitlicher Ordnung. Schließlich ist noch auf die Durchgliederung des Liber Traditionum hinzuweisen. Der Schreiber des 11.Jahrhunderts hat sich nur wenig in das hineinbewegt, was ihm sein Vorgänger vorgab. Er hielt die Reihenfolge im großen bei: Ratio fundationis, Königsurkunde, Ausstattungsurkunde für die presbiteri et diaconi, Memoratorium über die stipendia fratrum (woraus hier zitiert wurde), Ratio über die Schenkungen freier Franken, Schenkungs-Noticia aus der Zeit Ludwigs des Frommen und Karls des Kahlen, Commemoratio über verkaufte Schenkungsobjekte. Aber er hat dem alten Liber nicht nur die Annales Blandinienses vorangestellt, sondern ihn um weit mehr als das Doppelte durch Schenkungsurkunden und -notizen (bis 1041), die bisweilen überschrieben und gruppiert sind, ergänzt. ${ }^{49}$ Der Schreiber des 11. Jahrhunderts, so kann zusammengefaßt werden, zielt mit all den Modifikationen von Schreibweise ${ }^{50}$, Syntax, Wortlaut, Inhalt, Reihenfolge und Bestand auf mehr Deutlichkeit und Folgerichtigkeit ab. Zudem ergänzt er seine Vorlage der Sache nach erheblich, bringt sie gewissermaßen auf den Stand der Dinge und bindet die Belege für Gütererwerb und -nut-

45 Fayen, Liber 14-49; Gysseling, Fragment 272-299.

46 Fayen, Liber 37, 49. Im zweiten, nicht abschriftlichen Teil hat er aber selbst ähnliche Hinweise auf die cartae bzw. auctoritates vel testes gegeben $(50,105)$.

47 Fayen, Liber 20.

48 Fayen, Liber 34.

${ }^{49}$ Fayen, Liber 50-112.

50 Zur schriftgeschichtlichen Situation vgl. Adriaan Verbulst, L'activité et la calligraphie du scriptorium de Saint-Pierre-au-Mont-Blandin, in: Scriptorium 11 (1957) 37-49. 
zung an weitere narrative Überlieferung - ganz im Sinne seines Vorgängers die Komplikation fortsetzend. Aber er erklärt sich darüber nur in ersten Ansätzen. Was er bessert, stellt er nicht als zweckhafte Differenz zur Vorlage dar, rechtfertigt er nicht. Nahezu alles geschieht immanent, ohne Glosse, ohne Argument. ${ }^{51}$

Eine recht andere Haltung begegnet im bereits eingangs zitierten Vetus Aganon aus dem letzten Drittel des 11.Jahrhunderts. Paulus, der Mönch in St.-Père/Chartres, operiert in seinem Kartular als methoden-, ziel- und zweckbewußter intextor. ${ }^{52}$ Ich beschränke mich hier auf die Einführung und das erste von acht Büchern des ersten von zwei Teilen des Werkes, das der Zeit Abt Haganos (931-954) gewidmet ist. Schon im ersten Satz seiner Vorbemerkungen, die er sowohl titulus als auch epilogus nennt ${ }^{53}$, beschreibt Paulus treffend seine Aufgabe. Seine Mitbrüder haben ihn immer wieder gebeten, ex privilegiis, die er in den heiligen Schreinen der Abtei finden konnte, per ordinem colligendo ein Buch zu erstellen und zugänglich zu machen (edere). ${ }^{54}$

Allzuviel hat Paulus aus den Jahren, während derer Aganus die Abtei restaurierte, nicht finden können; der letzte große Brand (1078) hatte auch das Schriftgut dezimiert. Aber was er fand, hat er nicht nur ordentlich zusammengestellt und den ,neuen Seiten' anvertraut, sondern in capitula mit eigenen Überschriften untergliedert. Auch deren Reihenfolge verrät Bedacht für Inhalt und Form, Gegenwart und Vergangenheit: zuerst sind die urkundlich überlieferten cartae et res canonicorum aufgeführt, dann folgen die Inventar- und Urbarialnotizen über Güter aus der Zeit vor der Klosterreform (wahrscheinlich 10.Jahrhundert), über die die fratres und der edituus verfügten. Jedes Kaptitel besteht aus dem Wortlaut der alten scripta (oder Auszügen aus ihnen) und Adnotationen. Ersterer ist in einigen Kapiteln durch $Z$ wischenüberschriften untergliedert und bisweilen - sic itaque incipit ... scriptum - klar von dem abgesetzt, was Paulus dazu zu bermerken hat. Und das ist viel: wortreich ,inseriert' er, meist dem scriptum nachgestellt, Details zur genauen Lage der Güter, zu deren Nutzen und Nutzung, zum Verbleib - soweit er etwas darüber weiß. Er gibt die Schriftstücke an, aus denen er ,zitiert ${ }^{\text {c }}$ (cartae, privilegia, rotuli/rolli). Er ergänzt, was er von Gütern weiß, die der Abtei abhanden gekommen sind. In der Art, wie Paulus mit den Inventar- und Urbarialnotizen $^{55}$ umgeht, spiegelt sich, bis ins kleinste Detail, die Differenz zwischen al-

\footnotetext{
51 Ähnliches referiert Geary (wie Anm. 18) 103-107 über das Kartular Clunys, anknüpfend an Beobachtungen Bruels.

52 Ich verweise auf die treffenden Bemerkungen von Hägermann (wie Anm.14) 6f. sowie Geary (wie Anm. 18) 103. Zu Paulus allgemein: Robert-Henri Bautier, L'Historiographie en France aux $\mathrm{X}^{\mathrm{e}}$ et $\mathrm{XI}^{\mathrm{e}}$ siècles (France du Nord et de l'Est), in: Settimane di studio del centro Italiano di studi sull'alto medioevo XVII: la storia altomedievale (Spoleto 1970) 793-850, hier: 818. Zur Überlieferung des Kartulars -2 Hss. aus dem 12.Jahrhundert - vgl. Guérard (wie Anm. 2) CCLXXIIf. Zum geistigen Klima in Chartres zwischen Fulbert und Ivo: Heinrich Schipperges, Schule von Chartres, in: LdM II (München 1983) $1753 \mathrm{f}$.

${ }^{53}$ Guérard (wie Anm. 2) 3, 14, 15.

54 Guérard (wie Anm. 2) 3.

55 Guérard (wie Anm. 2) 35-48. Ein Abschnitt aus diesen Notizen zur Veranschaulichung (a.a.O. 37): "De Comonis Villa. (Überschrift) In Comonis Villa Albuinus, qui tenebat de
} 
tem Wortlaut und aktuellem Wissen ${ }^{56}$. Hier greift er - im Gegensatz zu den Zitationen der privilegia - unbekümmert in den überlieferten Wortlaut ein. Nicht nur, $\mathrm{daß}$ er jeden Abschnitt über Güter und Rechte in einem Ort zusätzlich betitelt. Der alte Wortlaut wird von ihm ins Präteritum gekleidet. Er annotiert Ergänzungen zur aktuellen Besitzsituation (oder Streit darüber), bekennt freimütig, wenn er alte Sachausdrücke nicht versteht oder nicht weiß, wo ein Ort liegt. ${ }^{57}$ Er wundert sich über ihm unsinnig erscheinende Details (usus dissociabilis). Um Wiederholungen zu vermeiden, verweist er auf bereits Ausgeführtes (sicut supra dicti o. ä.). Schließlich macht er den Leser mehrfach auf die Differenz der alten zu den neuen Zeiten bzw. Gewohnheiten nach qualitas und quantitas aufmerksam. ${ }^{58} \mathrm{An}$ gesichts solcher Bewußtheit im Redaktionellen und Sachlichen verwundert es nicht, wenn Paulus auch klar sagt, warum sein opusculum nötig ist - alle erreichbaren Unterlagen (omnes scire res) für den Fall etwaiger Gefährdungen der Güter und Einkünfte beisammen zu haben - und warum es als Buch von Vorteil ist: um leichter und schneller nachlesen zu können. ${ }^{59}$

Paulus erweist sich insgesamt als ein literarisch solide geschulter und selbstbewußter Kompilator und Kommentator, der sich nicht nur der wichtigsten drei Gliederungsprinzipien des Schriftwerks bedient (volumen, liber, capitulum ${ }^{60}$ ), sondern die Herkunft der von ihm benutzten scripta nachweist, sie selber nach Gattungen unterscheidet, ordnet und verschieden behandelt sowie sie schließlich mit einer Fülle von Adnotationen durchflicht und umgibt, die sein Wissen als Nachgeborener und Zeitgenosse mit dem in den alten scripta verbinden.

Auf welche Merkmale des schriftinternen grundherrlichen Ordnungsverhaltens haben die sechs Zeugnisse aus dem 11.Jahrhundert verwiesen? Ich meine dreierlei unterscheiden zu können.

Am wichtigsten scheint mir, daß die Ordnungsakte, obwohl meist nur in Momenten greifbar, deren nähere Umstände oft gar nicht mehr zu klären sind, als Zeugnisse formalen, inhaltlichen und zweckhaften Wandels verstanden werden müssen. Am Anfang steht - ich frage hier nicht nach der von Mündlichkeit geprägten, konkreten Situation ${ }^{61}$ - der Verschriftungsanlaß, z.B. die Bestandsauf-

terra bunuaria V, solvebat III modios frumenti et alios usus, sicut supra dictum est. Rainaldus tantundem; Adalveus VI bunuaria de terra, et dabat IIII frumenti modios, et alios usus; Gindbertus similiter."

56 Schöne Zusammenfassung bei Hägermann (wie Anm. 14) $6 \mathrm{f}$.

57 Guérard (wie Anm.2) 38. Dort auch das Bekenntnis: "quem locum penitus ignoro; set, quia scriptum repperio, ideo fuisse non dubito." Ob er alte Termini für die Abhängigen (etwa servi, coloni) durch zeitgemäße (agricola, ruricola, incola, habitator) ersetzt hat, muß offen bleiben.

58 Guérard (wie Anm. 2) 43, 48.

59 Guérard (wie Anm. 2) $3 \mathrm{f}$. (citius legendo invenire), 49 (facile agnoscere legendo).

60 Dazu Palmer, Kapitel (wie Anm. 15) 53.

61 Aus rechtsbildungsgeschichtlicher Sicht hierzu: Theodor Bübler, Gewohnheitsrecht - Enquête - Kodifikation (Rechtsquellenlehre, Bd.1, Zürich 1977) 14-54 und Davies/Fouracre (wie Anm.6) sowie jetzt die Wiederaufnahme der Debatte über den Charakter des Gewohnheitsrechts im Mittelalter: Gerbard Dilcher u.a., Gewohnheitsrecht und Rechtsgewohnheiten im Mittelalter (Schriften zur Europäischen Rechts- und Verfassungsgeschichte 6, Berlin 
nahme oder die Einigung: in den obigen Beispielen die descriptio (Oulx) oder die carta (Wasserbillig). Der Abfassung beider liegen je andere Verschriftungsstile zugrunde: dort die noch verlaufsprotokollarisch geprägte, aber streng geordnete Aufzählung (parataktisch, syndetisch) ${ }^{62}$, hier die ergebnisprotokollarische Darłegung (hypotaktisch, periodisch). Beide aber eint ihr enger Situationsbezug: , hier wurde vereidigt, befragt und geantwortet, ,heute' wurde verhandelt, beschlossen und beurkundet. Und beide bestimmt ein vielfach kongruenter, zu Teilen sogar identischer Bestand von Schriftrealität schaffenden Termini, ein Vokabular zu den Gütern, Rechten und Einkünften, dessen Einsatz deutlich formularischen Regeln gehorcht. Nach der Erst-Verschriftung folgen verschiedenerlei Übertragungen, zu deren überlieferungskritischer Einordnung neben der zu einseitig auf die Inhalte abhebenden Urbarkritik ${ }^{63}$ auch die ausgefeilte Lehre vom urkundlichen Schrifttum (Konzept, Original, einfache, beglaubigte, inserierte, nachahmende Kopie bzw. Abschrift erster, zweiter usw. Ordnung, Nachzeichnung ${ }^{64}$ nur in Teilen taugt. Man könnte sie, vorläufig und formalisierend, Stationen bzw. Resultate der Verschriftlichung nennen. ${ }^{65}$ Nach außen gerichtete und interne Belange scheiden

1992); zum Zusammenwirken von Rede und Schrift: Clanchy (wie Anm.9) chap. 8, 253 ff.; Einzelstudien: Ludolf Kuchenbuch, Verrechtlichung von Erinnerung im Medium der Schrift (9. Jahrhundert), in: Aleida Assmann/Dietrich Harth (Hg.), Mnemosyne. Formen und Funktionen der kulturellen Erinnerung (Frankfurt a.M. 1991) $39 \mathrm{ff}$.; Michael Toch, Asking the Way and Telling the Law: Speech in Medieval Germany, in: Journal of Interdisciplinary History 16,4 (1986) 667-682; Michael Prosser, Spätmittelalterliche ländliche Rechtsaufzeichnungen am Oberrhein zwischen Gedächtniskultur und Schriftlichkeit (Veröff. z. Volkskunde und Kulturgeschichte 47, Würzburg 1991).

62 In meinem o.g. Aufsatz (wie Anm. 30) habe ich die Differenz zwischen protokolliertem Zeugenwissen und divisionsgeleiteter Aufstellung im Detail herauszuarbeiten versucht.

63 Wolfgang Metz, Zur Geschichte und Kritik der frühmittelalterlichen Güterverzeichnisse Deutschlands, in: Archiv f. Diplomatik 4 (1958) 183-206, sowie Perrin, Fossier, Morimoto und Hägermann (wie Anm.13).

${ }^{64}$ Bresslau (wie Anm.4) $88 \mathrm{ff}$.; für den Zusammenhang von Urkunden und frühen Akten: $R$. van Caenegem, Kurze Quellenkunde des Westeuropäischen Mittelalters (Göttingen 1962) 67-74; zusammenfassend jetzt: Alfred Gawlik, Kopie, in: LdM V (München 1991) 1437f. Die hier meines Erachtens wichtigste Neuorientierung zur Gattungsbildung (in konstruktiver Auseinandersetzung mit der konventionellen Opposition Urkunde-Akte) bietet Richter (wie Anm. 16) 15-25. Allerdings ist sein Grundkriterium zur Stiftung der Gattung ,Amtsbuch" (das auch Lagerbuch und Urbar umgreift), die „Anordnung im Buch“, noch zu sehr vom Erfahrungshintergrund spezifisch spätmittelalterlicher ordinatio (im Sinne von Parkes (wie Anm. 14), der ihm entgangen ist) geprägt, als daß es für administrative Mischkodizes aus dem früheren Mittelalter ungeprüft gelten könnte.

${ }^{65}$ Damit optiere ich für eine begriffliche Unterscheidung, die $M$. Clanchys Dreiteilung making (I), keeping and using (II) auf die Zweiteilung, Erstverschriftung ${ }^{\circ}$ (I) und ,Folgeverschriftlichungen (II) reduziert. Aus linguistischer Sicht hierzu jetzt: Wulf Oesterreicher, Verschriftung und Verschriftlichung im Kontext medialer und konzeptioneller Schriftlichkeit, in: Schaefer, Frühmittelalterliche Schriftlichkeit (wie Anm.11) 265-290. An den modernen Textbegriff und die moderne Buchgestaltung geknüpfte Ordnungsleistungen zur Unterscheidung von Buch und Text, Autor und Text, Wirklichkeit und Text, Kontext und Text usf. waren mir hier sehr hilfreich, auch wenn ich mit der Entscheidung, hier auf den Textbegriff $\mathrm{zu}$ verzichten, auch nicht mehr auf sie rekurrieren konnte. So z. B. auf Gérard Genette, Paratexte. Das Buch vom Beiwerk des Buches (Frankfurt/New York 1989); Kazimierz Liman, 
solche Verschriftlichungsvorgänge maßgeblich. Auf erstere, die Rechtsquellenlehre ordnet sie im Blick auf die ,Kodifikation ${ }^{66}$, bin ich nicht gestoßen. Wohl aber auf verschiedene Situationen des internen, klostereigenen Einschreibens, Dazuschreibens, Umschreibens, Kompilierens, Redigierens, Kommentierens und Überschreibens, dies auf dem Einzelblattpergament (St.-Dié) ebenso wie im Konvolut urbarialer Schriften (St.-Remi), im Mischkodex (St.-Pieter) oder im detailliert durchgliederten und kommentierten Kartular (St.-Père). Die Überlieferung der einzelenen Stücke zeigt schlagend, daß die meisten nicht nur Neu-Schriften (St.-Pieter) sind, sondern zu Zusammenstellungen in einen Kodex gehören (St.Remi) oder bearbeitete Um-Schriftungen darstellen (St.-Père). Zeugnisse für Erstverschriftung, ebenso, Originale', sind für dieses Schriftgut ganz untypisch, die bearbeitete Nachschrift ist die Regel. Zweitens: Das ändernde Bewahren der scripta geschieht in verschiedenerlei Hinsicht. Mit der Neuschrift wird anders geschrieben: in deutlicherer Buchstaben- bzw. Wortfolge, oder ortho-graphischer (St.-Pieter). Das scriptum wird anders eingerichtet (Zeile, Absatz, Seite usf.), Sinneinheiten werden gebildet, Überschriften erdacht und hinzugefügt. Darin manifestiert sich der abstrahierende Blick auf Form und Inhalt des ganzen Schriftstücks oder seiner Teile. Man weiß nicht nur implizit, sondern drückt es auch aus, daß man ,von' etwas handelt, ,über" etwas schreibt. Ist dessen Wortlaut gültig, dann werden Anfang und Ende angezeigt, man beginnt zu zitieren. Das überdenkende Ordnen manifestiert sich weiter bei korrigierenden Eingriffen ins Latein, ins $\mathrm{Na}$ mensgut, in den Satzbau des scriptum, ebenso beim Hinweis darauf, was bereits (,oben' oder ,früher') gesagt oder geschrieben wurde oder noch (,unten' oder, später') zu erwarten steht. Ebenso wie die Schrift des Stücks und seine graphische Gestalt werden seine Aussagen, sein Stil durch-webt. Nicht zu vergessen sind Ansätze, den Sinn auf Wesentliches hin zu kontrahieren (Summenbildung: St.-Remi, Regestierung ${ }^{67}$ : St.-Père). Zu dem alten Wortlaut (bzw. an seine Stelle) tritt also eine selektive, aufs numerisch oder rechtlich Relevante abzielende Kurzfassung. Weiter wird das Stück in die Umgebung von seinesgleichen plaziert. Und es wird als Ganzes sowie in seinen Teilen begrifflich bestimmt. Dafür stehen präzise Titel in gleich welcher sprachlichen Form. ${ }^{68} \mathrm{Zu}$ dieser, auch auf Gattungsbildung abzie-

Metatextuelles in der Chronik des Widukind, in: Mittellateinisches Jahrbuch 24/25 (1989/ 1990) 267-276. Ich danke Walter Berschin für diesen Hinweis.

${ }^{66}$ Hierzu Bühler (wie Anm. 54) 80-127.

${ }^{67}$ Dazu der aufschlußreiche Aufsatz von Harald Zimmermann, Zu Flodoards Historiographie und Regestentechnik, in: Kurt-Ulrich Jäschke/Reinhard Wenskus (Hg.), FS f. Helmut Beumann (Sigmaringen 1977) 200-214.

68 Die Bildung und Entwicklung von Überschriften bzw. Titeln ist ein Forschungsfeld eigener Art - für das hier behandelte Schriftgut kaum in Angriff genommen. Wichtige Ausgangspunkte dazu bei Richter (wie Anm. 57) 111 ff. u. ö. Neben den numerischen und formalbegrifflichen Titulierungen scheint mir die Art und Weise wichtig, wie aus einem einleitenden, oft noch narrativ gehaltenen Satz durch (schrittweise) Reduktion des Redundanten der visuell und kognitiv bestimmte, satzlose', schließlich sogar umstandslose Titel wird. Im hier betreffenden Schriftgut besteht der Endpunkt vielfach in einer locus- oder res-bezogenen Ad- 
lenden Einordnung kommt schließlich eine weitere, die zeitliche. Das einzelne Stück bzw. das Zusammengestellte gerinnt zum Zeugnis vergangener Tage, wird als altes kenntlich und erklärungsbedürftig, und das Getilgte geht der Memoria (als Vergangenheit und Geschichte) verloren, wenn die Vorlage nicht erhalten bleibt. ${ }^{69}$

Kategorisch zusammengefaßt: der Wandel läßt sich skriptural und ordinativ, verbal und stilistisch, terminologisch und begrifflich, sowie im Gattungs-, Sachund Zeitbezug (als zunehmende Distanz von der Entstehungssituation) beobachten. Damit kommt das dritte Merkmal ins Spiel, die Tendenz zur Besserung. Obwohl sie nur eine Eigenschaft des Wandels selbst ist und sich in den gleichen vier Komponenten (Schrift, Sprache, Begriff, Zeit), jedoch in je eigener Ausprägung darstellt, sollte sie gesondert im Auge behalten sein. Beobachtbar ist dieser Trend im Spiegel der Abfolge neuer Erstverschriftungen ebenso wie im Übergang von einem Verschriftlichungsakt zum anderen.

Die folgenden Untersuchungen zur grundherrlichen Überlieferung im 9. und 12. Jahrhundert sind unausgewogen. Mir scheint es besonders wichtig, auf Zeugnisse aus dem 9.Jahrhundert ausführlicher einzugehen, weil damit ein breiter Grund gelegt wird für das Verständnis der langfristigen Entwicklungen, die dann im 12. Jahrhundert so offen zutagetreten, so daß es ausreicht, sie nur noch in aufs Typische abzielenden Andeutungen abzuhandeln.

\section{Jahrhundert}

In Kapitel LXII des bekannten Capitulare de villis ${ }^{70}$ verfügt Karl der Große, daß seine iudices alljährlich über den Gesamtertrag (conlaboratio) ihres Aufgabenbereichs berichten sollen. Diese Anweisung wird durch eine ausführliche Aufzählung der verschiedensten Einkunftsformen konkretisiert. Abschließend heißt es schürzend: omnia seposita, distincta et ordinata ad nativitatem domini nobis notum faciant, ut scire valeamus, quid vel quantum de singulis rebus habeamus. ${ }^{71}$ Hier werden für einen wichtigen jährlichen Berichtstermin der iudices vor dem Herrscher drei Verfahren für die Ermittlung und Übermittlung des Wissens über

verbialbestimmung. Ebenso wichtig ist der Usus, Betitelungen, ob geplant oder nicht, erst nachträglich hinzuzufügen. Darin sehe ich einen überaus wichtigen reflexiven Ordnungsakt.

${ }^{69}$ Dieser Effekt ist - auch mit der Intention, vergessen zu machen oder zu zerstören - von Geary (wie Anm. 18) prägnant herausgestellt.

70 Neben der Edition durch Alfred Boretius (MGH, Legum Sectio II, Capitularia Regum Francorum, Bd. 1 (Hannover 1883) Nr.32, 82-91) gilt heute folgende als die beste: Capitulare de villis. Cod. Guelf. 254 Helmst. der Herzog August Bibliothek Wolfenbüttel, hg. und eingeleitet von Carlrichard Brübl (Dokumente zur deutschen Geschichte in Faksimiles, Reihe 1, Bd.1, Stuttgart 1971). Die gültige Datierung: Adriaan Verbulst, Karolingische Agrarpolitik: Das Capitulare de Villis und die Hungersnöte von 792/3 und 805/6, in: Zeitschrift f. Agrargeschichte u. Agrarsoziologie 13 (1965) 175-189.

71 Brübl (wie Anm. 70) 61 f. 
Art und Umfang der Einkünfte vorgeschrieben: Im Nacheinander von seponere, distinguere und ordinare ist die dreistufige Praxis der Absonderung der Einkünfte vom nicht Appropriierbaren, ihrer sachlichen Klassifizierung und ihrer Bedeutungsreihung auf den Punkt gebracht. Die Bestimmung liest sich wie die Methodisierung der Appropriation im Blick auf die beiden Grundkategorien zur Erfassung der singulae res: quid vel quantum. ${ }^{72}$ Sieht man sich aber die vorausgehende Aufzählung näher an, dann ist man sehr überrascht, wie dürftig die Einzelrevenuen unterschieden sind und wie viel an bedachter und durchgehender Ordnung unter ihnen fehlt. Zwar sind kleine Gruppen affiner Einkunftsformen gebildet so zum Beispiel Salland- und Hufenerträge, Gerichts- und Friedensgelder, Abgaben von Handwerkern u. a.m. -, ohne erkennbaren Grund aber wird die Sachgruppe oder der rechtliche bzw. soziale Index der Einkunftsgruppen geändert. ${ }^{73}$

Dieser Widerspruch zwischen dem erklärten Anspruch im allgemeinen und seiner mangelnden Durchführung im Detail spiegelt sich auch in anderem. Für die Umsetzung des Gebots (Kapitel LV), die iudices sollten in getrennte brevia schreiben lassen und am Hof vermelden, was sie geleistet, ausgegeben und zurückbehalten hätten ${ }^{74}$, fehlen der Königsgutforschung bislang eindeutige Belege. ${ }^{75}$ Schließlich ist auch nicht zu vergessen, daß es der Forschung zum Capitulare de villis bislang nicht gelungen ist, in die Folge der 70 Kapitel eine sachlich stringente Ordnung hineinzulesen; sie ist und bleibt vorwiegend additiv ${ }^{76}$, von Fall zu

72 Die Kommentare zum Capitulare de villis gehen hierauf nicht ein. Vgl. Benjamin Guérard, Explication du Capitulaire de Villis in: Bibliothèque de l'Ecole des Chartes 14 (1853) 341-348; Die Landgüterordnung Kaiser Karls des Großen (Capitulare de villis vel curtis imperii), Text-Ausgabe m. Einleitung und Anmerkungen, hg. v. Karl Gareis (Berlin 1895) 9-15 pass., 55-58; sowie Barbara Fois Ennas, Il „Capitulare de villis“ (Milano 1981) 184-195.

73 Diese Erscheinung hat auch jüngst wieder Jean Durliat, Les finances publiques de Diocletien aux Carolingiens (284-888) (Sigmaringen 1990, Beih. d. FRANCIÁ 21) $321 \mathrm{f}$. bei seiner Konstruktion eines karolingischen,Budget de l'Empire' nicht für wichtig gehalten. Der Wille zur eigenen Formation des Finanzhaushalts nach einem modernen Schema (Einnahmen, Ausgaben, Verwaltung der öffentlichen Finanzen) steht bei ihm so im Vordergrund, daß die Ordnungsdetails innerhalb der Überlieferung selbst nahezu verschwinden.

74 Brühl (wie Anm. 70) 61: "Volumus, ut quicquid ad nostrum opus iudices dederint vel servierint aut sequestaverint, in uno breve conscribi faciant, et quicquid dispensaverint, in alio; et quod reliquum fuerit, nobis per brevem innotescant." Diese und andere Details aus dem Capitulare wurden immer wieder zum Bild einer (auch doppelten) Buchführung systematisiert. Dies zuletzt aus ,betriebswirtschaftlicher' Sicht: Anton Tautscher, Betriebsführung und Buchhaltung in den karolingischen Königsgütern nach dem Capitulare de villis, in: VSWG 61 (1974) 1-28; aus der Sicht auf die Staatsfinanz nach spätantikem Muster: Durliat. (wie Anm.71) Teil III pass.

75 Wolfgang Metz, Das karolingische Reichsgut. Eine verfassungs- und verwaltungsgeschichtliche Untersuchung (Berlin 1960) 53 (villikale Ausgaben betreffend); was man über Einnahmen weiß, bewegt sich nur im Bereich der Ansprüche, nicht des realen, laufenden receptum - daran können auch die Systematisierungen Durliats (wie Anm. 72) nichts ändern; es sei denn, man subsumiert wie D. sämtliche einzelkirchlichen Inventare der Zeit unter einen staatlichen Fiskalkataster spätantiken Typs. $\mathrm{Zu}$ vieles an Einzelinitiative und besondertem Appropriationsgebaren innerhalb der Einzelherrschaften spricht aber dagegen.

${ }_{76}$ Hierzu systematisch Walter Ong, Oralität und Literalität. Die Technologisierung des Wortes (Opladen 1987) 42f. Auf die Debatte darüber, welcher Status den Kapitularien im 
Fall ,springend', nur einige subordiniert gestaltete Kapitelgruppen sind erkennbar. ${ }^{77}$

Dennoch: Die Formulierung der Ansprüche an das appropriierende und dispensative Gebaren der domanialen Diener sowie die damit einhergehenden Verschriftungsgebote können hier als terminologische und mediale Richtschnur für die Untersuchung des grundherrlichen Ordnungsverhaltens im 9.Jahrhundert dienen, zumal die karolingischen Herrscher nicht ruhten, Güter- und Einkünftebeschreibungen zu verschiedenen Anlässen und Zwecken zu gebieten. ${ }^{78} \mathrm{Im}$ folgenden soll eine Auswahl von Zeugnissen näher betrachtet werden, die im Blick auf diese Gesichtspunkte Ertrag versprechen: ein Traktat, einige Güter- und Einkünfteverzeichnisse und ein urbarialer Mischkodex mit Urkunden und Traditionsnotizen.

\section{Die Statuta seu Brevia Abt Adalhards von Corbie (822)}

Ich beginne mit dem prominentesten Überlieferungsfall im dispensativen Bereich, den Statuta seu Brevia Adalhards von Corbie. Der Vetter und Vertraute Karls diktierte die Statuta Anfang 822, kurz nachdem er aus dem ihm von Ludwig dem Frommen bestimmten Exil im Kloster Noirmoutier nach Corbie zurückgekehrt war. ${ }^{79}$ Sie sind nur in späteren Abschriften (ab 10., mit Zusätzen bis in 12.Jahrhundert) und nicht vollständig überliefert, wurden 1963 sorgfältig ediert von J.Semmler. ${ }^{80}$ Obwohl Adalhard sich nicht über seine Absichten und ihre Hinter-

mündlich-schriftlichen Hin und Her beim Regieren zukam, ist hier nicht einzugehen. Die proschriftliche Position: McKitterick, Carolingians (wie Anm. 11) 23-37; Janet L. Nelson, Literacy in Carolingian government, in: McKitterick, Uses (wie Anm.11) 258-296 (zum CV 273f.). Die Gegenposition (Verschriftung/Abschrift zu mnemopraktischen Zwecken) zuletzt: Arnold Bübler, Wort und Schrift im karolingischen Recht, in: Archiv f. Kulturgeschichte 72 (1990) 275-296.

$77 \mathrm{Ob}$ die mangelnde Ordnung auf kompilatorisches Ungeschick im Umgang mit älteren Bestimmungen zurückgeht oder in der casus-bezogenen Erstverschriftung gründet, ist wohl nicht mehr zu entscheiden. Cap. I und LXIII markieren durchaus den Willen, einleitend und abschließend (auch mit Bezug auf vorher Ausgeführtes) zu resümieren (Cap. LXIIII-LXX gelten als Zusätze), doch fehlt der interne, Gedankengang'. Für die Benutzung älterer Vorlagen plädierte schon Klaus Verbein, Studien zu den Quellen zum Reichsgut der Karolingerzeit, in: DA 10 (1953) 313-394(I), 11 (1954) 333-392(II) hier: 390ff.(I).

78 Zusammenstellungen bei Metz (wie Anm.74) 18-26 und Verbein (wie Anm. 76), 378-384; trotzdem bleibt unersetzt: Emile Lesne, Histoire de la propriété ecclésiastique en France. Bd. III (L'inventaire de la propriété. Eglises et trésors des églises du commencement du VII ${ }^{e}$ à la fin du XI ${ }^{\mathrm{c}}$ siècle, Lille 1936) 1-17; Hägermann, Abt (wie Anm.6) 369-375, belegt ausführlich Vergleichbares seitens der Äbte.

$79 \mathrm{Zu}$ Adalhard vgl. die Biographie von Brigitte Kasten, Adalhard von Corbie. Die Biographie eines karolingischen Politikers und Klostervorstehers (Studia Humaniora 3, Düsseldorf 1985), sowie David Ganz, Corbie in the Carolingian renaissance (Beih. d. FRANCIA 20, Sigmaringen 1990) 22-29.

80 Joseph Semmler (Hg.), Consuetudines Corbeienses (ante 826), in: CCM I (Siegburg 1963) $365-420$, mit sehr gutem laufendem Kommentar, basierend auf der vorbereitenden Studie 
gründe äußert, steht dennoch fest, daß er keine umfassende Beschreibung aller für den Klosterhaushalt wichtigen Bereiche, Aufgaben und Beauftragten intendierte. Sondern er wollte mittels einer Serie in sich abgeschlossener brevia die Verfahren dafür bestimmen und gültig festhalten, wie allen ständigen Klosterangehörigen sowie den verschiedenen Gästen die tägliche Kost und Kleidung zukommen könne, und zwar ea mensura, quae eis competit, ita ut nec penuriam patiantur nec aliqua superfluitate distendantur. ${ }^{81}$ Die sieben weitgehend lückenlos und unverworfen überlieferten brevia handeln von den prouendarii (I), dem Hospiz (II), dem Brotgetreide (III), den vier Klostergärten vor den Toren (IV), dem Benehmen in Refektorium und Küche (V), den für die Pforte bestimmten Zehnten (VI) und von der Vorratshaltung der geschlachteten Schweine (VII).

In jüngster Zeit ist das Interesse an diesen brevia deutlich gewachsen. Sie wurden zum Teil ausführlich gedeutet, wobei die interne Klosterverwaltung als ganze die Sichtweise bestimmte. ${ }^{82}$ In all diesen Studien wird nicht mit Lob über die Umsicht gespart, mit der Adalhard verfährt. Hier soll es weniger um die sachliche Seite von Adalhards Regelungen gehen, sondern zum einen um die Begriffe und Methoden, mit denen er dabei operiert. Anknüpfungspunkte dazu bieten Dieter Hägermann, dem der "nicht seltene Gebrauch des Wortes ratio“ in den Statuta auffiel ${ }^{83}$, und Johannes Fried, der Adalhards Verfahren als an der damaligen Rudimentärdialektik orientiertes Dividieren einstufte und es in den größeren Zusammenhang eines "beginnenden Wirtschaftsrationalismus" stellte. ${ }^{84} \mathrm{Zum}$ anderen ist ein Blick darauf zu werfen, welche Rolle Schriftstücke in Adalhards Vorstellungen von ordentlichem appropriativem und dispensativem Gebaren im Kloster spielen.

In der Tat: Adalhard modelliert seine Erwägungen und Anweisungen, für die er ständig, abwechselnd (also austauschbar) oder kombinierend (also nuancierend) Allgemeinbezeichnungen wie ratio, ordinatio, consideratio und divisio benutzt, nach auffallend ähnlichen Mustern. Das wichtigste von ihnen kommt im einleitenden Satz zum dritten Einzelbreve über die rechte Beschaffung und Verteilung des Brotgetreides deutlich zum Ausdruck: RATIO UEL NUMERUS ANNONAE SEU PANIS, qualis uel unde uel quantum ad monasterium debeat annis singulis venire uel qualiter custos panis illud debeat dispensare. ${ }^{85}$ Die beiden Gesichts-

von Adriaan Verbulst/Joseph Semmler, Les statuts d'Adalhard de Corbie de l'an 822, in: Le Moyen Age 68 (1962) 91-123, 233-269, in vielem ausgehend von Emile Lesne, L'économie domestique d'un monastère au IX ${ }^{\mathrm{e}}$ siècle d'après les statuts d'Adalhard, abbé de Corbie, in: Mélanges d'histoire du moyen-âge offerts à Ferdinand Lot (Paris 1925) 385-420.

81 Semmler (wie Anm. 72) 388, $12 \mathrm{ff}$.

82 Frühere Lit. bei Semmler/Verbulst (wie Anm. 72), ansonsten: Fred Schwind, Zu karolingerzeitlichen Klöstern als Wirtschaftsorganismen und Stätten handwerklicher Tätigkeit, in: Institutionen, Kultur und Gesellschaft im Mittelalter. FS f. Josef Fleckenstein z. s. 65. Geburtstag, hg. v. Lutz Fenske/Werner Rösener/Thomas Zotz (Sigmaringen 1984) 101-123, hier: 112f., 118-123; Kasten (wie Anm.77) 121-137; Hägermann, Abt (wie Anm.6) 354-369; Ganz (wie Anm. 77) $26 \mathrm{ff}$.

${ }^{83}$ Hägermann (wie Anm. 6) 360.

${ }^{84}$ Fried (wie Anm. 6) 399 f., 402.

85 Semmler (wie Anm. 80) 375. 
punkte, die hier Adalhards Bestimmungen und Abwägungen leiten, sind das nach Art, Herkunft und Menge ins Kloster jährlich (Ein-)Kommende und der Modus seiner Verteilung (durch den Beauftragten). Ob Adalhard über die prouendarii, das Hospiz, die Schweine handelt, zuerst bildet er den numerus plenus bzw. certus $^{86}$ zur Sache. Solche Gesamtheiten (omnia ${ }^{87}$ ), die er immer wieder als großzügig bemessene necessitates ${ }^{88}$ pro Tag, Monat oder Jahr faßt, werden dann im zweiten Schritt im Wege einer divisio ihren Bezugsinstanzen zugeordnet: den Empfängern von Brot und Zubrot (Schinken, Speck bzw. Wurst), Bier und Most, Kleid und Schuhen. Immer wieder aber ist Adalhard gezwungen, auch Subdivisionen zu erörtern, mag dies in standesspezifischen Brotqualitäten, Unregelmäßigkeiten des gruppeneigenen Fleischverzehrs im Jahreslauf, der unterschiedlichen Reifungsdauer und Haltbarkeit von Schinken und Wurst, den nahen oder fernen Standorten von Pflichtigen gründen.

An einigen Beispielen sei verdeutlicht, wie im Grundsatz gleich, im Detail aber variabel Adalhard seiner methodischen Maxime folgt, semper ex singulis divisionibus singulas rationes deducere. ${ }^{89}$

Im Breve über die provendarii ${ }^{90}$ benennt Adalhard zuerst den numerus plenus und begründet, wie er konstant zu halten ist. Im weiteren erscheint diese ,Gattung' in die zwei ,Arten' der clerici und laici, also standesspezifisch, geteilt. Beide wiederum werden subdividiert nach dem Platz, an dem sie innerhalb oder außerhalb der Abtei wirken, bzw. nach dem Handwerk, das sie verrichten. Damit ist der Grund gelegt für die eigentliche Aufgabe, die Distribution der Pfründen. Zuerst ist der victus an der Reihe. Er wird aufgeteilt in die tägliche Brotration, die Reichung von potio bzw. moratum (aufgelistet nach den fälligen Tagen im Jahreslauf) und zusätzliche Feiertagsverpflegungen. Nach einem Einschub de festis ab opere dominico vacuis wird über die Aufteilung des vestitus (besonders an die pulsantes) gehandelt. Hier ist die ratio wieder eine andere: das jährliche quantum an Tuniken, Schuhwerk, Handschuhen, Mantel, Mütze, Kissen, Decke aus dem Bestand der von den Mönchen abgelegten Stücke wird bestimmt. Adalhard läßt sich bei diesen rationes deutlich von wechselnden Gesichtspunkten leiten: bestimmte Statuseigenschaften, Sachgüter, Ortsbezüge, Tätigkeiten, Zeitpunkte regieren jeweils die einzelne Division.

Etwas einfacher entwickelt Adalhard die Austeilung von Brot, Bier, Wein, companaticus (Käse, Speck, Gemüse), Pfennigen, Holz und Kleidung an die Insassen und Diener des Hospitals (Breve II); dabei legt er großen Wert darauf, daß sich die

86 Semmler (wie Anm. 80) 365, 372, 375, 403. Bei deren - deutlich additiver - Bildung achtet A. auf Regelhaftigkeit und Durchschnittlichkeit - Ausnahmen verschiedenster Art werden angeführt und ausgeschlossen, seien es nun auswärtige Pfründner (365), schwankende Getreidequalitäten (375, dazu Fried (wie Anm.6) 399) oder Schweinequanta für die porta (396). ${ }^{87}$ Einmal spricht Adalhard sogar vom Insgesamt des Dispensiblen (omnis substantia nostra: 376).

88 Semmler (wie Anm. 80) 396, 401 u.ö.

89 Sermmler (wie Anm. 80) 407, $2 \mathrm{f}$.

${ }^{0}$ Semmler (wie Anm. 80) 365-372. 
Verantwortlichen sicher zwischen der numerisch genauen Quotierung (einschließlich dessen, was übrig bleibt oder woran es fehlt) und der Verteilung secundum consuetudinem bewegen. ${ }^{91}$

Der dritte Traktat über Getreide und Brot beginnt mit einem Kabinettstück vorbudgetärer Haushaltung, dem Erdenken und der Errechnung eines durchschnittlichen Jahresgesamtverbrauchs an Brot im Kloster, ausgehend von in corbus und modius mensurierten Getreide-Mehl-Brot-Relationen (VII). ${ }^{92}$ Wie der custos panum zu verfahren hat, wird im zweiten Teil in mehreren Schritten, bezogen auf besondere, die schlichte Verteilung gewissermaßen störende Umstände (Brotqualitäten und -größen, gruppeneigene Verbrauchsansprüche) dargelegt. $\mathrm{Daß}$ Adalhard seine Erwägungen nicht für das letzte Wort darüber hält, zeigt sich an der Bemerkung: Si ipse aliam rationem meliorem ad hoc probandum invenire potest, cum dei gratia faciat. ${ }^{93}$

In Breve VII, der divisio porcorum ${ }^{94}$, ist Adalhard nach der Teilung der Jahresmenge von 600 geschlachteten Schweinen in vier Empfänger-partes (Pforte, Kellerei, Pfründner, Abt) darum bemüht, dem Kellner Richtlinien dafür an die Hand zu geben, wie dieser mit den im lardarium nach Monaten gehängten Schinken, Speckseiten und Würsten so umgeht, daß für den kommenden Monat bestimmte Bestände im laufenden grundsätzlich nicht angebrochen werden oder irgendetwas (etwa infolge von Fastenzeiten) verdirbt. Ohne gesonderte rationes über die verschiedenen Reifungszeiten und Verbrauchstermine von Speck und Wurst geht es dabei nicht ab. Und schließlich soll der Kellner bei seiner Rechenschaft vor seinem Nachfolger das lardarium wohlgeordnet vorweisen können. Was die Vorratshaltung der Schweine für die porta betrifft, so kann Adalhard mit Bezug auf das zur Kellerei Gesagte sich kurz fassen: Omnes quidem sexaginta infra ipsum lardarium suspendantur et secundum illam rationem quomodo cellerarius facit de mense in mensem per triginta et triginta, ita portarius per singulas septimanas fatiat per unum et unum..$^{95}$ Am ausführlichsten traktiert Adalhard die Verzehntung der Salland- und Hufenerträge für den Unterhalt der porta (breve VI.) ${ }^{96}$ Der breite Fächer des Zehnten und sein Schwanken analog zum Jahresertrag macht es Adalhard unmöglich, einen stabilen Gesamt-numerus zu bilden. So bestimmt er die omnis decima de omnibus et in omnibus ausgehend von humanem und göttlichem $\mathrm{Zu}$ tun, und zwar wie folgt: id est uel de his quae ad monasterium elemosynae causa ecclesiis uel fratribus in diuersis corporalibus spetiebus uel mobilibus rebus sponte condonatur; similiter quicquid in diuersis laborationibus quolibet modo adquiritur uel in uariis peculium generibus enutritur uel in ipsis peculiis deo dis-

91 Semmler (wie Anm. 80) $372 \mathrm{ff}$.

$92 \mathrm{Zu}$ Adalhards Maßangaben vgl. Jean-Pierre Devroey, Units of measurement in the early medieval economy: the example of carolingian food rations, in: French History 1 (1987) 68-92.

${ }_{93}$ Semmler (wie Anm. 80) 377, 22 f.; ähnlich 382,18.

94 Semmler (wie Anm. 80) 403-408.

95 Semmler (wie Anm. 80) 407, 25-28.

${ }^{96}$ Semmler (wie Anm. 80) 388-402. 
pensante sine humana prouidentia sponte producitur ut est lac et lana; similiter fenum uel quae in arboribus gratis nascuntur ut est pastio uel diuersi generis fructus, quantum possibilitas admittit data fuerint, secundum qualitatem et quantitatem singularum rerum iuxta quod tempus permiserit sufficere possint. ${ }^{97}$ Wohl selten wird man im früheren Mittelalter eine so konzentrierte Formulierung des Ineinanders von menschlichem sich Mühen bzw. Planen und Gottes Fürsorge im Bereich von naturaler Erzeugung und Ernährung finden - auffällig ist dabei auch die Betonung des ,Suffizienz'-Prinzips. Entscheidend ist aber etwas anderes. Der Passus ist überdeutlich geprägt vom Programm und Vokabular der Schuldialektik, wie sie von Alkuin, dem Lehrer und Freund Adalhards, im Rahmen seines Artesprogramms, vorrangig in der Form von Lehrdialogen, erstellt worden war. ${ }^{98}$ Nicht nur die einführenden Begriffe zur grundlegenden Unterscheidung der Dinge wie genus und species sind explizit präsent, sondern ebenso wesentliche Kategorien für ihre nähere Bestimmung (modus, qualitas, quantitas, tempus). Betrachtet man die weiteren rationes zur Verzehntung, dann verdichtet sich dieser Eindruck. Die erste auf die allgemeine Charakterisierung des Zehnten folgende Erwägung bezieht sich auf Probleme des locus bzw. situs. Es geht Adalhard darum, wie die Heranschaffung der Zehnten aus weit entfernten villae bewerkstelligt werden kann, ohne daß den Bringpflichtigen dort (im Vergleich zu denjenigen, die in Nachbarschaft zur Abtei leben) Unrecht geschieht und unterwegs

97 Semmler (wie Anm. 80) 389, 6-12; ähnlich - ohne die Almosen - 402, 2-14.

98 De dialectia, in: MPL 101, hg. v. D. Frobenius (1863) 949-976; hierzu überblickend: Franz Brunbölzl, Geschichte der lateinischen Literatur des Mittelalters, Bd.1 (München 1975) 273 f., 547; sowie Jan P. Beckmann, Logik, in: LdM V (München 1991) 2072. Grundlegend zur Beziehung der Dialektik auf Theologie und Philosophy bei Alcuin und in seinem Umkreis: Jobn Marenbon, From the circle of Alcuin to the school of Auxerre. Logic, theology and philosophy in the early middle ages (Cambridge studies in medieval life and thought, 3rd series, 15, Cambridge 1981) $30 \mathrm{ff} ., 144 \mathrm{ff}$. sowie Gangolf Schrimpf, Das Werk des Johannes Scottus Eriugena im Rahmen des Wissenschaftsverständnisses seiner Zeit. Eine Hinführung zu Periphyseon (Beiträge zur Geschichte der Philosophie und Theologie des Mittelalters NF 23, Münster 1982) $23 \mathrm{ff}$. Zur dialogischen Methode bei Alkuin vgl. Wolfgang Edelstein, Eruditio und Sapientia. Weltbild und Erziehung in der Karolingerzeit. Untersuchungen zu Alcuins Briefen (Freiburg 1965) $114 \mathrm{ff}$. Zur Freundschaft zwischen Alkuin und Adalhard vgl. Kasten (wie Anm. 77) 47-51; sowie Ganz (wie Anm.77) 24 u.ö.; wichtig dort auch - als Indizien für die Präsenz Alkuinscher Denkpädagogik - die Nachweise von Schriften Alkuins im Bücherbestand von Corbie: Index s.v. Alcuin, corbie manuscripts. Die suche nach Anklängen an die Schuldialektik außerhalb der Statuta ist schwierig. Adalhards komputistische Schrift ist verloren. Zur Frage des Anteils von Adalhards verlorenem Traktat De ordine palatii et reipublicae dispositione $(781$ bzw. $810 / 14)$ am zweiten Teil von Hinkmars De ordine palatii von $882 \mathrm{vgl}$.Kasten (wie Anm. 79) 72-84. Vfn. stellt aber nicht heraus, inwieweit Adalhards Denkstil in Hinkmars Traktat präsent ist. Auffällig ist mir nur, daß der Begriff der divisio, zentral für die Gliederung des zweiten Teils (MG Font.Iur. III, hg. v. Thomas Gross/ Rudolf Schieffer (Hannover 1980) Z. 222, 225, 466) sich im ersten, Hinkmars Diktion rein repräsentierenden Teil nicht findet. Manche Passagen (402ff.) erinnern stark an die Statuta. Fragen nach divisionsgeleitetem Denkstil in den karolingischen Herrscher- bzw. Herrschaftsspiegeln wären anzuschließen an Fried, Vorbemerkungen (wie Anm.6), Herrschaftsverband (wie Anm.37). 
nichts verloren geht. ${ }^{99}$ Erst danach dividiert Adalhard die Zehnten, ohne dies explizit zu sagen, in sieben species, deren Erörterung zwar immer unter dem Hauptgesichtspunkt, quomodo verzehntet werden soll, abgehandelt werden, jedoch ihre eigene ratio erfordern. Die verschiedenen fruges (1) aus Feld, Garten und Baumbestand machen den Anfang; alle Sorten sind vor der Aussonderung des Saatguts zu verzehnten. Dann folgen die bestiae (2). Hier wird zuerst generaliter über den Verzehntungsmodus für alle gehandelt (sture Abzählung beim Durchtrieb durchs foramen clausure ohne Berücksichtigung der qualitas des Einzelstücks), dann specialiter über die neugeborenen Kälber, die Lämmer, die Zicklein. Die Verzehntung der Schweine muß Adalhard anders abhandeln, propter necessaria et incerta tempora illorum generandi et pariendi! Der zeitlichen Unberechenbarkeit ihres Vermehrungsverhaltens steuert Adalhard - als Suffizienzstratege - durch eine methodische Kehrtwendung, indem er die jährliche necessitas (auch unabhängig davon, ob die Eichelmast fette oder magere Schweine bringt) festsetzt, man kann schon sagen: kalkuliert. ${ }^{100}$ Darauf folgt das Verzehntungsgebot der Mühlen- und der Back- bzw. Brauhauserträge (3/4), eine von Adalhard eingeführte Neuerung. Anschließend geht es um Hopfen (5) und Holz (6). Den Schluß bildet die Verzehntung all dessen, was die vassi (Benefiziare) und casati homines (Hufner) ad opus suum erarbeiten oder was ihnen zuwächst. Auch in dieser ratio regiert der trivialdialektische Habitus die Gedankenfügung, kulminierend in der Forderung an die Pflichtigen: De omni genere autem diversarum animalium simile studium mittant, ut a iumentis usque ad pullos uel ova quicquid uiuum nutrierint aut a familia sua ... ex annali debito datur nihil in sua domo quantum provideri et rationabiliter fieri potest non decimatum remaneat. ${ }^{101}$

Im Licht dieser Beobachtungen nehmen sich Adalhards Divisionen über Getreide und Brot, über victus und vestitus der Pfründner und des Hospitals, über die geschlachteten Schweine wie das adäquate Umfeld der aufs Alltagshandeln durchschlagenden Rudimentärdialektik aus.

Was nun läßt sich über Schriftbezüge in den Statuta sagen? Vorweg verdient die Maxime betont zu werden, die Adalhard, gerade in Vorbereitung auf einen der Fälle schriftbezogenen Handelns im Kloster, zum besten gibt: Quod ideo hic scribere necesse non fuit, quia ex usu cotidiano tam dantibus quam accipientibus notissimum est. ${ }^{102}$ Immer wieder fallen in den Statuta die Worte memoria und consuetudo im Zusammenhang mit bewährtem Wissen und eingespielten Handlungsweisen ${ }^{103}$; sie bekräftigen nur, wie wenig nötig der Bezug auf scripta für die All-

99 Die Lösung ist eine genau kontrollierte Verkoppelung einer klosternahen mit einer klosterfernen villa. Auch hierbei stellt Adalhard dem Verantwortlichen eine andere coniunctio frei, unter der Bedingung allerdings, ut predicta ratio firmiter permaneat (Semmler (wie Anm. 80) 394, 9).

100 Weitere konkrete Bestimmungen über die Belassung des verzehnteten Viehs am Standort, über Verkauf draußen oder durch den portarius schließen sich an.

101 Semmler (wie Anm. 80) 402, 9-14. Es folgt die Anweisung an Uneinsichtige oder Unwissende, sie sollten sich im Zweifelsfalle an den zuständigen magister im Kloster wenden.

102 Semmler (wie Anm. 80) 365, 17-19.

103 Semmler (wie Anm. 80) 373f., 381, 385, 387f., 395, 406. Zur Bildung von Brauch durch 
tagshandlungen im Kloster war. Dennoch bezeugen fünf Hinweise auf Schriftstücke solchen Schriftbezug.

Abgesehen von Verweisen auf die Geltung der regula ${ }^{104}-\mathrm{da}$ ist zuerst der Hinweis, daß die drei wichtigsten ministri im Kloster, camerarius, cellerarius und senescalcus, je ein eigenes Exemplar vom breve über die Pfründner haben sollen. ${ }^{105}$ Ähnliches gilt für einen weiteren Beleg: die Benefiziare der Abtei sollen über die Verzehntungsordnung verfügen, damit sie instruiert sind et nullus se de ignorantia excusare possit. ${ }^{106}$ Beide Gebote belegen den Willen Adalhards, seinen Ordinationen bei den obersten Internen und beim Gefolge draußen ${ }^{107}$ gezielt Geltung zu verschaffen. Schriftbezug ganz anderer Art bezeugt der Hinweis, der cellerarius solle bei der Übergabe der Speck- und Fleischbestände an seinen Nachfolger diese nicht nur im lardarium vorzeigen, sondern auch per ordinem per brevem aufrufen (dicere). ${ }^{108}$ Hier wird listenförmige Bestandsführung angemahnt, die - mindestens - am Tag der Rechenschaft zur Inventur dienen soll. Die verbleibenden beiden Bezüge stehen im Zusammenhang mit Adalhards Verbesserung der Heranschaffung der Zehnten von entlegenen villae. Erstens soll ein treuer missus anhand eines brevis, qui illam decimam in Uualiaco (Wailly, dem entfernteren Gut) dinumerauit, im näheren Vaire die probatio daraufhin machen, ob alles angekommen ist, bevor es dann nach Corbie gebracht wird. Zweitens soll der portarius in Corbie per brevem ... de singulis locis omni anno semper omnia aufnehmen (suscipere), ut si necesse fuerit cognosci possit, utrum ipsi ministri hoc fideliter peregissent. ${ }^{109}$ Das Gebot zu einer doppelten, auf schriftliche Aufstellungen bezogenen Kontrolle der porta-Einkünfte - die eine bei der Verzehntung vor Ort, die andere bei Ankunft im Kloster - wird hier deutlich.

Hinter den Worten brevis/breve verbergen sich also sehr verschiedene Schriftstücke und -praxen: die auf langfristige Geltung angelegte Anweisung, sinnvoll zu verfahren, und die ad hoc erstellte bzw. laufend für einen festgelegten Zeitabschnitt geführte Aufstellung einkommender Dinge. Beide Typen sind in verschiedenen Händen innerhalb und außerhalb der Abtei. Der erste Typ steht den monastischen Ordines bzw. Consuetudines, ebenso aber auch königlichen Ordnungsversuchen wie dem Capitulare de villis nahe. Bedeutsam ist hier, daß die auctoritas, deren Traditions- oder Reformwille im scriptum bekundet wird, auf Verteilung des Wortlauts unter verschiedenen Betroffenen drängt, um dessen Wirkung zu garantieren. Der zweite Typ erinnert an das Gebot im Capitulare de villis, brevia über Einkommendes zu führen. Leider sind solche auf befristete Zwecke zu-

Wiederholung: 387, $18 \mathrm{ff}$; im vorliegenden breve erstmalig festgehaltener neuer Brauch: 399 , $21 \mathrm{f}$. (Verzehntung von Mühlenerträgen).

104 Semmler (wie Anm. 80) $383 \mathrm{f}$.

105 Semmler (wie Anm. 80) 365, 19f. Dazu Verhulst/Semmler (wie Anm. 80) 106.

106 Semmler (wie Anm. 80) 403, 7 ff.

107 Bemerkenswert ist hier, daß - wie oben angemerkt - die Hufner im Zweifelsfalle sich mündlichen Rat beim zuständigen magister im Kloster holen sollen.

108 Semmler (wie Anm. 80) 406, 2-6.

109 Semmler (wie Anm. 80) 392, 5-11 u. 21-393, 2. 
geschnittene, also kurzlebige Aufstellungen - bis auf eine frühe Ausnahme ${ }^{110}$ nicht überkommen. Sie bezeugen, für Klöster wie Corbie, aber den Willen, bestimmte Bereiche externer Appropriation (Einkommen) und interner Dispensation (Zuteilung) schriftbezogen zu bewältigen - Vorstufen zur Ausbildung von Einlauf und Innenlauf.

Natürlich erschöpfen diese beiden Typen keineswegs die damaligen Möglichkeiten. Bezeugt sind - meist kurze, im Ton barsche - Briefe von z. B. Einhard und Lupus, in denen Fragen bzw. Anweisungen an verschiedene Diener über Güter und Rechte, Lieferungen und Leistungen ergehen. ${ }^{111}$ Also auch die administrative ad hoc-Verständigung innerhalb der Grundherrschaft lief nicht allein über berichtende Boten ${ }^{112}$, sondern auch mittels schriftlicher Botschaften. Schließlich nimmt Lupus in einem seiner Briefe sogar Bezug auf diejenigen breves ${ }^{113}$, denen ich mich nun zuwenden möchte, die Güter- und Einkünfteverzeichnisse.

Zuvor sollte aber doch gerafft festgehalten werden, daß Adalhards Statuta in formaler Begrifflichkeit, Denk- und Darlegungsverfahren sowie Anwendungsbezug von der Trivialdialektik geprägt sind, die in seiner Zeit zunehmend als wichtiges Werkzeug geistiger Schulung propagiert wird. Die Statuta belegen die tiefgreifende Applikation divisionsgeleiteter Methodik bei der schriftgestützten Ordnung des klösterlichen ,Haushalts'-Jahrs. Schließlich zeugen sie von differenziertem, d.h. auf dauerhafte Geltung sowie auf begleitende Kontrolle ausgerichtetem Schriftbezug im Blick auf die gerecht gestufte Unterhalts-Suffizienz im Zentrum der Abtei genauso wie auf deren Gütern draußen. Der Denkstil Abt Adalhards wirkt mittels seiner schriftlichen Erwägungen und Anweisungen unmittelbar auf diejenigen ein, die sich nach den Statuta richten, sie also verstehen und - auch verschiedentlich schriftbezogen - anwenden sollen. Damit wird also auch das praktische Wirkungsfeld dieses Denkstils ahnbar. ${ }^{114}$

110 Gemeint sind die (Abrechnungs?)Listen von Saint-Martin (Tours, 2.H.7./beginnendes 8.Jahrhundert), hg. v. Pierre Gasnault, in: Chartae latinae antiquiores, hg. v. A. Bruckner/R. Marichal, Teil XVIII, France VI (Paris 1985) Nr.659, 3-39; für die Einordnung dieser Listen in den Rahmen der Grundherrschaft plädieren Walter Goffart, Merovingian Polyptychs. Reflections on two recent publications, in: FRANCIA 9 (1981) $65 \mathrm{ff}$. sowie Dieter Hägermann, Die rechtlichen Grundlagen der Wirtschaftsentwicklung im Nordwesten des fränkischen Reiches, in: Hartmut Atsma (Hg.), La Neustrie. Le pays au nord de la Loire de 650 à 850 (Beih. FRANCIA 16,1, Sigmaringen 1989) 358ff.; für die Deutung als fiskalisches Dokument (Steuererhebung) plädiert Durliat (wie Anm. 19) 129-138.

111 Einhard: MG Epp.V. (Hg. Karl Hampe, Berlin 1899) 105-143, bes. Nr.5/111, 9/113, 55/ 137; Lupus: MG Epp.VI (Hg. Ernst Dümmler, Berlin 1902/1925) Nr. 48/54, 75/70.

$112 \mathrm{Zu}$ grundherrlichen Botendiensten allgemein Thomas Szabó, Botenwesen, in: LdM II (München 1983) 484ff.; zur Karolingerzeit: Alfons Dopsch, Die Wirtschaftsentwicklung der Karolingerzeit vornehmlich in Deutschland (3. Aufl. Darmstadt 1962) II, 226-229; Einzelfall: Ludolf Kuchenbuch, Bäuerliche Gesellschaft und Klosterherrschaft im 9. Jahrhundert. Studien zur Sozialstruktur der Familia der Abtei Prüm (Beih. d. VSWG 66, Wiesbaden 1978) $142 \mathrm{ff} ., 323-330$.

113 Breves de facultate monasterii: MG Epp.VI (wie Anm. 103) Nr. 80/72.

114 Über Schulung in Corbie ist nicht allzu viel bekannt. Vgl. Corbie, abbaye royale (Facultés catholiques de Lille, XIII ${ }^{\mathrm{e}}$ centenaire, Lille 1963) $135 \mathrm{ff}$. (Mathon), $215 \mathrm{ff}$. (Wiesemeyer). Ganz (wie Anm. 79) $68 \mathrm{ff}$. hat - neben den Leistungen des Scriptoriums - über Annotationen 


\section{Die descriptio mancipiorum von St.-Victor/Marseille $(813 / 814)$}

813/14 entstand im Auftrag Bischof Wadalds die descriptio mancipiorum des Klosters St.-Victor (Marseille), ein ca. $200 \mathrm{~cm}$ langer und $15 \mathrm{~cm}$ breiter Rotulus, der, von einer Hand geschrieben, dreizehn villa-bezogene Aufstellungen von colonicae und den dazugehörigen Abhängigen samt ihrer Güter und Pflichten enthält. ${ }^{115}$ Das Stück bezeugt in vielem seine Nähe zur Erstverschriftung. Schon äußerlich fällt auf, daß das Geschriebene die ganze (seitlich kaum begradigte) Schreibfläche füllt. Nirgends wurde Platz für Ergänzungen gelassen. Jede descriptio ist als eigener Zeilen-Block abgesetzt und durch einen Querstrich von der folgenden getrennt. Die in der Regel auf die einzelne colonica (bzw. vercaria) bezogenen Aussageeinheiten, aus denen die descriptio besteht, sind nicht als zeilen- oder absatzförmige Einträge, sondern - einleitend durch eine gleich wiederkehrende Abbreviatur des Wortes colonica abgesetzt - direkt aufeinander folgend geschrieben. ${ }^{116}$ Jede descriptio wird von einem titelartigen Protokollsatz eingeleitet, der Invokation, villa-Bezug, Actum und Datum enthält. ${ }^{117}$ Dann folgt die syntaxarme Reihung der Angaben zu den einzelnen colonicae, deren Aufzählungscharakter bisweilen durch einleitendes item ausgedrückt ist. Sie bestehen meist aus einer zusätzlichen Ortsangabe, einer Folge von ungewöhnlich genau qualifizierten Leuten, deren Verhältnis zueinander nur nominal, nicht syntaktisch gefaßt ist, sowie

in verschiedenen Kodizes viel von dem geistigen Klima aufweisen können, das die Abtei sowohl zur Zeit Adalhards als auch in der Generation danach zu einem der Zentren der karolingischen Renaissance machte.

115 Benutzt habe ich: Benjamin Guérard (Hg.), Cartulaire de l'abbaye de Saint-Victor de Marseille (Coll. de Cartulaires de France IX, Paris 1857) II, 633-654; mir nicht zugänglich war: J. F. Breggi, Le polyptique de l'abbaye Saint-Victor de Marseille, essai de réédition. Thèse de Droit Université de Paris (Paris 1975). Eine eingehende Quellenkritik fehlt bislang. Britta Lützow (Berlin), der ich an dieser Stelle für Bereitstellung von Fakssimiles der Hs. danke, hat dies im Rahmen einer kurz vor dem Abschluß stehenden Studie (Familie und familia im Rahmen kirchlicher potestas) getan. Das Stück wurde bislang vornehmlich für regionalgeschichtliche Untersuchungen (wichtig: Jean-Pierre Poly, Régime domanial et rapports de production ,féodalistes' dans le Midi de la France (VIII ${ }^{e}-\mathrm{X}^{\mathrm{e}}$ siècles, in: Structures féodales et féodalisme dans l'Occident méditerranéen ( $\mathrm{X}^{\mathrm{e}}-\mathrm{XIII}{ }^{\mathrm{e}}$ siècles). Bilan et perspectives de recherches (Coll. de l'Ecole Française de Rome 44, Roma 1980) 57-84) oder unter demographisch-haushaltsgeschichtlichen Gesichtspunkten untersucht (Stepben Weinberger, Peasant Households in Provence: ca. 800-1100, in: Speculum 48 (1973) 247-57; Monique Zerner-Chardavoine, Enfants et jeunes au IX siècle: la démographie du polyptyque de Marseille 813-814, in: Provence Historique XXXI (1981) 355-384; David Herliby, Medieval Households (Cambridge Mass./London 1985) $76 \mathrm{ff}$. ).

116 Die Zeilen tanzen oft, wurden sicher nicht vorliniiert; die Schrift ist eine sehr unregelmäBige frühkarolingische Minuskel, mit Ansätzen zur Worttrennung. Bisweilen wird das Ende einer Aussageeinheit durch ein liegendes, mit Tinte ausgefülltes Rechteck markiert.

117 Z.B.: "(In nomine patris et filii et spiritu sancti et virtutes sanctae mariae ...) Discriptio (mancipiorum sanctae mariae massiliensis) de villa bedada (vel agro) factum temporibus domno vuadaldo episcopo de indiccione VI" $(633,635,641)$. 
deren Verpflichtungen zu verschiedenen Zinsen. ${ }^{118}$ Sechs der Beschreibungen schließen mit einer kurzen summarischen Bemerkung über die Gesamtzahl der vorher aufgeführten colonice. ${ }^{119}$ Die Rolle wurde vom Schreiber nicht als in sich abgeschlossenes Schriftstück ordiniert. Dementsprechend fehlt jeder Versuch, sich Wiederholungen zu sparen, weiter fehlen jegliche internen Bezüge (Anfang und Ende, oben und unten, vorher und nachher) sowohl in den einzelnen Beschreibungen als auch untereinander. Alles deutet darauf hin, daß die Niederschrift ohne Abstand nehmende, reflexive Einstellung zur verlaufsprotokollarisch stilisierten Sache erfolgte. Demgegenüber ist das Vokabular zur Aufzeichnung des Wissenswerten zu Teilen erstaunlich, elaboriert'. Meines Wissens gibt es kein Register aus dem früheren Mittelalter, in dem derart differenziert versucht wird, die Familiaren einer Herrschaft zu bestimmen. Ein Beispiel aus der am ausführlichsten gehaltenen descriptio de agro galadio: (2.) Colonica in Primo Capa. Giso, mancipium. Uxor Muscula. Adaltrudis, filia baccalaria. Ermentrudis, filia baccalaria. Tomas, filius, ad scola. Ilius, filius annorum VIII. Arsinda, annorum V. Dat tributo nummum I, pasco verbecem I. Maxima, vidua. Vibiana, filia annorum X. Magna, filia annorum VIII. Ermesindis cum infantes suos. Dominici, verbecarius. Maurobertus, mancipum. Uxor Superantia. Mauregotus, filius baccalarius. Scaemerus, baccalarius. Scolastica, vidua. (3.) Colonica in Caladio. Dominicus, colonus. Uxor Bene Nata. Cogneramnus, faber. Uxor Auteria. Ingiliramnus, filius, ad scola. Victor, filius annorum VII. Filia annorum VI. Onoratus, diaconus. ${ }^{120}$ Auch wenn man darauf verzichtet, den Sinn der einzelnen Termini vollends zu klären: die zu zwei colonicae gehörenden über 25 Leute werden mittels verschiedener Eigenschaften bestimmt - Rechtsstände (colonus, mancipium), Verwandschaftsgrade (uxor, vidua, filius, filia, infans), Aufgabenbereiche (diaconus, verbecarius, faber), Stellungen innerhalb oder außerhalb der colonia (baccalarius, ad scola) und das Alter, in Jahren gezählt, dienen dazu. Auch wenn meist die Kombination zweier Merkmale zur Einordnung ausreicht, der Wille zur treffenden Charakterisierung und Distinktion aller Familiaren ist überdeutlich. ${ }^{121}$

Die descriptio schreitet fast durchgängig von Name zu Name voran, geht also von der wirklichen Erscheinung, d.h. - im dialektischen Sinne - vom proprium aus. Die abstraktive Kennzeichnung nach verschiedenen Merkmalen folgt also der Markierung ad hominem, proprium'. Erst mit der Angabe verschiedener Qualitäten wird plausibel, wie sich die Stellung in der Nennungsfolge - sie könnte eine Aufrufsordnung zur effektiveren Erhebung am Ort darstellen - begründet. Man

118 Die einzelnen descriptiones sind aber jeweils ganz unterschiedlich ausführlich gehalten. Darauf kommt es hier nicht an.

119 Kapitel B-G, (Guérard (wie Anm.115) 633-641. Für die Beschreibungen, die den zweiten Teil des Stücks bilden ( $\mathrm{H}-\mathrm{N}$ ), hat es offensichtlich kein Gebot zur Addierung am Ende gegeben. Auch andere Merkmale deuten darauf hin, daß dies in leicht abweichenden Vorgaben für die Inventarisierung gründet.

120 Guérard (wie Anm. 115) 642.

121 Eine lockere Zuordnung mehrerer Merkmale zu wichtigen Akzidentien wäre unschwer möglich. 
beginnt mit dem colonica-Vorstand ${ }^{122}$, dann folgen Frau und Kinder, worauf weitere assoziierte Erwachsene (mit Kindern) angeführt sind. Eine rangartige Stufung nach Kombinationen von Merkmalen wie auctoritas, genus, aetas, consanguinitas, propinquitas u.a. ist recht deutlich. Welcher Gruppierungssinn in jeder Aufreihungseinheit insgesamt steckt - ,Betrieb', ,Haushalt', (Kern- oder Stamm-)Familie', ,koresidierende Verwandtschaftsgruppec-, soll hier nicht diskutiert werden. Es ist anzunehmen, daß die auf den colonicae lebenden Leute das vorrangige Ziel der Erstverschriftung waren, denn es fehlen vergleichbar detaillierte Bestimmungen der liegenden Güter sowie der Pflichten gegenüber der Herrschaft. Die colonica bzw. die vercaria werden nur benannt; woraus sie bestehen, muß man anderweitig erschließen. Mit den Abgaben steht es nicht viel besser; sie werden ohne weitere Erklärungen und Umstände aufgeführt (census: Schwein, Hühner, Eier; pascu(ari)um: Schafe; tributum: Geld); besonders jede nähere Zeitangabe fehlt - es gilt der pauschale Jahresbezug.

Umso auffälliger ist angesichts dieser descriptio-Struktur, daß die abschließenden Additionen (fiunt in summa) sich nicht auf die Leute und Zinse erstreckt, sondern allein auf die Anzahl der colonicae pro villa. Nur in einem Fall, wichtig genug, werden die colonicae in vier Arten geschieden (colonice, qui censo redere debent, c. de ministeriales, c. in beneficio, c. apste), bevor dann die Gesamtzahl genannt wird. ${ }^{123}$

Insgesamt gesehen hat man eine entstehungsnahe Fassung der Aufstellung vor sich, die nur in Ansätzen als Schriftstück ordiniert ist. Sie muß mit Bedacht auf eine klar gestaffelte Erfassung der Familiaren vorbereitet gewesen sein. So steht eine auffallend detailliert, nahezu kategorisierend angelegte, aber nicht stringent durchgeführte Differenzierung der namentlich aufgeführten Familiaren auf den colonicae im Vordergrund. An ihr ist eine mehrdimensionale Rangstufung erkennbar, deren regierendes Prinzip jedoch nicht begrifflich ausgedrückt ist. Es genügte eben die locus- und situs-basierte Charakterisierung der einzelnen Leute, in der, wenn auch nicht konsequent durchgehalten, mittels wechselnder Merkmalskombinationen eine tief gestaffelte Gliederung erreicht wird. Diesem allen entspricht durchaus die Bezeichnung im Protokollsatz der villa-orientierten Abschnitte: descriptio mancipiorum.

Die zusammenfassenden Aggregierungen (summae) beziehen sich allerdings überhaupt nicht mehr auf diese Differenzierungsleistung, sondern schürzen den dinglichen Bestand anhand des lokalen Ausgangsindex (colonica) - und zwar auch nur in einem Teil der villa-Beschreibungen. Was bei der Planung und Herstellung der descriptiones im Blick auf die mancipia differenziert wurde, fällt dem Summierungskalkül wahrscheinlich deshalb zum Opfer, weil dabei das Kriterium der Dauerhaftigkeit regiert. Der kategorialen Entfaltung des Aktuellen (familia) folgt die numerische Reduktion aufs Beständige (colonica).

122 Bisweilen begegnet der erstaunliche Relativsatz: qui ipsa colonica regere debet (Guérard (wie Anm. 115) 638, 643, 645, 651f.). Diese Bestimmung kann aber auch für Nachgenannte gelten (einschließlich Frauen).

${ }_{123}$ Guérard (wie Anm.115) 641. Dabei ist wieder verwunderlich, daß die colonice bei der voraufgehenden Einzeldescriptio nicht in dieser Art qualifiziert sind. 


\section{Das Polyptychon von St.-Germain-des-Prés}

(825-828)

Wohl in den Jahren 825-828, sicher aber vor 829 sind, wahrscheinlich im Auftrag des Abtes Irmino und im Vorfeld einer Aussonderung von Abteigütern für die mensa fratrum, mindestens 24 villikale Beschreibungen von Gütern, Familialen und Rechten der Abtei St.-Germain-des-Prés aus zwei Vorlagen in einzelne Hefte geschrieben und dann in ein volumen versammelt worden, das seit der Edition und dem Kommentar von Benjamin Guérard (1844) als das prominenteste grundherrliche Schriftdokument des früheren Mittelalters neben dem Capitulare de villis und dem Domesday Book gilt. ${ }^{124}$ Nach den kodikologischen und stilkritischen Untersuchungen von Jean-Pierre Devroey ${ }^{125}$ darf folgendes gelten: Der Kodex, von dem Anfang und Ende verloren sind, enthält recht sorgfältige Arbeitsabschriften, die bald nach dem Eintreffen der vor Ort erstellten villikalen EinzelBrevia im Klosterskriptorium ausgeführt wurden. Dafür spricht mehrerlei: die einheitliche Seitengestaltung (zwei Kolumnen, gegen Ende der einzelnen Brevia auch weitere Aufgliederung in Unterkolumnen), die Ausführung durch 11 Hände in recht klarer Minuskelschrift, wobei Wortabstände erst im Werden, Zahlzeichen und Namen durch mittelzeilige Punkte eingeschlossen, d.h. abgesetzt sind. Dazu kommt die Verdeutlichung von Sinneinheiten am Anfang durch links ausgestellte, nach Größe gestufte Initialen und am Ende durch Freilassung von Zeilenanteilen oder ganzen Zeilen samt abschließendem mittelzeiligem Punkt. So ist die Seite doppelt gegliedert: vertikal durch die Kolumnen, horizontal durch Absätze bzw. Abschnitte. Am Ende der descriptio findet man regelmäßig Spatien für (mehrzeilige) Ergänzungen. ${ }^{126}$ Jedes Breve beginnt mit einer neuen Seite, hat also seinen distinkten paginalen Beginn und Schluß, auch wenn Incipit- und Explicit-Formeln fehlen. Nur fünf Brevia tragen eine zeitgenössische pagus- bzw. locusbezogene

124 Die an Guérard orientierte Ausgabe von Auguste Longnon (Hg.), Polyptyque de l'Abbaye de Saint-Germain-des-Prés rédigé au temps de l'abbé Irminon (Paris 1895, ND 1978) Bd.2 wird nun ersetzt durch: Das Polyptychon von Saint-Germain-des-Prés. Studienausgabe, unter Mitwirkung von Konrad Elmshäuser und Andreas Hedwig hg. v. Dieter Hägermann (Köln/Graz 1993). In der Einleitung (Vff.) gibt Hägermann, unter Berufung auf Studien B. Bischoffs und F. Mütherichs zum aus St.-Germain stammenden Stuttgarter Bilderpsalter, einleuchtende Gründe für die Entstehungszeit an. Ich danke an dieser Stelle den Herausgebern herzlich für den Einblick in Faksimiles der Hs. (bes. Breve VIII) und Fahnen der Edition (Breve II, V, XIII, XIV, XVI). Ich zitiere nach der konventionellen Zählung: Breve (röm.), Abschnitt (arab.).

125 Jean-Pierre Devroey, Problèmes de critique autour du polyptyque de l'abbaye de SaintGermain-des-Prés, in: Atsma (wie Anm. 110) 441-465. Keine wesentlichen Modifikationen dieser Ergebnisse, aber genauere Beschreibungen der Hände bei Hägermann (wie Anm. 124) X-XVI sowie bei Konrad Elmshäuser/Andreas Hedwig, Studien zum Polyptychon von Saint-Germain-des-Prés (Köln/Graz 1993) Teil A (unter, Handschrift' pass.).

${ }_{126}$ Devroey hat - abzüglich moderner Zusätze - rund 100 Gebrauchsspuren ausgemacht. Seinem Eindruck nach (wie Anm. 125) 454 blieb der Codex etwa eine Generation lang ,lebendig'. Weitere Präzisierungen bei Elmshäuser/Hedwig. 
Überschrift. ${ }^{127}$ Die Numerierung der Brevia fehlt ganz, ebenso Verbindungen zwischen ihnen, etwa durch Verweise. ${ }^{128}$ Die villikalen Beschreibungen sind also nicht nur ordinativ, sondern auch inhaltlich klar voneinander geschieden: eine, allerdings unausgesprochen, topographische Komposition, deren Teile nicht ineinandergreifen.

Dagegen ist die Durchgliederung einzelner Brevia nicht nur durch Freizeilen, sondern auch mit Hilfe von Zwischenüberschriften schon recht weit fortgeschritten. ${ }^{129}$ Drei Typen sind abschnittsbildend eingesetzt. Relativ selten ist die Bezeichnung der Dekanie, eines Verwaltungsbereichs innerhalb der Villikation, in dem mehrere Ortschaften unter einem namentlich genannten decanus zusammengefaßt sind. Zwischenüberschriften dieses Typs lauten: DE DECANIA AGEMBOLDI. ${ }^{130}$ Wesentlich häufiger sind stets gleich formulierte Ortsbezeichnungen (De Fontanito: XXIV, 43/44 usf.), durch die Abschnitte innerhalb der descriptio gebildet werden. ${ }^{131}$ Mit dieser Ergänzung eines Ortsbezugs wird nicht nur mehr Konkretion in die descriptio gebracht, sondern im ,Umschlag' von der situativen Ortsnennung innerhalb von Satz und Zeile (in Cumbis) zur topographischen Ortsherausstellung außerhalb von Satz und Zeile sowie über dem Zeilenblock entsteht zugleich optische Prägnanz und sachliche Distanz (DE CUMBIS) in Schriftbild und Sinngliederung. ${ }^{132}$ Im dritten Typ wird die Folge der Sachaussagen graphisch (und terminologisch) profiliert. Nur ein simples Beispiel. In Breve II folgt nach der Aufführung aller Mansusinhaber (samt familia, Gütern, Abgaben und Diensten) eine Aufreihung von 26 Namen (und ihrer jeweiligen Zinspflicht von 4 Denaren), überschrieben mit DE CAPATICO, und eine weitere Namensreihung (21 Männer), überschrieben mit ISTI IURAVERUNT (II, 119, 120). ${ }^{133}$ Ohne die Titel wären die Namenreihen nicht verständlich, jene allein eröffnen den Sinn der Abschnitte: auf eine Gruppe Kopfzinspflichtiger folgen die eidverpflichteten Männer, die am Ort auf die Fragen über Güter, Leute und Rechte geantwortet haben. Aus anderen Brevia ist ersichtlich, daß Bezeichnungen dieser Art durchaus noch im Zeilenblock, den Abschnitt einleitend, verblieben sein können. ${ }^{134}$ Man kann im Vergleich förmlich ,sehen', wie einleitende Sätze bzw. Satzteile ohne jede Änderung ihrer sprachlichen Form zu Betitelungen werden. Man

\footnotetext{
127 "XIII, XVI, XXI, XXV: DE MANSIONIS VILLA QUAE EST IN PAGO PINCIACENSE, XXII: BREVE DE SICCAVALLE SIUE FORESTE."

${ }^{128}$ Nur in einem Falle (XXIII, $7 \mathrm{ff}$.) wird auf die Gleichheit der Abgaben und Dienste mit den coloni im Breve XXII verwiesen.

${ }_{129}$ Ohne solche Überschreibungen von Breveteilen kommen die Brevia III, VI, XII, XVXVIII aus.

130 XXIV, 55/56ff. Ebenso im Breve IX.

131 So einmal in Breve V, VII, XXIII, mehrfach: IX, XIII, XIX, XXI, XXII, XXIVf.

132 Man kann diesen Vorgang noch weiter ,zerlegen ${ }^{c}$ : die Profilierung des Schriftbildes durch heraushebende Versalien; der Unterschied zwischen geplanter und nachträglicher Überschriftung (durch Freilassung einer Zeile zwischen den Abschnitten oder durch Eintrag in freigebliebene Zeilenspatien). Derlei ist z. B. gut am Breve XIII zu ersehen.

133 Ähnlich I, 19; IV, 26, 33, 34.

134 Z. B. VI, 56; IX, 293 ff.; XIV, 89. In V, 86 schon in Versalien geschrieben.
} 
hat damit Überschriften vor sich, die entweder noch deutlich auf das Folgende zeigen, es nahezu ,mündlich ' ankündigen: isti sunt servi. ${ }^{135}$ Oder - wie in der Mehrheit der Fälle - die Betitelung ist schon im Bewußtsein gefaßt, ,über' das Folgende das Treffende sagen zu sollen, dies noch nahezu in Satzform beschreibend (z. B.: de (h)is qui multones solvunt; XXIV, 92) oder in schon nominaler Kürze (de hospitibus; XXIV, 105). ${ }^{136}$

Der Höhepunkt formaler Gliederung der descriptio ist erreicht, wenn die Absätze bzw. Abschnitte mit römischen Ziffern durchgezählt sind, so etwa im Breve II, XII, XIII und XXII. ${ }^{137}$ Schließlich fehlen auch marginale Zusätze nicht, die vielfach in tironischen Noten geschrieben sind. Sie dienen sowohl zur Korrektur als auch zur (späteren) Ergänzung. Im Blick auf das Schriftbild und die Ordination des ganzen Polyptychums und seiner Einzelbrevia gewinnt man also den Eindruck, daß eine breite Palette von Ordnungsmitteln im Spiel ist, von denen jedoch die Erhebenden vor Ort oder die Schreiber im Kloster neben- und nacheinander sehr unterschiedlich Gebrauch gemacht haben. Möglichkeiten zu ,mehr' Ordnung im Innern der Brevia waren also vorhanden und wurden genutzt. Allerdings bleibt unklar, welchen Anteil an Ordnungsleistung den Akten der Erstverschriftung zukommt und was spätere Zutat ist. Die Bearbeitungsspuren rechtfertigen es, insgesamt von einem „document de travail“ zu sprechen. ${ }^{138}$ Verglichen mit dem Rotulus aus der Abtei St.-Victor schließlich ist das Ordinationsniveau des Codex aus St.-Germain-des-Prés insgesamt deutlich höher.

Wie steht es nun mit dem Beschreibungsstil? Devroey hat durch Vergleich wichtiger Formeln und ihrer Sequenzen festgestellt, daß - wie bereits angedeutet die Reihenfolge der Brevia im Kodex einer räumlichen Ordnung, d.h. der Lage der Güter in Bezug auf einander und zur Abtei entspricht. Dies bedeutet, daß entweder die erhebende Gruppe einen nach Lage und Bedeutung der Güter geordneten Umgang hinter sich gebracht hat (Itinerar) oder die bereits vorliegenden Brevia im Kloster in eine diesbezügliche Reihenfolge gebracht wurden (Redaktion) beide Vorgänge sind natürlich kombinierbar. ${ }^{139}$ Das Polyptychum ist in der vorliegenden Fassung also als ein geordnetes Ganzes konzipiert und ausgeführt worden, einschließlich verorteter Spatien für Ergänzungen. Wichtiger für meine Frage nach dem Zusammenhang von Denkstil und Schriftpraxis ist jedoch, daß die Kommission, die die villae aufsuchte, dortselbst die Befragung der ausgewählten

135 XI, 11, IX, 140: "isti sunt hospites de decania Warimberti."

${ }^{136}$ Ein undekliniertes Nomen, die Abstraktion zum syntaxlosen Begriffstitel, ist mir als Titel nicht begegnet.

137 In Breve XII sind zuerst die Abschnitte über den mansus indominicatus und die mansi ingenuiles durchgezählt (I-X CII), dann folgen die mansi serviles (113-118 als I-V); die restlichen drei Absätze sind nicht mehr numeriert. Vgl. auch Devroey (wie Anm. 125) 450.

${ }_{138}$ Devroey (wie Anm.125) 453.

139 Über villikale Erhebungen als geplante und in Kommissionen durchgeführte Reisen (Erhebungs-,Itinerar') vgl. zu Prüm: Ingo Schwab (Hg.), Das Prümer Urbar (Rheinische Urbare Bd.5 = Publikationen der Gesellschaft für Rheinische Geschichtskunde XX, Düsseldorf 1983) 38-152, 337-345 (Karten); zum Domesday-Book: V. H. Galbraith, The Making of the Domesday Book (Oxford 1961) 59-66. 
Zeugen (isti juraverunt ${ }^{140}$ ) nach einem überall nahezu schematisch angewandten "questionnaire unique particulièrement détaillé" ${ }^{\text {“141 }}$ vornahm. Es bietet sich also die Möglichkeit, das Vokabular und die Darlegungsfolge als Resultat einer verschriftungsorientierten Wirklichkeitswahrnehmung zu interpretieren, die bis ins Detail vorbereitet und konsequent durchgehalten wurde. Zweierlei vorweg. Man hat eine streng stereotypierte Sprache vor sich. Die Brevia bestehen aus asyndetischen Reihungen von Sätzen mit nahezu identischer Aussagesyntax: Habet ibi farinarium I, unde exit in censum de annona modios XXX. Die mit Prädikaten wie est, habet, tenet, solvit, facit beginnenden Sätze münden, egal durch welche Adverbialbestimmungen bzw. Nebensätze sie erweitert sind, in numerische Qualifikationen des Objekts. Was am Satzende steht, ist das Ziel der Einzelaussage: eine verzifferte Anzahl. Gleich ist auch der Aufbau der Brevia: nach dem Herrenhof (mansus indominicatus) folgen die mansi der Familiaren, nach Unterorten und ständischen Rängen gruppiert, danach die nicht verhufbaren kleineren Besitzungen (hospitia), dann, soweit vorhanden, die Kopfzinser, Zeugen und Benefiziare sowie schließlich die durch freie Zeilen deutlich abgesetzten, aber nicht überschriebenen summae. Jedes Breve ${ }^{142}$ zeugt also schon seiner groben Gliederung nach von strengem Formalismus.

Er gilt aber auch für die Details. Man hat bisweilen den Eindruck, daß die Brevia sich mindestens in Teilen nur durch die Orts- und Personennamen und die Zahlzeichen voneinander unterscheiden: ubi, quis und quantum als quasi einzige Variable in einem starren Schema. Nach heutigen Maßstäben kommt dies alles einer ,Erhebung' nahe.

Das Schema selbst ist nun etwas näher zu betrachten. Die descriptio des Indominicatum-Komplexes könnte man als, habet ibi-Abschnitt bezeichnen, denn er besteht, wenn er vollständig vorliegt, aus 6 mit (Sanctus Germanus) habet ibi beginnenden Sätzen, in denen in relativ fester Reihenfolge mansus, terra arabilis, vinea, prata, silva, farinarium und ecclesia aufgeführt sind. Die Ordnung geht also vom ,Hof' aus, die Pertinenzen sind nach ihrem Aufwands- bzw. Versorgungsrang gestuft. In den näheren Bestimmungen regieren die dort und damals geläufigen, in ihrem Realbezug und ihren internen Beziehungen heute so schwer zu begreifenden Stück- bzw. Maß-Bezeichnungen. ${ }^{143}$ Im Blick auf die Ausstattung des

140 II,120; VI,56; XIII,111 u. ö.; isti jurati dixerunt: IX,295.

141 Devroey (wie Anm. 125) 446. Zur ,Fragebogen'-Frage vgl. meinen in Anm. 30 genannten Aufsatz.

142 Auszunehmen ist Breve XII. Es enthält über 40 Schenkungsnotizen, ergänzt um die aktuellen Inhaber und deren Pflichten.

143 Longnon (wie Anm. 123) 17-30; auf das dornige Terrain frühmittelalterlicher Maßformen und Meßpraktiken kann ich mich, so wichtig dies für das Zusammenspiel von Denkstil, Subsistenz und Appropriation ist, hier nicht begeben. Grundlegende Orientierung über traditionales Messen bietet Witold Kula, Measures and Men (Princeton 1986); wichtige geistesgeschichtliche Einzelstudien zum Mittelalter sind beisammen in: Albert Zimmermann $(\mathrm{Hg}$.), Mensura. Maß, Zahl, Zahlensymbolik im Mittelalter (Miscellanea Mediaevalia 16, Berlin/ New York 1984); zur mittelalterlichen Agrarmaßproblematik vgl. den Überblick von Harald Witthöft, Wirtschaftliche und soziale Aspekte des Umgangs mit Agrarmaßen in Mittelalter 
Herrenhofs mit Gebäuden genügt das Attribut sufficienter - hier machte eine detaillierte Auf- und Auszählung offensichtlich keinen Sinn. Das in ,Schläge‘ (culturae) gegliederte Ackerland ist aufgeteilt bzw. gemessen in bunuaria; dazu wird das jährlich notwendige Saatgut in modii angemerkt. Wiesen und Wingerte sind in aripenni gezählt, ihr jährlicher Ertrag in Karren Heu bzw. Scheffel Wein taxiert. Der Wald ist in ,Umkreis'-Meilen geschätzt (sicut estimatur totum in gyro), sein Ertrag auf die Anzahl Schweine fixiert, die zur Eichelmast im Spätherbst in ihn getrieben werden können. ${ }^{144}$ Jeder Bereich des Indominicatum, das gilt auch für die hier nicht weiter erläuterte Mühle und die Kirche, wird also mit einer ihm eigenen Kombination von Größe und jährlich zu erwartendem Ertrag charakterisiert. Wo dieser prinzipiell ungewiß ist, dies gilt damals für die Getreideernten, wird der jährliche Aufwand (Saatgutmenge) zum Angelpunkt der Charakterisierung.

Nicht minder fein distingiert wird im zweiten Teil der descriptio. Drei Sinnbereiche sollten hier unterschieden werden: der mansus, die auf ihn radizierten Pflichten und die ihm zugehörigen Familiaren. Drei, wenn nicht gar vier verschiedene Distinktionsdimensionen stehen allein zur Qualifikation des mansus bereit. Leitend ist die rechtsständische Tripartition in mansus ingenuilis, lidilis und servilis - unverhufte Landanteile und ihre Bebauer einmal abgezogen. Diese Rangstufung wird in der Aufzählungsfolge recht rigide durchgehalten; zuerst sind die Ingenuilmansen an der Reihe, dann folgen die rangniedrigeren Typen. Zweitens wird regelmäßig die liegende Habe der Hufen verzeichnet. Es sind gezählte bunuaria an Acker-, aripenni an Wein- und Wiesenland. Die Erfassung folgt hier also recht genau dem Formular für den Dominikalhof. Dabei wird deutlich, daß ein mansus ingenuilis (MI) in der Regel mit mehr Acker-, Wein- und Wiesenland ausgestattet ist als ein mansus servilis (MS). ${ }^{145}$ Feinere Bemessungen der verschiedenen Landanteile werden regelmäßig durch Halbierung, Drittelung und Viertelung ausgedrückt. Sie dürften damalige Vermessungspraktiken und die ihnen entsprechenden Rechenarten ausdrücken. Auffällig ist nämlich, daß die Hälfte (medietas, dimidius) von etwas (mansus, bunuarium, aripennum, antsinga u.a.) nicht als pars gilt wie das Drittel oder Viertel. ${ }^{146}$ Hier dürfte sich die Halbierung als damals eigenständige Divisionsart spiegeln. Drittelung und Viertelung erweisen den Bezug

und Neuzeit, in: ders./J.-C. Hocquet/I. Kiss (Hg.), Metrologische Strukturen und die Entwicklung der alten Mass-Systeme (Sachüberlieferung und Geschichte 4, St. Katharinen 1988) 104-118.

144 Eine weitere Division der Ackermaße ergibt sich dadurch, daß das mansus-Land nicht nur in bunuaria, sondern zusätzlich in ancingae und iurnales aufgeführt werden kann. Damit nicht genug: das dominikale Ackerland wird aus dem Blickwinkel der bestellungspflichtigen mansus-Inhaber nicht in bunuaria, sondern in perticae gezählt.

${ }_{145}$ Nur zwei Beispiele: In Breve IV etwa verfügt der MI durchschnittlich über etwa 4,5 bunuaria Ackerland, 1,6 aripenni Wingert und 0,5 aripenni Wiese, beim MS sind es dagegen im Schnitt 3,5, 1,5 und 0,15. Ähnlich ist die Stufung in Breve VIII (MI: 5-1,3-3; MS: 3,6-1-1,3). Bei diesen geringen Unterschieden ist natürlich im Einzelfall mancher, große‘ MS besser ausgestattet als viele ,arme“ MI.

${ }_{146}$ Der Bezeichnungsbestand ist der folgende: tertia pars, duae partes (2 Drittel), tres partes (3 Viertel), quarta pars. Nur eine quinta pars de aripenno (XXIII,16) habe ich finden können. 
auf Duodezimal- bzw. Sexagesimaldivision. Obwohl es bisweilen auch zur Viertelung des mansus kommt ${ }^{147}$, regieren solche Teilungen die Angaben im Bereich der aripenna-gemessenen Wingerte und Wiesen. Drittens wird, wenn auch selten, der mansus als absus, d.h. ohne aktuellen Bebauer bzw. Ertrag, qualifiziert - dies im Gegensatz zum mansus vestitus. ${ }^{148}$ Schließlich wird mehrmals zusammenfassend darauf hingewiesen, daß es auf einzelnen mansi (im engeren Sinne der Hofstätte) mehrere foci gegeben haben muß. ${ }^{149}$

Die Differenzierung und Aufführungsfolge des Pflichtensolls der mansi hängt einerseits daran, welchem Rentenformular man bei der Aufnahme am Ort gefolgt ist. ${ }^{150}$ Die Unterschiede sind, was die Formenkombination und die Detaillierung einzelner Frondienste betrifft, beträchtlich. ${ }^{151} \mathrm{Zum}$ anderen sind die meisten $\mathrm{Ab}-$ gaben und Dienste auf die verdinglichte Rechtsqualität des mansus radiziert und haben kaum etwas mit dem Umfang seiner Landausstattung sowie der Anzahl und den Standesverhältnissen der auf ihm lebenden Familiaren zu tun. Über diesen ,abstrakten', die dingliche und familiale Aktualität der Hufe außer acht lassen-

147 Z.B. Breve II, IX. Vergleicht man die Land-Ausstattung halbierter bzw. geviertelter mansi miteinander, dann wird deutlich, daß die Teilungskriterien nicht allein auf ersterer fußen können, sondern der überlieferte Rechtsstand sowie der Stand der Besetzung (Zahl der Kernfamilien und der foci) mitentschied.

148 Z.B. IX, 291, 304; XI, 10; zum vielschichtigen Sinn von absus ist hier nicht Stellung zu nehmen. Vgl. dazu Jean-Pierre Devroey, Mansi absi: indices de crise ou de croissance de l'économie rurale du haut moyen âge? in: Le Moyen Age 82 (1976) 421-451.

149 So in IX, 4; XI, 10; XII, 1, 77, 99; XXII, 97; XXIII, 26.

150 Eine ausführliche Interpretation der verschiedenen Rentenformulare in Polyptychum fehlt bislang. Einen Eindruck über die sachlichen Variationen (im Blick auf lokale Besonderheiten und regionale Traditionen) vermittelt Hans-Werner Goetz, Bäuerliche Arbeit und regionale Gewohnheit im Pariser Raum im frühen 9. Jahrhundert. Beobachtungen zur Grundherrschaft von Saint-Germain-des-Prés, in: Atsma (wie Anm. 110) 505-522.

151 Hier zwei Beispiele zur Veranschaulichung der Unterschiede. (1) VIII,3: "Vulfardus colonus ... tenet mansum ingenuilem I ... Solvit ad hostem de vino modios X, in pascione modios III, soalem I, valentem solidum I. Arat ad hibernaticum perticas VI, ad tramisem perticas III. Corvadas, caplim, caropera, manopera, quantum ei iubetur. Pullos III, ova XV. Carritat vinum et iniungitur. Scindolas C. Facit in prato aripennum I. ..; 28: Uuarimbertus servus ... Tenet mansum servilem I .. . Solvit de vino in pascione modios III, multonem I. Facit in vinea aripennos IIII. Arat ad hibernaticum perticas III, ad tramisem perticam I. Manopera, caropera, corvadas, caplim, ubi ei iniungitur. Pullos III, ova XV; scindolas C. De sinapi plenum staupum.” (2) XIII,1: “Hildegaudus ... Nadalinus ... Rainlandus .. Isti tres ... tenent mansum ingenuilem I ... Solvunt ad hostem omni anno, solidos III; de lignericia denarios IIII. De capite suo denarios IIII; de spelta, omnes qui aliquid de ipso manso tenent et ingenui fuerint, modios II; et de unoquoque foco, de viva annona dimidium modium; et inter totos qui ipsum mansum tenent, asciculos C, scindolas totidem, dovas XII, circulos VI; et unusquisque III pullos, ova X. Arant ad hibernaticum perticas IIII et ad tramisum IIII et ad proscendendum IIII; et per unamquamque sationem curvadas III, et quartam et quintam, cum pane et potu. Et quando curvadas non faciunt, in unaquaque ebdomada III dies operantur cum manu; et quando curvadas faciunt, nullum diem operantur ad opus dominicum, nisi summa necessitas evenerit. Et claudunt de tunini perticam I in curte dominica; et claudunt ad messes perticas VIII. Faciunt caropera propter vinum in Andegauo cum duobus animalibus de manso, et ducunt illud usque ad Sonane Villam. Et in madium mense facit caropera Parisius cum asciculos, similiter cum duobus animalibus." 
den Formalismus ist hier nicht zu diskutieren. ${ }^{152}$ Aus ihm ergeben sich aber ordinative Möglichkeiten. Vor allem kann man sich Wiederholungen sparen. Das Verfahren stellt sich wie folgt dar. Dem ersten mansus ingenuilis bzw. servilis des Breve ist das für die Domäne typische Gesamt an Abgaben und Diensten beigegeben. Er exemplifiziert für alle folgenden mansi gleichen Rechtstyps; so kann man sich danach auf die Formel beschränken: (solvit) similiter. ${ }^{153}$ Konsequenz dieser verweisenden Verkürzungen ${ }^{154}$ ist natürlich, $d a ß$ Ausnahmen bzw. Abweichungen vom normalen, Ganzen' gesondert notiert werden müssen. ${ }^{155}$ Census und servitium selbst sind im einzelnen recht verschieden aufgefächert. ${ }^{156}$ Meist beschränkt man sich auf die bloße Nennung der jährlichen Leistungen. Doch finden sich immer wieder breite Entfaltungen ad rem. Eine Holzabgabe etwa wird zur Sequenz verschiedener Einzelformen (Scheite, Schindeln, Faßdauben, Reifen) aufgefächert. Im Zeitbezug ergibt sich mehr Tiefe, wenn der betreffende Zins in der Abfolge von zwei oder drei Jahren der Sache oder Höhe nach wechselt, wenn für Dienste die Dauer (Tag), der Fälligkeitstakt (Woche) oder ein fester bzw. variabler Termin (Mitte Mai; Pflüge-, Saat- und Erntezeiten) vermerkt sind. ${ }^{157}$ Auch Konkretisierungen des Ortsbezugs sind häufig: en passant lernt hier der Leser die Flurgliederung, die Gärten, die Hofreite und die Bestimmungsorte der Fronfuhren kennen. Neben quid, quando und ubi kommt es auch hin und wieder zur Präzisierung des quis (Mann bzw. Frau als Standes-,Person', als Hufen-Inhaber, als Repräsentanten einer Herdstelle) und auch des qua de causa (Troßpflicht im Heereszug, Waldnutzung, Weidenutzung). Es fehlt noch die Aufführung der Familiaren auf den Hufen. Ausgehend vom proprium des Namens kann - ähnlich, aber nicht so breit ausgefächert wie im Rotulus von St.-Victor - nach dem Rechtsstand (colonus/a, lidus/a, servus/ancilla), der Zugehörigkeit zum Herrschaftsverband (homo Sancti Germani) und der Stellung in ihm (votivus/luminarius, advena/ex-

${ }^{152}$ So ,unangepaßt $\mathrm{t}^{\mathrm{i}}$ im Blick auf die Ausnutzung des Dienst- und Ertragspotentials auf der Hufe dieser Formalismus auch wirken mag - zunächst sollte er als auf Stabilität hin artikulierter Anspruch ernstgenommen werden. Neuere Debatten über das Irreale bzw. Wirklichkeitsfremde der Polyptychen auf der einen, ihren situationsgerechten Realismus auf der anderen Seite werden diesem Grundsatz nicht gerecht.

153 Mit Bezug auf den namentlich genannten Inhaber des exemplifizierenden mansus wird in Breve VII operiert. In Breve XXI,3 findet sich die Formulierung: solvunt aequaliter omne censum sicut alii mansi ingenuiles.

154 Sie können auch pauschalere Formen annehmen: sicut superiores o. ä.

155 Eine Fülle von Ausdrücken wie: excepto (preter, absque) memoratum censum steht dafür. Auch die Halbierung kommt vor (medietas: z. B. XIII pass.).

156 Ich beziehe mich hauptsächlich auf die in Anm. 151 gegebenen Beispiele.

157 Feste und variable Saison-, Monats- oder Festtagstermine sind im Polyptychon von St.Germain noch ausgesprochen selten. Eigenartigerweise sind die Zins- und Frondiensttermine im früheren Mittelalter bislang nicht eingehend untersucht. Ich kann die Zeitbezüge der Appropriation und ihre Entwicklungen hier nur punktuell andeuten. Die Jahrhunderte währenden, regional recht unterschiedlichen Wege vom pauschalen Jahresbezug aller Pflichten (8. Jahrhundert) über die Kombination von monatssituierten Fronden mit festtagsorientierten Abgaben (Mitte 9.-Mitte 11. Jahrhundert) bis zur termingeleiteten Abgabenordnung (ab Mitte 11.Jahrhundert) bleiben noch zu rekonstruieren. 
traneus, hospes), der Verwandtschaft (uxor, mater; frater, soror, uxor; filius, filia, nepta), schließlich auch dem besonderen Aufgabenbereich (ministeriales: iudex, maior, decanus, cellerarius, forestarius, mulinarius u. a.) differenziert werden. Die Standardkennzeichnung der namentlich Genannten besteht jedoch in der Koppelung von Rechtsstand, Zugehörigkeit zur familia und kernfamilialem Verwandtschaftsgrad. Ein beliebiges Beispiel: Bertulfus lidus et uxor eius colona, nomine Gisoberga, homines sancti Germani ... (VIII, 4). Die Gruppierung folgt zum einen dem kernfamilialen Rangschema: der verheiratete Mann mit seiner Frau sowie den zugehörigen Kindern oder ein Mann (wahrscheinlich der älteste Sohn), die Mutter sowie unverheiratete Brüder und Schwestern. Auch im Falle mehrerer Inhaber eines mansus verfährt man so; der zweite Mitinhaber (socius) folgt erst nach der familia des ersten usf. Nimmt man noch hinzu, daß den vorwiegend mit coloni besetzten mansi ingenuiles die vorwiegend mit servi besetzten mansi serviles und danach die unverhuften (d.h. landarmen oder landlosen) Leute folgen, dann ergibt sich ein klares Schema, nach dem die Familiaren distingiert, rangiert und gruppiert werden: Ausgangskriterium ist die Bindung an den mansus, die erste Subdivision erfolgt nach dessen Rechtsqualität, innerhalb des mansus wird nach Inhaberrang aufgeführt, dann gelten die familialen Stellungen - also eine präzise, fast starr anmutende Verschachtelung nach klaren Kriterien.

Wenige Bemerkungen noch zu den Zusammenfassungen der einzelnen Brevia. Devroey ${ }^{158}$ hat herausgefunden, daß von den 20 überschriftslosen summae 15 in einem Zuge von der das Breve anlegenden Hand, 5 hingegen später, wohl in der 2. Hälfte des 9. Jahrhunderts hinzugefügt wurden. ${ }^{159}$ Insgesamt kann man 8 verschiedene Formulare unterscheiden; die Schreiber hatten also nahezu freie Hand beim Addieren. Alle gleichen sich jedoch darin, daß nur die wichtigsten Abgaben, nicht die Dienste der mansi, sowie vereinzelt auch Kopfzinse summiert sind.

Ein Beispiel: SUNT in Novigento, secundum quod supra scriptum est, mansi ingenuiles XXIIII et medius. Solvunt pro hostilicio vini modios CCV, pastione vini modios LXXIIII, soales XX et medium, multones IIII, pullos cum ovis LXXIIII.

Sunt mansi serviles X. Solvunt pastionem vini modios XXI et medium, multones VIII et medium, scindolas DCL, pullos cum ovis. ${ }^{160}$

Auffällig an diesen Zinssummen ist, daß sie sowohl mit ihrem Hebungsgrund als auch mit dem Mansustyp verbunden geblieben sind. Die verschiedenen Scheffelmengen Weins hätte man mühelos dieser Bezüge entkleiden und zur Gesamtsumme addieren können ${ }^{161}$, ebenso die Schafe. Diese Abstinenz zu weitergehender Abstraktion von Spezifika verschiedener Art läßt sich verallgemeinern. Dies

158 Devroey (wie Anm. 125) $445 \mathrm{f}$.

159 Gerade sie beginnen mit Rückverweis: sicut suprascriptum habetur o. ä. (VI-VIII, XIX).

160 VIII, 42. Verglichen mit den Abgabenreihen der exemplifizierenden MI $(3,24)$ und MS (28) fehlt der MS-spezifische Senfzins; die Eier sind nicht addiert. Es fehlen weiter die Geldzinse (39). Anderswo fehlen Schindeln, Wolltücher.

161 Dies geschieht auch einmal in XVI, 93: Solvunt insimul, inter ingenuiles et serviles, de vino in pascione modios CXXX. 
betrifft auch die Geldzinse. ${ }^{162}$ Zur abgaben- und hufenübergreifenden Stückbzw. Formaddition ist man also kaum vorgedrungen. Erst dort, wo dies - selten genug - geschieht, stellt sich die Formulierung ,sunt in summa' ein.

In den die Brevia abschließenden Zusammenfassungen ist also beileibe nicht alles Addierbare enthalten. Nur die mansi und ihre wichtigsten Abgaben ,zählten' die Leute auf den mansi nicht, die kleineren Anwesen nicht, der Herrenhof nicht. Diese Additionen verbleiben im Rahmen des Spezifischen: der mansus-eigenen Abgabe, des mansus-Typs pro villa. Selbst wenn man diese Bindungen überspringt und gleiche Sachen verschiedener Herkunft addiert, dringt man nicht zur übergeordneten, subsumtiven Abstraktionsstufe vor: aus den librae, solidi und denarii wird kein ,argentum', aus Ochsen, Schafen und Schweinen keine Anzahl ,Vieh` (capita). ${ }^{163}$

Ich hoffe, wenigstens in Ansätzen gezeigt zu haben, wieviel das Polyptychon von St.-Germain-des-Prés, auch im Vergleich zur Rolle von St.-Victor, zu bieten hat. Nicht nur die Folgen der karolingischen Schriftreform sind deutlich spürbar. ${ }^{164}$ Auch die Ordinationsgewinne durch geplante Neuschrift in Einzelhefte Seiteneinrichtung, Überschreibung, Betitelung, Durchgliederung, Absatzbildung und -zählung, Freilassung von Spatien u.v. a. - fallen ins Auge. Dazu kommen die Indizien für fortgesetzten Gebrauch (Korrekturen, Summen, Zusätze).

Das sehr einheitliche Beschreibungsvokabular für alle Brevia ist deshalb wesentlich erweitert, weil nicht nur der Herrenhof, sondern auch die Landausstattung der mansi und ein breiter Fächer von Abgaben, besonders aber Diensten hinzugekommen sind. An diesen Gegenstandserweiterungen ist noch besser zu sehen, wie im Detail distingiert, gruppiert und dabei rangiert wird, wie vielstufig der Bestimmungsweg bis zum erstrebten Deskriptionsziel ist, wie man dabei bemißt und zählt, wo man Wiederholungen vermeiden bzw. verkürzen kann, wie Ausnahmen von der Regel zu verzeichnen sind. Demgegenüber sind die abschließenden, vielfach auch später erfolgten Reduktionsleistungen, die numerisch aufs sachlich Wesentliche abzielen, eher kümmerlich zu nennen. Man addiert Einkommenserwartungen wichtiger Einzelrealien, ohne diese, wo es möglich wäre, weiter zur summa summarum zu verdichten. Auch der begriffliche Abstraktionswille fehlt.

Im übrigen bleibt alles präsentisch gehalten, egal ob in der Erhebungs- oder der Bearbeitungshaltung. Sachliche oder zeitliche Distanz zum Ganzen oder zu Teilen hat man wohl kaum empfunden, jedenfalls nicht formuliert. So systematisch und ins komplexe Detail hinein die Distinktion von Habe und Soll getrieben ist-auch dabei dürfte monastische Trivialdialektik Pate gestanden haben -, eine differenzierte Rechenhaftigkeit, wie wir sie bei Adalhard mit dispensativem Ziel finden konnten, ist im appropriativ ausgerichteten Polyptychon des frühen 9. Jahrhun-

162 Z.B. II, 121; III, 62; IV, 35; V, 93.

163 Vgl. meinen Aufsatz (wie Anm. 30).

$164 \mathrm{Zu}$ Skriptorium und Bibliothek in St.-Germain vgl. Emile Lesne, Histoire de la Propriété ecclésiastique en France. Bd.IV: Les Livres. „Scriptoria“ et Bibliothèques du Commencement du VIII à la Fin du XI ${ }^{e}$ Siècle (Lille 1938) $203 \mathrm{ff} ., 594 \mathrm{ff}$. 
derts und seinen zeitgleichen oder bald folgenden Bearbeitungen nicht recht zu entdecken. Auffällig ist dagegen wie in St.-Victor der Wille, vom Aktuellen, dem Bestand der Familiaren also, wegzukommen und das sachlich Bleibende im Basisindex, dem mansus, festzuhalten - eine lakonische Reduktion auf Anteile des zählbaren Debitum von den Hufen.

\section{Die Brevium Exempla und das Capitulare de villis im Codex Helmstadensis $254(825 / 850)$}

Es gibt nur wenige Handschriften des frühen 9.Jahrhunderts, die per se und in ihren Einzelabschnitten so gründlich erforscht wurden wie der schmale handliche Kodex Helmstadensis 254 in der Herzog August Bibliothek in Wolfenbüttel. Er entstand in den Jahren zwischen 825 und 850 in einer bis heute unbekannten Schreibstube. ${ }^{165}$ Mir kann es hier - und das in aller Kürze - nur um zweierlei gehen: um einige Beobachtungen zum Deskriptionsstil in den seit A. Boretius (1883) so genannten Brevium exempla ad describendas res ecclesiasticas et fiscales sowie um die ordinativen Gegebenheiten im zweiten Teil der Handschrift, der die Brevium exempla und das Capitulare de villis enthält. ${ }^{166}$

Die Brevium Exempla bestehen aus drei Bruchstücken verschiedenartiger Aufstellungen. ${ }^{167}$ Das erste ist das dreiteilige Schlußstück einer größeren, um 810 entstandenen Zusammenstellung über die Güter und Rechte des Bistums Augsburg: dem Inventar der Klosterkirche auf der Insel Wörth im Staffelsee folgen die descriptio des dortigen Herrenhofs samt der zugehörigen 41 Hufen und die Hufensumma des Bistums Augsburg. ${ }^{168}$ Der zweite Teil besteht in zwei treffend überschriebenen, stark formelhaft gehaltenen Auszügen über sechs Schenkungen zu Nießbrauch und über die Lehnsgüter von sechs Benefiziaren der Abtei Weißenburg. ${ }^{169} \mathrm{Im}$ dritten folgen fünf Inventare von Königshöfen bei Tournai, Valenciennes und Douai. ${ }^{170}$

Die Deskriptionstechnik sowohl der Beschreibung von Staffelsee als auch der

$165 \mathrm{Vgl}$. Brühl (wie Anm. 70) $5 \mathrm{ff}$.; Wolfgang Metz, Brevium Exempla, in: LdM 2 (München 1983) 642f.; die ausführlichsten Kommentare sind immer noch: Metz (wie Anm. 75) 26-53 und Verbein (wie Anm. 77) 333-392.

${ }^{166}$ Dieser Teil (Quaternio XII) ist noch heute mit dem anderen, Briefe Leos III. an Karl d. Gr. enthaltenden (Quaternio XIII) vertauscht.

167 Brübl (wie Anm.70) 50-55.

168 Zur Sache ausführlich: Konrad Elmshäuser, Untersuchungen zum Staffelseer Urbar, in: Rösenern (wie Anm.16) 335-369.

169 Hierzu Wolfgang Metz, Die Weißenburger Prekarien der sog. Brevium Exempla ad describendas res ecclesiasticas et fiscales, in: Bll. f. pfälz. Kirchengesch. u. rel. Volkskunde 34 (1967) $160 \mathrm{ff}$. sowie Werner Rösener, Strukturformen der adligen Grundherrschaft in der Karolingerzeit, in: ders. (wie Anm. 16) 126-180, hier: 162-167.

170 Alles Wichtige bei Verbein (wie Anm.77) 352-373 und Wolfgang Metz, Die Königshöfe der Brevium Exempla, in: DA 22 (1966) 598-61. 
der Königshöfe steht der in den Polyptycha von St.-Victor und St.-Germain recht nahe, sodaß Bekanntes hier nicht wiederholt zu werden braucht. Die Unterschiede liegen vor allem darin, daß die Erfassung und Beschreibung der vor Augen liegenden Gegenstände und Güter in verschiedenen Sachbereichen noch genauer wird. Eine domus regalis z.B. wird als exterius ex lapide et interius ex ligno bene constructa bezeichnet. In der Beschreibung der Pertinenzen der St. Michaelskirche ${ }^{171}$ dringt man im Abschnitt über die liturgischen Geräte bis zu dem vergoldeten Kupferkreuz, dem Kristallapfel und den bunten Perlenketten vor, die zu einer über dem Altar hängenden Krone gehören. In den Viehinventaren des Staffelseer Herrenhofs und den Königshöfen kommt es innerhalb der Arten zu Differenzierungen nach Geschlecht und Alter, bis hin zur Unterscheidung z.B. des Rindviehs verschiedenen Alters. Die Angaben zum conlaboratus (jährlicher Getreideertrag) und den utensilia aus Eisen in den Fiskusinventaren gehören zum Wertvollsten, auf das die heutige Forschung zur agrikolen Produktivität und zum Stand der Agrartechniken im 9.Jahrhundert rekurrieren kann.

Die Distinktion im Detail geht immer wieder so weit, daß sogar das nicht Zählbare oder nicht Zählenswerte in den Blick kommt: Bäume in den Gärten (arbores diversi generis) ${ }^{172}$, Fische im Teich, Jungtiere bei den Muttertieren, Würste und Schmalz beim Schinken, Gerätschaften aus Holz. Die Formel zum letzteren ist aufschlußreich: utensilia lignea (ad ministrandum) sufficienter. Die Eigenschaft des ,Hinreichenden', sie begegnete schon im Polyptychon von St.-Germain-desPrés, berührt eine Grenze, jenseits derer das Zählen keinen Sinn mehr macht - ob dies in der Fülle oder der geringen Bedeutung der zugehörigen Dinge gründet, soll hier nicht entschieden werden. Schließlich wird, wenn auch nur selten, das nicht Vorhandene berührt. De annona nihil repperimus, excepto quod ... heißt es einmal; ein andermal: De ministeriales non invenimus aurifices, neque argentarios, ferrarios, neque ad venandum, neque in reliquis obsequiis. ${ }^{173}$ Diese Passagen bezeugen, daß derlei wohl regelmäßig erwartet und deshalb - dem Fragenbestand entsprechend - angefragt wurde. Sie geben ansatzweise Auskunft über das Verhältnis zwischen ,Soll' und ,Haben' am Ort und führen vor Augen, wie die konsequente Befolgung des Befragungsauftrags zur Verschriftung des, Nichts von Etwas' führt. ${ }^{174}$

Neben den Formen der deskriptiven Entfaltung sind aber auch solche der Reduktion beachtenswert. Am auffälligsten ist im Vergleich zu den Aufstellungen von St.-Victor und St.-Germain die Beschreibung der mansi in Staffelsee ${ }^{175}$ : ihnen fehlt die Anbindung an namentliche Inhaber oder einen exemplifizierenden Einzel-mansus; sie sind rechtsständisch (in MI und MS) aufgeteilt und rechtstypus-

$171 \mathrm{Zu}$ Inventaren dieser Art vgl. Bernhard Bischoff, Mittelalterliche Schatzverzeichnisse 1 (Veröff. des Zentralinstituts für Kunstgeschichte in München 4, München 1967).

172 Mehrfach wird mit eröffnendem id est eine Artenreihung von nicht Gezähltem vorgenommen (regelmäßig in den Abschnitten de herbis hortulanis).

${ }_{173} \mathrm{Brübl}$ (wie Anm. 70) 50 Z.5; 53 Z.32ff.

${ }^{174} \mathrm{Vgl}$. meine Bemerkungen hierzu im in Anm. 30 genannten Aufsatz.

175 Brübl (wie Anm. 70) $50 \mathrm{Z} .24 \mathrm{ff}$. 
intern nach Zins- bzw. Frondiensteigenheiten gruppiert. Man hat also von allen instabilen Inhaberkonstellationen abstrahiert und auf rigide dingliche Radizierung aller Pflichten abgestellt - bis auf den MS-spezifischen Passus, in dem das opus textile sowie der Brau- und Backdienst an die Frau des mansus-Inhabers gebunden wird. ${ }^{176}$

Weiter ist die summa am Ende des ersten Bruchstückes aufschlußreich. Ohne Rekurs auf die Herrenhöfe wird lediglich die Anzahl aller mansi ingenuiles und serviles der Diözese, geschieden nach vestiti und absi, genannt; dann wird noch einmal zum Gesamt der mansi vestiti und absi (inter ingenuiles autem et serviles) addiert. Auch auf Einkünfte-Mengen ist also nicht abgehoben worden. Dieser Summationstypus gleicht den Schlußsätzen in den villikalen Brevia von St.-Victor und St.-Germain. Er paßt dazu, daß seit dem späten 8.Jahrhundert, spärlich dokumentiert durch königliche Gebote, die Gewohnheit Platz greift, den Güterbesitz der Herrschaften zu verschiedenen Zwecken in mansus-Zahlen auszudrücken. ${ }^{177}$

Die hier interessierenden Teile der Handschrift sind wie folgt ordiniert. Der Schriftblock, der die ganze Seite nahezu randlos bedeckt, ist gegliedert durch Überschriften (Teil 3: Incipit Capitulare de villis ...), explicit-Vermerke, Betitelung von Abschnitten (Teil 2) sowie durch Absatzbildung, auch in Verbindung mit teilweise versalisierten $Z$ wischentiteln (DE PECULIO o.ä.). Inhaltlich Neues wird schließlich regelmäßig - auch binnenzeilig - durch Initialen hervorgehoben. Die Abschnitte (capitula) des Capitulare de villis sind sogar in Ziffern von I.LXVIIII. durchgezählt ${ }^{178}$; ob dies eine Leistung des Schreibers ist, sei dahingestellt.

Von besonderem Interesse sind Bemerkungen, die mehrfach am Ende von $\mathrm{Ab}$ schnitten in die Restzeile eingetragen wurden und die man nur als direkte Anweisungen an den Leser verstehen kann, bei Aufgaben ähnlicher Art (breviare, numerare) so zu verfahren wie im vorliegenden Falle. ${ }^{179}$ Sie lesen sich aber eher wie reflexive Nachträge, nicht wie ursprünglich geplante Anweisungen, die den eigent-

176 Ebd.: "Uxor vero illius facit camsilem I et sarcilem I; conficit bracem et coquit panem." Zum sachlichen Zusammenhang vgl. Ludolf Kuchenbuch, Opus feminile. Das Geschlechterverhältnis im Spiegel von Frauenarbeiten im früheren Mittelalter, in: Hans-Werner Goetz (Hg.), Weibliche Lebensgestaltung im frühen Mittelalter (Köln 1991) 139-175.

${ }_{177}$ Walter Schlesinger, Die Hufe im Frankenreich (1979), in: Hans Patze/Fred Scbwind (Hg.), Ausgewählte Aufsätze von Walter Schlesinger 1965-1979 (VuF XXXIV, Sigmaringen 1987) 587-614, hier: 607ff.; Durliat (wie Anm.73) 195-203; Elisabeth Magnou-Nortier, Remarques générales à propos du manse, in: dies. ( $\mathrm{Hg}$.), Aux sources de la gestion publique. Bd.1: Enquête lexicographique sur fundus, villa, domus, mansus (Travaux \& Recherches, Lille 1993) 196-207.

178 Verbalisiert-ordinale Durchzählung (primo capitulo, secundo etc.) begegnet in den von Hubert Mordek, Karolingische Kapitularien, in: ders. (Hg., Überlieferung und Geltung normativer Texte des frühen und hohen Mittelalters (Qu. u. Forsch. z. Recht im Mittelalter 4, Sigmaringen 1986) 25-50, hier 32f. besprochenen Statuta Murbacensia (Rotulus von 816, Faksimile im Anhang).

179 Brübl (wie Anm.70) 51 Z.52: “Et sic cetera breviare debes; 52 Z. 28: Et sic cetera de talibus rebus breviare debes; $55 \mathrm{Z}$. 52 : et sic de ceteris omnibus praeteritis et praesentibus vel reliquia numerabis." 
lichen Zweck der Abschrift ausdrücken sollen. Ähnlich steht es mit Auslassungen von Namen und Zahlen im zweiten und dritten Teil der Brevium Exempla; sie sind kaum als Anzeichen für eine detaillierte Ausrichtung der Vorlagen zu Mustern zu verstehen, sondern gehen wohl auf Unleserlichkeit in der Vorlage bzw. auf die Ungeduld oder das Unverständnis des Schreibers zurück. ${ }^{180}$

Weitere ordinative Inkonsequenzen schließlich ${ }^{181}$ bestätigen den Eindruck, daß man im Codex Helmstadensis 254 verschiedene Ansätze zur übersichtlichen Anordnung und zur anwendungsorientierten Kenntnisnahme finden kann, daß es ihnen aber an graphischer und funktionaler Folgerichtigkeit fehlt. Diese Beobachtungen bestärken in der Skepsis, die Bruchstücke der Brevium exempla und das Capitulare de villis zu strategischen Zeugnissen einer zentralen karolingischen Wirtschaftsverwaltung zu erheben - was natürlich nichts gegen den Erfolg der Bemühungen der Karolinger und der ihnen alliierten Führungsgruppen sagt, die Güterorganisation und die Einkommensverhältnisse umzubauen und zu effektivieren. ${ }^{182}$

Dagegen ist an Details der Deskriptionstechnik deutlich geworden, daß die Beschreibung von Habe und Soll ganz nahe ans einzelne Spezifische (proprium) heranführt und auch nicht Vorhandenes beachtet. Die summarische Behandlung der Staffelseer mansus-Pflichten bezeugt die schon oben beobachtete Tendenz, von deren Radizierung auf die Familiaren wegzukommen. Das summative Kalkül ist ganz auf den Hufenbesitz abgestellt.

\section{Die Dispositionen und Ordinationen der Reimser Bischöfe (7.-9.Jahrhundert)}

Schon 1936 hatte Emile Lesne, um die kontinuierliche grundherrliche Schriftpraxis im frühen Mittelalter zu belegen, darauf aufmerksam gemacht, daß Flodoard, Kanoniker, Priester und Archivar der Kathedrale von Reims, in seiner um die Mitte des 10.Jahrhunderts geschaffenen Historia ecclesiae Remensis ${ }^{183}$ mehrfach

180 In Teil 2 mehrfach: in villa illa, in Teil 3: in illo fisco sowie: baccones tantos, vaccas tantas etc. Mir leuchtet die Skepsis von Verbein (wie Anm. 77) II,348-352 ein, die er auf der Grundlage einer sorgfältigen Unterscheidung zwischen Muster, formelhafter Vorlage und vollendetem Formular getroffen hat. Vgl. auch Hägermann (wie Anm. 16) $54 \mathrm{f}$.

181 Gemeint ist etwa, daß der Schreiber einmal am Abschnittsbeginn ganze Wörter versalisiert, dann wieder nur ein Initiale am linken Zeilenrand ausstellt, daß er die einen Absätze betitelt, die anderen nicht (besonders in Teil 3).

182 Hierzu Dieter Hägermann, Die rechtlichen Grundlagen der Wirtschaftsentwicklung im Nordwesten des Fränkischen Reiches, in: Atsma (wie Anm.110) 341-365; Jean-Pierre Devroey, Réflexions sur l'économie des premiers temps carolingiens (768-877): Grands domaines et action politique entre Seine et Rhin, in: FRANCIA 13 (1985) 475-488; Robert Delatouche, Regards sur l'agriculture aux temps carolingiens, in: Journal des savants (1977) 73-100.

${ }^{183}$ MGH SS XIII, 405-599. 
über episkopale Akte schriftlicher Güterverwaltung seit dem frühen 8.Jahrhundert berichtet hat. ${ }^{184}$ Walter Goffart hat diese kurzen Bemerkungen ${ }^{185}$ dann als Zeugnisse für ordnende Eingriffe ins lokale Agrarregime mit anschließender Verschriftung gedeutet und sie in den Zusammenhang der allmählichen Verwandlung der spätantiken öffentlichen Katasterführung in einzelherrschaftliche Land- und Leistungsregister gestellt. ${ }^{186}$ Daran anknüpfend hat Jean-Pierre Devroey die Passagen, die Goffart als aus Vorlagen im Reimser Archiv übernommene formelhafte Variationen gleicher Sachverhalte ansah, gründlicher untersucht und ist $\mathrm{zu}$ dem Ergebnis gekommen, daß sich in ihnen nahezu exemplarisch grundlegende Entwicklungen vom späten 6 . bis ins 9.Jahrhundert spiegeln: zum einen, im faktischen Sinne, der allmähliche Übergang vom zu (öffentlichem) Geldtribut veranlagten Grundbesitz zum bipartiten Domanialsystem, zum anderen, im schriftkulturellen Sinne, die allmähliche Entfaltung der Deskriptionstechnik zu mehr sachlicher Reichweite und funktionaler Adäquanz. ${ }^{187}$ Wenngleich vieles an dieser Deutung hypothetisch bleiben muß, weil Flodoards Vorlagen, aus denen er für das 7. und 8. Jahrhundert schöpfte ${ }^{188}$, nicht bekannt sind, so läßt sich die spätere Phase dieser Entwicklung anhand des Polyptychons von St.-Remi konkretisieren, das der neueren Quellenkritik entsprechend ${ }^{189}$ in die Jahre 848-861 zur Zeit Hinkmars, in Teilen eventuell in die Zeit vor 816/825 gehört und gegen Ende des 9. Jahrhunderts ergänzt worden ist. ${ }^{190}$

Nur um wenige sachliche Aspekte kann es hier gehen. Im allgemeinen ähneln die Deskriptionstypen der Reimser Brevia denen aus St.-Germain-des-Prés - nur

184 Lesne (wie Anm. 78) 7.

185 Z.B. SS XIII 454 (zu Bischof Sonnatius/610-630): Colonias etiam villarum quarundam episcopii dispositis ordinavit servitiis; 464 (zu Tilpinus/748-794): nonnullarum quoque iura villarum dispositis ordinasse coloniis (reperitur); 484 (zu Hincmarus/842-882): Res preterea et villas episcopii pene omnes, ordinatis rationaliter coloniis, describi fecit.

186 Walter Goffart, From Roman taxation to medieval seigneurie: Three notes, in: Speculum 47 (1972) 373-394, hier: $374 \mathrm{ff}$.

187 Jean-Pierre Devroey, Les premiers polyptyques rémois, $\mathrm{VIII}^{\mathrm{e}}-\mathrm{IX}^{\mathrm{e}}$ siècles, in: Adriaan Verbulst $(\mathrm{Hg}$.), Le grand domaine aux époques mérovingienne et carolingienne (Centre Belge d'Histoire Rurale Publ. 81, Gent 1985) 78-97; ders., Les préoccupations de gestion des évếques de Reims ( $\mathrm{VI}^{\mathrm{e}}-\mathrm{XI}^{\mathrm{e}}$ siècles), in: La Champagne et ses administrations à travers le temps (Paris 1990) 53-68.

i88 Zur Arbeitsweise Flodoards vgl. Zimmermann (wie Anm. 67).

189 Britta Lützow, Studien zum Reimser Polyptychum Sancti Remigii, in: FRANCIA 7 (1979) 20-99; Devroey (wie Anm. 27) XXI-CIV; zu Devroeys Edition: Dieter Hägermann, Anmerkungen zum Stand und den Aufgaben frühmittelalterlicher Urbarforschung, in: RhVjbll. 50 (1986) 35-46; Pierre Desportes/Francois Dolbeau, Découvertes de nouveaux documents relatifs au Polyptyque de Saint-Remi de Reims. A propos d'une édition récente, in: Revue du Nord LXVIII (1986) 575-607.

190 Für die frühere Datierung der Kapitel I-V entsprechend der Zählung Benjamin Guérards (mit Zusätzen - familia intra villam/summa) plädiert Devroey (wie Anm. 27) LVII ff., für Zusammengehörigkeit von Kap. I-V und XIV-XXIV, XXV, XXVI Hägermann ebd. im Anschluß an Lützow $47 \mathrm{ff}$. Hinzugefügt wurden die Kap. XI, XII, XXVII, XXVIII. Das Polyptychum des Hospitals aus dem 3. Viertel des 10. Jahrhunderts (VI-X) berücksichtige ich hier nicht. Zur Überlieferung Anm. 27. 
fehlt ihnen die Landausstattung des einzelnen mansus. Wichtig waren den für die Reimser Erhebungen Verantwortlichen die Herrenackeranteile (mappae), die von den Hufnern zu bestellen waren; sie führen stets den Pflichtenkatalog an und sind der Länge und Breite nach in Ruten gemessen. Am auffälligsten aber ist der Aufwand, mit dem man die Familiaren in den Brevia XV-XXII erfaßt hat. ${ }^{191}$ Ein für alle Domänen gleiches Schema fehlt, doch gerade die verschiedenen Lösungen, die gefunden wurden, um nicht nur die nomina tenentium ibi mansa ingenuilia (bzw. servilia) samt ihrem kernfamilialen Anhang aufzuführen, sondern die nomina totius familiae praefatae ville, interius commanentes scilicet vel exterius (so in Breve $\mathrm{XX}$ formuliert), zeugen von der Intention, am Ort selbst mit Hilfe treffender $\mathrm{Ka}$ tegorien das soziale Gesamt, die tota familia, verschriften zu können. Ausgehend vom Namen ${ }^{192}$ sind dies der Rechtsstand ${ }^{193}$, der Verwandtschaftsgrad, die Verfügung über mansus oder accola, der Aufenthalt bzw. die Herkunft (innerhalb oder außerhalb der villa bzw. curtis), besondere Aufgaben. Das leitende Gruppierungskriterium ist der Landbezug, es folgt das Geschlecht, dann der Stand, dann der Aufenthaltsort. Dieser Rangierung entsprechend - hier vereinfache ich natürlich sind die freien Männer, die Ingenuilhufen vorstehen, zuerst, auswärtig weilende, unfreie und landlose Frauen zuletzt erfaßt. Diese Vereinfachung täuscht aber darüber hinweg, daß die Gruppierungen verschiedenen Zielen dienten. Das ist zum einen, wie Lützow nachgewiesen hat, daran erkennbar, daß man verschiedentlich Mehrfachnotierungen der gleichen Leute in Kauf genommen hat. ${ }^{194}$ Zum anderen zeigen die Überschriften besonders zu den landarmen accolae und den auswärtig lebenden forenses sowie Details aus den villikalen summae über sie klar, daß es um deren jährliche Frontage bzw. Kopfzinse ging - um beträchtliche, persönlich radizierte Geldeinnahmen und Frondienstreserven also. ${ }^{195}$ Über weitere Ziele - etwa die Kontrolle der intervillikalen Mobilität, des interständischen Konnubiums und der Freilassungs-,Politik' etwa - wird die künftige Forschung befinden. Im Vergleich zur descriptio mancipiorum von St.-Victor, in der allein die colonica den Bezugsrahmen der sozialen Differenzierung bildet, sind Zielsetzung und Verfahren also deutlich komplexer. Indem man insgesamt - bei Verwendung etwa gleicher Merkmale - die Gruppierungen auf verschiedene Ziele auszurichten versucht, wird ein höheres Niveau deskriptiver Methodik erreicht: die detaillierten Distinktionen heben umfassend auf die Unterscheidung zweier übergeordneter Zwecke, d.h. der Erfassung sowohl der dinglich als auch der persönlich radizierten Einkommensansprüche und der ihnen entsprechenden Kontrollformen ab.

191 Devroey (wie Anm. 27) 10-54.

192 Nur die infantes werden als namenlose Anzahl bei der Mutter mitgeführt.

193 In den Brevia XV, XVII, XVIII, XX und XXII begegnen über die ingenui/ingenuae und servi/ancillae hinaus viele Freigelassene verschiedenen Typs (epistolarius, cartularius). Auch von ihnen werden einmal 26 Namen gesondert gruppiert unter der Überschrift: "NOMINA FEMINARUM ingenuitatem habentium per cartam ..." Dies ist ein meines Erachtens noch zu wenig ins schriftgeschichtliche Kalkül gezogenes Detail. Schließlich werden auch vicarati/ vicaratae genannt (XXII).

194 Lützow (wie Anm. 189) $92 \mathrm{ff}$.

195 Hägermann (wie Anm. 189) 51. 
Dieses Mehr an Bedacht spiegelt sich auch in den regelmäßigen summae am Ende der Einzelbrevia sowie in einer summa generalis. Sie sind nicht nur tituliert, sondern in ihnen werden - unter Abstraktion von allen homines und aller ständischen Attribute - die mansus-radizierten Zinssummen notiert; hinzu kommen die status-radizierten Geldeinnahmen bestimmter Leute, und schließlich wird eine SUMMA argenti errechnet. Verglichen mit St.-Victor und St.-Germain hat also in der Einzel-summa eine Verschiebung von der dauerhaften Habe zum jährlichen Einkommen, natürlich in der Form des erwarteten debitum, nicht des realen redditus, stattgefunden. In der das Polyptychon abschließenden summa generalis ${ }^{196}$ trifft man auf die gleichen Vorgänge der Tilgung von Spezifika, seien es die Rechtsqualität der Hufen, die Radizierung einzelner Abgaben, ja auch kleinere Maße. Diese detailtilgenden Abstraktionen schlagen dann gewissermaßen in begriffsbildende um, wenn 104 Mutterschafe, 138 Lämmer verschiedenen Alters und 4 Widder zu 246 capita veruecum werden. Ähnliches geschieht auch mit verschiedenen Geldzinsen. Die summa census am Ende des Abschnittes liest sich dann durchaus schon im Blick auf ein mögliches jährliches, Gesamt'-Einkommen.

Inwieweit solche ordinativen Praktiken auch das schriftkulturelle Niveau in den Reimser Skriptorien spiegeln, muß hier offengelassen werden. ${ }^{197}$ Man kann angesichts all dessen aber durchaus verstehen, daß Flodoard ein Jahrhundert später, diese Aufstellungen vor Augen, Hinkmars schriftbezogene Ordinationsleistungen so auf den Punkt brachte: Res preterea et villas episcopii pene omnes, ordinatis rationabiliter coloniis, describi fecit. ${ }^{198}$

Glücklicherweise erlauben gegen Ende des 9. Jahrhunderts entstandene Zusätze zum Polyptychon, weitere Trends im Deskriptionsstil auszumachen. Besonders das Breve über Nanteuil-la-Fosse ${ }^{199}$ ist dafür bezeichnend. Zum einen trifft man auf deutlich mehr Zeit-,Bewußtsein'. Nicht nur der ungewisse Zinsertrag des Brauhauses (camba) wird damit begründet, prout ratio temporis permiserit. Dazu kommen drei präzise terminierte Abgaben: der Getreide- und der Strohzins zur Remigiusmesse (1.10.) sowie die Pfennige zur Ablösung des Heerestroßdienstes Mitte Mai. Derlei Fixierungen jährlicher Abgaben auf genauere Termine fehlen im früheren 9.Jahrhundert noch weitgehend. ${ }^{200}$ Zweitens sind neben Naturalabga-

196 Text: Devroey (wie Anm.27) 55f.; Quellenkritik: Lützow (wie Anm. 189) 29, 47 ff.; zum Summationsstil mein Aufsatz (wie Anm.30).

$197 \mathrm{Zu}$ den Skriptorien in Reims vgl. allgemein Lesne (wie Anm. 78) $258 \mathrm{ff} . ;$ Frederick M. Carey, The scriptorium of Reims during the archbishopric of Hincmar (845-882), in: Classical and medieval studies in honour of Edward Kennard Rand, hg. v. Leslie Webber Jones (1938), 41-60; sowie die Studie von Jean Vezin, La répartition du travail dans les, scriptoria“ carolingiens, in: Journal des Savants (1973), 212-227 mit Hinweisen auf weitreichende Aufgabenteilung und parallele Erstellung von Kodizeslagen zur Zeit Hinkmars in Reims.

198 MGH SS XIII 84. Zur Rolle der Schriftlichkeit im Verwaltungshandeln Hinkmars: Martina Stratmann, Hinkmar von Reims als Verwalter von Bistum und Kirchenprovinz (Qu. u. Fsch. zum Recht im Mittelalter 6, Sigmaringen 1991) 5-19; vgl. auch Jean Devisse, Les méthodes de travail d'Hincmar de Reims, in: Culture et travail (wie Anm. 14) $145 \mathrm{ff}$.

${ }_{199}$ Devroey (wie Anm. 27) 373-375. Zur Datierung XLIVf.

200 S. o. Anm. 157. Kurze Bemerkungen anhand der Werdener Überlieferung bei Hans-Wer- 
ben nun auch erste Dienste in den Geldnexus geraten: die Ingenuilhufner können sich vom winterlichen Holzschlag (caplim), von Getreide- bzw. Weinfuhren und vom Wiesenschnitt durch geringfügige Denarquanta frei-,kaufen'. Drittens: Die Verteilung der Hufen unter die ingenui und servi ist so schematisch, daß sich der Eindruck einstellt, mit der descriptio sei eine Neuordnung der ganzen Domäne erfolgt. Dies geschah offensichtlich mit Bedacht für den Handlungsspielraum beider Rechtsgruppen, denn den ingenui wird die Möglichkeit eingeräumt, im Verarmungsfalle ihren mansus zu verlassen, und sie können die jährliche Salzlieferung per successiones sibi convenientes organisieren. Für beide Rechtsgruppen gilt der Grundsatz, daß bestimmte Fronden nur cum praebenda sibi data geleistet werden. Derlei Bestimmungen zeugen von dem Willen zur generalisierenden Bestimmung mit Geltung für möglichst viele Betroffene. All diese Erscheinungen sind charakteristisch für spätkarolingische Güter- und Einkünfteverzeichnisse, von denen hier nur noch die Urbare aus Prüm und Werden zur Sprache kommen sollen.

\section{Das Prümer Urbar (893)}

Das wahrscheinlich durch die Normannenzüge von 882 und 892 veranlaßte, weit über hundert Domänenbeschreibungen umfassende Prümer Urbar ${ }^{201}$ gilt als das letzte umfassende Polyptychon einer Klosterherrschaft aus der Karolingerzeit. $\mathrm{Da}$ es nur in einer viel späteren, allerdings recht sorgfältigen und ausführlich glossierten Abschrift des Prümer Abtes Caesarius von Mylendonk überliefert ist, der diese nach eigener Aussage, nachdem er resigniert und sich in die Abtei Heisterbach zurückgezogen hatte, im Auftrag seines Nachfolgers Friedrich im Jahre 1222 erstellt hat, lassen sich keine Fragen an das Schriftbild, die paginale Einrichtung und die Ordnung des ganzen vetus liber im 9.Jahrhundert stellen. Wegen dieser Überlieferungslage ist die Debatte um die ursprüngliche Form des Polyptychons, trotz aller Differenzierungsgewinne höchst intensiver Quellenkritik (Lamprecht, Willwersch, Perrin, Schwab, Morimoto) bis heute nicht gültig entschieden. ${ }^{202}$ Einig ist man sich aber doch über die Grundzüge seiner Entstehung: drei bis fünf Kommissionen haben nahezu ein Jahr gebraucht, um die Güter der Abtei, die sich - abgesehen von westfränkischen Besitzkomplexen - von der mittleren Lahn bis an die mittlere Maas, vom Niederrhein bis zum unteren Neckar erstreckten und etwa 1700 bis 2000 Hufen ausmachten, vor Ort zu erfassen. Nach Charles-Ed-

ner Goetz, Kirchenfest und weltliches Alltagsleben im früheren Mittelalter, in: Mediaevistik 2 (1989) 123-171; hier: 148-152.

201 Neueste, kritische Edition (mit Faksimile im Anhang): Ingo Schwab (wie Anm. 139) 158259. Ich zitiere nach der Kapitelzählung von Caesarius.

${ }^{202}$ Kurze Charakterisierung der Forschungssituation nach dem Erscheinen der Edition durch Schwab: Kuchenbuch (wie Anm. 16) 302f.; die jüngste Darlegung von Ingo Schwab, Das Prümer Urbar - Überlieferung und Entstehung, in: „anno verbi incarnati DCCCXCIII conscriptum“. Im Jahre des Herrn 893 geschrieben. 1100 Jahre Prümer Urbar, hg. v. Reiner Nolden (Trier 1993) 119-126. 
mond Perrin sind dabei zwölf, verschiedenen regionalen Besitzgruppen entsprechende Formulare - er nennt sie die Redaktionstypen der Teilurbare - benutzt worden. ${ }^{203}$ Mit welchem redaktionellen Aufwand die Teilurbare, die die Kommissionen nach Prüm brachten, kodifiziert wurden und wieviel in den Jahren danach berichtigt, ergänzt, modifiziert wurde, ist heute wohl nicht mehr zweifelsfrei zu ermitteln. ${ }^{204}$ Unabweisbar ist aber eine grobe Ordnung nach den regionalen $\mathrm{Be}$ sitzschwerpunkten in der Form einer sich im Uhrzeigersinn von Prüm entfernenden Spirale mit den Teilurbaren der Filialklöster St. Goar und Altrip am Ende. Auch zu diesem für das Thema sehr ergiebigen Polyptychon nur wenige Anmerkungen, die alle aufs trendhaft Neue gegen Ende des 9.Jahrhunderts abheben.

Am auffälligsten ist die variationsoffene Verwendung der Formulare. Dies gilt zum Beispiel für den Deskriptionstyp der Kapitel XLV-XLVII, der dem von St.Germain-des-Prés bzw. St.-Remi ähnelt (u. a. namentliche Aufzählung aller Mansusinhaber). Bei der Deskription dieser Abteigüter in den Ardennen ist man aber in zweierlei Hinsicht noch dichter an die vorgefundenen Verhältnisse herangekommen als in St.-Germain und St.-Remi. Zum einen sind bei der Beschreibung der Salländereien die Flurnamen der betreffenden culturae aufgeführt: Rotunda Hasila, Merilonis Cruce, Hulsiz, Albieg, Reimanbarba, secus fontem qui vocatur Scaitla, Ruchengas - das sind einige der eigenartigen mikrotoponymischen $\mathrm{Be}-$ zeichnungen. ${ }^{205}$ Neben solcher Genauigkeit in der örtlichen Zuordnung der Ländereien ist die Stufung bestimmter Abgaben (Geldzinse anstelle von Schweinen, für den Troßdienst, für erbetene Erntearbeiten) in Abhängigkeit von der Besetzungsdichte des mansus ingenuilis auffällig. Dem Gedanken, von vier Hufnern, die sich eine Hufe teilen, den Pfennigwert von vier Schweinen zu verlangen, von einem auf einer aber nur den eines Schweins ${ }^{206}$, liegt die Gewißheit zugrunde, daß der jährliche Ertrag der Schweinehaltung nicht von der Hufe als dinglichem Konglomerat abhängt, sondern von der Zahl der Leute, die sich dort verantwortlich um die Schweine kümmern. Gleiches gilt für Heeres- und bestimmte Feldfronden. Die Variationsbreite der Appropriation in einigen viril bestimmten Bereichen der mansus-Wirtschaft wird hier analog zum aktuellen Männer-,Bestand' bestimmt. Man begegnet hier also einem sozusagen ,beweglichen` Appropriations-Kalkül,

203 Perrin (wie Anm. 16) 3-98, hier: 58-60 (Aufstellung der Redaktionstypen).

204 Perrin (wie Anm. 16) 46-82 pass. hielt die vielen, zum Teil sinnwidrigen Zusätze zur ursprünglichen Fassung der descriptio für nicht präzise datierbar (kurz nach der Erstellung bis zu Caesarius), vermutete im übrigen auch eine Abschrift zwischen dem, Original' und der Arbeit von Caesarius. Schwab (wie Anm.139) 38-152 pass. plädiert für nahezu zeitgleiche Ergänzung bzw. Überarbeitung. Vermittelnde Position aufgrund der These, mit dem erstellten Urbar sei in der folgenden Zeit, gearbeitet' worden: Yoshiki Morimoto, Un aspect du domaine de l'abbaye de Prüm à la fin du IX ${ }^{\mathrm{e}}$ siècle et pendant la première moitié du $\mathrm{X}^{\mathrm{e}}$ siècle. Essai d'une utilisation dynamique du polyptyque, in: Rösener (wie Anm. 16) 266-284; sowie ders., Die Bedeutung des Prümer Urbars für die heutige Forschung, in: Nolden (wie Anm. 202) 127-136.

205 Schwab (wie Anm. 139) Kap. XLV, 201.

206 Schwab (wie Anm. 139) 202 Z.11 ff. Der Passus beginnt: "Hoc autem scitote, quia in ipsa villa, si homines IIII unum mansum tenent, .." 
das sich von den statischen Bedingungen der Hufe absetzt und das aktuelle familiale Ertrags-,Potential' im Auge hat. ${ }^{207}$

Die große Mehrheit der Brevia des Prümer Urbars gleicht eher dem Breve-Typ von Staffelsee, jedoch fehlt prinzipiell eine ausführliche descriptio des Herrenhofs und seines Zubehörs. Sie besteht in der Regel nur aus der Salland-Angabe, kann das Kapitel einleiten oder der Aufführung der Hufen nachgestellt sein. Meist jedoch beginnt man mit der lokalen mansus-Anzahl, der das anonyme solvit unusquisque folgt; bisweilen ist auch ein namentlich genannter Mansusinhaber aufgeführt, der exemplifiziert. ${ }^{208}$ Bei diesem Grundtyp stehen eindeutig die Abgaben und Dienste im Vordergrund. Es gibt kein frühmittelalterliches Polyptychon mit derart differenzierten Aufstellungen über die Pflichten der Hufen.

Doch wie wird im Einzelfall verfahren? Auffällig ist zunächst die flexible ,redaktionelle 'Handhabung der verschiedenen Verhältnisse pro Ort. Einmal sind die Pflichten bereits ins Gesamt (totum) aller Hufen am Ort zusammengefaßt (Kap. XXXIIII-XL); man hat dort also schon von vornherein summiert. Anderswo erklärt man census und servitium für ausnahmslos gleich gültig für alle Hufen gleichen Typs am Ort (Kap. CIIII-CXI). Immer wieder hat man aber auch von Gruppe zu Gruppe (Kap. XXX, XXXIII, LXXXIX) oder sogar von Einzelhufe zu Einzelhufe (Kap. LXXXXVII) spezifiziert. Diese Art des gruppierenden und vergleichenden Einordnens zeigt sich an Formeln wie: sicut superiores bzw. ceteri, isti inferiores, ex his supradictis bzw. prescriptis, alii enim, insuper sunt, excepto, plenus census, dimidium servitium usf. Die Kapitel strotzen von solchen Verweisen, übergreifen auch jene selbst und orientieren sich an Verhältnissen in vorangehenden, mehrfach eine ganze Gruppe anführenden Domänenbeschreibungen, deren erstgenannter mansus exemplifiziert hat (besonders in Abschnitt CIIII-CXI). Oder - und das läßt an die Teilurbare übergreifenden Bedacht bei der Zusammenstellung der domanialen Einzelbrevia im Kloster denken - es wird auf Verhältnisse räumlich und im Korpus weitentfernter Orte Bezug genommen. ${ }^{209}$ Mit derlei Verfahren sparte man sich viele Wiederholungen und konnte doch ausreichend spezifizieren, ohne am Einzelfall ,kleben' zu bleiben. Sie spiegeln elastischen Umgang mit inhaltlich Gleichem ebenso wie mit Eigenheiten - Regel und Ausnahme werden adäquat artikuliert.

Genauso wichtig ist der Umgang mit Vergangenheit und Gegenwart. Immer wieder wird auf die Herkunft der Güter angespiel $t^{210}$, man schenkt aber ebenso

207 Eine ähnliche Erwägung findet sich bereits in der descriptio der ehemals königlichen, 861 aber Reimser Domänengruppe um Condé-sur-Marne (Devroey (wie Anm. 27) 65); dort wird über die Höhe eines Hammelzinses in Relation zur Mansusinhaberzahl räsonniert.

${ }^{208}$ Z.B. Kap. I-XXIII, XXVI-XXVIIII, XLVIII-LI.

209 In Kap. LXXXVIII (Wissersheim) wird auf Kap. LXXXXVI (Rheinbach) vor-, in Kap. CXIIII (Rhein-Gönheim) auf Kap. XXIIII (Mehring) zurückverwiesen. Daß es sich hier um dominant literarische Bezüge handelt, wird daraus klar, daß Wissersheim $20 \mathrm{~km}$ nördlich von Rheinbach liegt, Rhein-Gönheim gegenüber Mannheim, Mehring aber an der mittleren Mosel. Solche Verweise sind wohl nur möglich, wenn das schon schriftlich Vorliegende ordnend überblickt wird.

${ }^{210}$ Die Schenker werden in Kap. XVI-XVII, XXIV, XXIX, LXX, XCVII genannt. In 
aktuellen Änderungen im lokalen Rentenregime Beachtung. Derlei beginnt mit Details über Frondienstpräbenden ${ }^{211}$ und setzt sich (besonders in Domänen im Umkreis um Prüm) fort in Bemerkungen über Hufner, deren Pflichtenkanon neuerlich auf ausschließlichen Botendienst (scara) umgestellt worden ist. ${ }^{212}$ Diese Bemerkungen bezeugen eine Etappe in der Formation auf bestimmte Aufgaben festgelegter bäuerlicher ministri (scararii), der für die funktionale und soziale Differenzierung der familia für die Zukunft bekanntlich große Bedeutung zukommt. ${ }^{213}$ Zugleich erweist sich die descriptio als locus herrschaftsverändernder Maßnahmen; man aktualisiert Details, wodurch das Polyptychon selbst sich vom $\mathrm{Zu}$ standszeugnis zum Instrument dynamischer Rechts- und Herrschaftspraxis zu wandeln beginnt. ${ }^{214}$

Mehr Genauigkeit trifft man auch bei Bemessungen an. In Kapitel CIIII etwa, das für die Güter an der Lahn exemplifiziert, wird präzisiert, wieviel Scheffel Korn pro angaria (Fuhre über weite Strecke) zu karren sind; ebenso wird die Zaunstrecke, für die der Hufner zu sorgen hat, in Ruten zu fünfzehn Fuß gemessen. Andernorts (Kap. CXIIII) ist das Wolltuch, das zu weben ist (sarcilis), nach Länge und Breite in Ellen gemessen, und es wird bestimmt, wieviel Karren Gras der Hufner während seines Ernte-Frontags zu schneiden und einzufahren hat.

Derlei ordinative und deskriptive Anpassung an die lokalen Verhältnisse, die Zeitläufte und die Arbeitsakte und -resultate findet ihren Höhepunkt im Kapitel XLI über den Salzpfannenbesitz der Abtei in Vic-sur-Seille.215 Dort waren ja nicht nur die eigenartigen Einrichtungen des Solsiedevorgangs (Solbrunnen, Leitungen, Hütten, Pfannen) zu erfassen, sondern es mußte besonders darum gehen, die Appropriation den Zeitformen der Ertragsbildung entsprechend zu fassen. Es ging um nicht den jährlichen, sondern den monatlichen und wöchentlichen Durchschnittsertrag von April bis Dezember, den - bisweilen möglichen - Winterbetrieb, um die schwankenden Verkaufschancen - ausgedrückt in ,Preis'-Bewegungen - und um alle in diese Handlungszusammenhänge gehörigen Familiaren:

Kap.XLIII ist eine als actio antiqua bezeichnete Notiz über Güterrückgaben zur Amtszeit Abt Faraberts (886-892) eingefügt.

211 In Kap. XXIV z. B. wird auf eine neuerlich erhöhte Beköstigung bei der Mahd angespielt.

212 Kap. II: "Gunttherus (tenet) similiter II (mansa) servilia que etiam similiter servire debuissent sicut superiores et modo scara faciunt"; ähnlich: V, VIII, XV. Zur Sache: Kuchenbuch (wie Anm. 112) 323-328.

${ }^{213}$ Hierzu jetzt Thomas Zotz, Die Formierung der Ministerialität, in: Die Salier und das Reich. Bd.3: Gesellschaftlicher und ideengeschichtlicher Wandel im Reich der Salier, hg. v. Stefan Weinfurter (Sigmaringen 1991) 3-50.

${ }^{214}$ Dies betont mit Nachdruck Yoshiki Morimoto, Considérations nouvelles sur les „Villes et Campagnes" dans le domaine de Prüm au haut moyen âge, in: Villes et campagnes au moyen âge. Mélanges Georges Despy, hg. v. Jean-Marie Duvosquel/Alain Dierkens (Lüttich 1991) 515-531.

215 Schwab (wie Anm. 139) 197-199; Interpretationen: Matthias Willwersch, Die Grundherrschaft des Klosters Prüm (Diss. Berlin 1912) hg. v. Ingo Scbwab und Reiner Nolden, Trier 1989, 50-53; Kuchenbuch (wie Anm. 112) 293-297; Dieter Hägermann/Karl Heinz Ludwig, Mittelalterliche Salinenbetriebe. Erläuterungen, Fragen und Ergänzungen zum Forschungsstand, in: Technikgeschichte 51 (1984) 155-189. 
die Salzsieder (operatores) und andere ansässige Hörige mit ihrem Besitz und ihren Nutzungsrechten, den maior, den magister/praepositus. Auch wenn die Ordnung der Einzelheiten im Breve nicht immer durchsichtig ist: hier ist eine deskriptive Intensität erreicht, die im früheren Mittelalter ihresgleichen sucht. Dabei werden ganz neue Haltungen zur Sache und zum Wortlaut kenntlich. Zum einen wird für Benutzer des Breve genauer erklärt, was unverständlich sein könnte. Explikative Formeln wie: id est oder que vulgo nuncupantur, sind über das ganze Breve verstreut. ${ }^{216}$ Es werden (romanische) Wörter, Einrichtungen, Zeitspannen erläutert. Man könnte manches davon als auf den Betrieb bezogenen Sachkommentar bezeichnen; schrift-methodisch aber markiert derlei den Einsatz der ,Glosse. 217 Zweitens zwingen die Kontinuierlichkeit der Ertragsbildung, zugleich aber deren Auf und $\mathrm{Ab}$ im Veräußerungswert offensichtlich dazu, näher auf die laufende $\mathrm{Be}-$ triebsführung einzugehen. Bestimmungen über die Kontrolle der operatores, zur Befragung über das quando und quantum des Geldwerts der Salz-Last (burdura) und zur vierwöchentlichen Abrechnung bezeugen dies. ${ }^{218}$ Das rationem reddere, auch wenn nicht sicher ist, ob es schriftlich geschah, erinnert sehr an die den Zehnttransport überwachenden Boten, die Adalhard erwähnt. Diese aktive Haltung zur Sache am Ort kulminiert darin, daß die in der dritten Person gehaltenen Anweisungen einmal in einen direkt ausgesprochenen Befehl (wohl an den Salzmeister) münden, den jährlichen Zins für die Benutzung des Solbrunnens zu erheben: ... solidos $\mathrm{V}$ per annum exigere debes! Hier liegt ein Umschlag in der Ausdruckweise von der geordneten Beschreibung in die Anordnung vor, die mir sonst nirgends im appropriativen Schriftgut begegnet ist. ${ }^{219}$

Drei weitere Erscheinungen, auf die man in diesem Breve, aber ebenso in vielen anderen Kapiteln des Polyptychons stößt, müssen noch kurz erläutert werden: das fallweise Auftreten von Allgemeinbestimmungen, viele terminliche Präzisierungen im Rentensystem und münzgebundene Wertangaben zu bestimmten Zinsformen. Immer wieder notieren die Kommissionäre Bestimmungen, in denen von

216 " $\mathrm{O}(\mathrm{ff})$ cinas II, id est casas II; in qua sunt ine III, que vulgo nuncupantur patelle; in ebdomada burdure VI, id est cotidie I; heralem I, id est curtilem I; de cyconia vel stadiva dominica, id est locus, ubi stat, quando aquam haurit; de canla, id est, si tota hieme tempore sal fieri permittitur." Eine ähnlich intensive id-est-Haltung findet man in Kap. 9 des Polyptychons von St.-Maur-des-Fossées (hg. v. Dieter Hägermann/Andreas Hedwig (Beih. d. FRANCIA 23, Sigmaringen 1990) 93), der descriptio einer weit entlegenen Domäne; sie enthält Termini, die in der Zentrale nicht bekannt gewesen sein dürften und deshalb erklärt wurden (zur Sache: d.a.O., $62 \mathrm{ff}$.).

217 Natürlich ist hier nicht die Glosse im Sinne ausgebildeter Auslegungstechnik gemeint. Dennoch ist intendiert, das Aufkommen explikativer Sinnerweiterungen oder -vertiefungen im grundherrlichen Schriftgut an diejenigen Bereiche monastischer Schriftpraxis heranzurücken, zu deren Signatur das Glossieren zählt.

218 "Querendum est a vicinis vel a melioribus hominibus, si operator noster fidelis non fuerit, sicut sepe contingit. Ideo precipimus inquirere, quando vel quantum burdura ascenderit vel descenderit, que aliquando duobus constat denarios tantum aliquando usque ad XVI denarios, aliquando usque ad unciam pervenit. De missatico per quatuor ebdomadas, reddunt balcarii rationem."

219 Dieser Haltung nahe ist der Appell, der oben in Anm. 206 zitiert wurde. 
der Einzelhufe oder dem Rentenkanon abgelöste Verhältnisse gefaßt sind: seien es Verköstigungsregeln bei Fronden (Kap. XXIIII; überschrieben mit: qualis prebenda detur illis), Zinsforderungen im Falle des Heiratens oder der Mansusübernahme außerhalb der Prümer potestas (Kap. XXIX), Todfall und Erbrecht (Kap. LV), Schadenshaftung bei Stallfütterungsverlusten und nächtlichem Diebstahl (Kap. CXIII). Hier wird das für alle Familiaren Geltende formuliert, wird fallbezogenes Recht festgehalten - man kann von Ansatzpunkten der Verschriftung villikalen Gewohnheitsrechts sprechen. Zweitens findet man im Prümer Urbar Redaktionstypen, in denen die Entrichtungstermine der Abgaben und Dienste innerhalb des Jahreslaufs fixiert sind: sei es die monatliche Bindung (Kap. XLV, XLVIII), sei es bereits der später normale Kanon der wichtigsten Festtage (Martini, Weihnachten, Ostern, Pfingsten, Johannis (Kap. LXXXXVII-CII)) oder die Koppelung von Festtagszinsen und Jahrzeits- bzw. Monatsfronden (Kap. CXIIICXVII). ${ }^{220}$ Dies sind deutliche Zeichen dafür, das Abgeben und Dienen als jahreszyklische Zeitordnung zu artikulieren, vor allem dann, wenn der Termin die Aussagefolge der Sätze zu bestimmen beginnt, indem er an den Beginn der Sätze gerückt wird (Kap. XXXIII, XXXVII). Schließlich sind in 52 Kapiteln des Urbars für die Schweine- bzw. Ferkel- und die Schaf- bzw. Lämmerzinse Münzgeldquanta als Wertangabe (valente) zu finden. In 28 Kapiteln fungieren analoge Angaben als Alternativzins zur, Naturalform'. Man verschriftet also aufmerksam den schrittweisen, lokal und regional unterschiedlichen Bezug auf den Münzersatz, die Geldform von Zinsen - Dienste sind noch kaum in diesem Nexus zu fin$\operatorname{den}^{221}$-, der bis zur pauschalen Geldzinsveranlagung besonders peripher liegender Streubesitzungen gediehen ist. ${ }^{222}$

Im Vergleich mit den oben besprochenen Polyptycha bezeugen die hier beigebrachten Beobachtungen aus dem Prümer Polyptychon ein Mehr an redaktioneller Flexibilität und Übersicht, hier und da mehr Genauigkeit im Blick auf lokale Gegebenheiten, auf Zins- und Fron-Termine, auf den Zusammenhang zwischen Zinsspielraum und Besetzungsdichte der Hufen sowie auf die Monetisierung bestimmter Zinse, und schließlich erkennt man auch den Willen zur hofrechtlich anmutenden Zuspitzung typischer domanialer und hufenbäuerlicher Gegebenheiten, zur direkteren Organisation und Kontrolle vor Ort sowie Ansätze, neuerliche Entwicklungen durch Korrekturen oder Ergänzungen festzuhalten.

${ }^{220}$ In Kap. CXV geht man sogar so weit, die Wochentage zu benennen, an denen vom Anfang Februar bis Martini die Weinberge zu bestellen sind.

${ }_{221}$ Nur in Kap. CIIII wird in einem auf die landlosen feminae bezogenen Passus der Münzwert von Frontagen ausgedrückt: aut camsilem aut denarios XII sive duos dies ad messem et ad fenum et VI denarios solvere debent.

222 Systematisch: Kuchenbuch (wie Anm.112) 156-167; in genauerer Vermittlung mit den münzpolitischen Gegebenheiten, der Marktkreise und den Münzfunden im letzten Viertel des 9. Jahrhunderts: Klaus Petry, Die Geldzinse im Prümer Urbar von 893. Bemerkungen zum spätkarolingischen Geldumlauf des Rhein-, Maas- und Moselraumes im 9. Jahrhundert, in: RhVjbll. 52 (1988) 16-42; daran anknüpfend Morimoto (wie Anm. 214). 
Bleiben nur noch die 22 von Caesarius als summae gekennzeichneten Zusammenfassungen. ${ }^{223}$ Vieles gleicht den erwähnten Summierungen - d.h. meist sind entweder nur die Hufen selbst (XXIII) oder hufenbezogene Einzelabgaben und Dienste am Ende eines Kapitels ohne weitere Abstraktionen addiert (z.B. XXIIIIf., XXX, CIIIIff.). In einem Fall (XLIV) hat man aber eine Gesamtsumme aus fünf verschiedenen, bereits in Münzquanta gewandelten Naturalabgaben 224 erstellt und drei verschiedene Getreidearten unter ein annona-Gesamt gefaßt. Diese Formen dienen wie üblich dem schnelleren Überblick über den Bestand an Hufen und deren jährliches debitum. Zwei Passagen aber weisen in eine neue Richtung. Es sind Summen von Getreide- und Weinfuhren über weite Distanzen (angaria) im Anschluß an die Kapitel XIIIII und LVIII. ${ }^{225} \mathrm{Nach}$ Schwab beziehen sich diese Additionen auf das Transportgesamt aller Hufen von zwei Kapitelgruppen (I-XLIIII; LV-LXXII). In diesen Summierungen kann man den Versuch sehen, diejenigen Abgaben der Hufen und der Sallanderträge regional zu aggregieren, auf die es in den monastischen Zentren des frühen Mittelalters primär ankam: Getreide und Wein. ${ }^{226}$ Ich erkenne hier die Absicht, vom Gewirr domanialer debitum-Verhältnisse zur Vorstellung möglicher, ja vielleicht auch reeller redditusQuanta zu kommen. Der Antransport der Abgaben, das wurde schon daraus ersichtlich, welches Gewicht Adalhard auf ihn in seiner ratio der Zehnten der Klosterpforte legte, ist der Vorgang, durch den bäuerlich-lokales Soll in herrschaftlich-zentrales Haben ,umschlägt ${ }^{\dagger}$ - und wie man damit rationaliter umgehen kann, zeigt wiederum Adalhard. Funktional und ordinativ gesehen zeigen die beiden unscheinbaren Bemerkungen die Stufe an, mit der - quellentypologisch zugespitzt - aus dem Polyptychon ein Urbar wird. Um ganz kurz zusammenzufassen: am Prümer Urbar hat sich gezeigt, welche Zeichen für genauere Orts-, Zeit-, Maß-, Wirtschafts- und Rechtsbezüge im Deskriptionsstil erkennbar sind, daß das Aneignungskalkül sich verfeinert, der Organisationswille sich verdeutlicht und direkter wird, die Reflexion über den durch die Erhebung verfügbaren Wortlaut aufkommt und die ohnehin schon dominante Ausrichtung des Ganzen am Rentensoll dann anschließend zu Lieferungsberechnungen entscheidender Güter zugespitzt wird. Auch wenn all dies - daran muß erinnert werden - nur in Ansätzen greifbar ist, es dokumentiert das schriftkulturelle Niveau in Prüm gegen Ende des 9. und zu Beginn des 10.Jahrhunderts. ${ }^{227}$

223 Scbwab (wie Anm. 139) 136-142, an den ich mich hier halte, hat plausibel gemacht, daß diese Additionen (bis auf 2 Irrtümer, die auf Caesarius zurückgehen) durchweg von einem an der Erhebung vor Ort bereits beteiligten Bearbeiter erstellt worden sind, der das Polyptychon im ganzen vor sich hatte.

224 Es sind die Zinse pro pasto, pro lino, pro axilis et scindalis, pro lignario und pro porco donativo.

${ }^{225}$ Schwab (wie Anm.139) 200: "Ducunt de vino carradas XCIIII, de annona modios MMMCCL; 221: Ducunt ad Prumiam de vino seu de annona carradas CCL, ad Novum Monasterium (Münstereifel) similiter carradas CCL"; zur Deutung: 139-142.

${ }^{226}$ Hierzu den schönen Artikel von Georges Duby, Le monachisme et l'économie rurale, in: ders. (wie Anm. 8) 381-387.

${ }_{227}$ Leider lassen sich meine Beobachtungen nicht mit den Verhältnissen in Skriptorium, Bi- 


\section{Der urbariale Mischkodex der Abtei Werden (Ende 9.-11.Jahrhundert)}

Rudolf Kötzschke hat 1906 mit seinen Studien zur Grundherrschaft der Abtei Werden nicht nur das Bild von der frühmittelalterlichen Grundherrschaft um den Typ der ,Hebeamtsverfassung entscheidend erweitert, sondern mit der Edition der frühen Werdener Urbare auch editorische Maßstäbe für diese Überlieferungsgattung gesetzt. ${ }^{228}$ Alle jüngeren Bemerkungen zur Quellenkritik bezeugen die Gültigkeit dieser Leistung. ${ }^{22}$ Hier soll es nur um das älteste Schriftstück der auBergewöhnlich reichhaltigen Überlieferung gehen, das von Kötzschke so benannte ,Urbar A ${ }^{230}$. Dies deshalb, weil mit ihm der Forschung der älteste vorwiegend urbariale Mischkodex zur Verfügung steht. Die Handschrift besteht aus vier nach Haupthänden, Inhalten und Zeitstellung unterscheidbaren Gruppen Kötzschke nennt sie Grundbuch (A1: $\mathbb{\$} 1-20$ ), ostfriesisches Register (A2: $\mathbb{S} 21-$

bliothek und Unterrichtung in der Abtei Prüm verbinden. Die damaligen Zerstörungen durch plündernde Normannen (882 und 892) und spätere Bücherverluste (1511) sind zu groß, als daß sich die schriftkulturelle Praxis - über den Nachweis des bekannt regen literarischen Lebens (Wandalbert, Regino; Briefwechsel Abt Marquards mit Lupus von Ferrières; dazu die Annales Prumienses) hinaus - ausreichend konkretisieren ließe. Vgl. Wolfgang Haubrichs, Die Kultur der Abtei Prüm zur Karolingerzeit. Studien zur Heimat des althochdeutschen Georgsliedes (Rheinisches Archiv 105, Bonn 1979); Wattenbach-Levison, Deutschlands Geschichtsquellen im Mittelalter, H.6: Heinz Löwe, Die Karolinger vom Vertrag von Verdun bis zum Herrschaftsantritt der Herrscher aus dem sächsischen Haus. Das ostfränkische Reich (Weimar 1990) 895-904. Übergehen sollte man aber doch nicht, mit welcher Differenziertheit und Übersicht Regino sein Kirchenvisitationsmanuale (Libri duo de synodalibus causis et disciplinis ecclesiasticis, hg. F. G. A. Wasserscbleben, Leipzig 1840/ND Graz 1964) ordiniert hat. Er legt in einer praefatio (1 f.) nicht nur klare Rechenschaft über Zweck, Anlage und Methode seiner Arbeit ab, sondern verfügt in beiden Büchern über alle Instrumente damaliger Ordinationskunst (Einteilung in Bücher, Kapitel, Abschnitte; capitulationes, Überschriften, Durchzählungen; auctoritates-, canones-, decreta-Nachweise; Vorund Rückverweise, Verbindungssätze). So ist eine beeindruckende formale Ordnung vorfindlich, die m. W. noch nicht umfassend untersucht worden ist. Die Erforschung von Reginos Quellenbenutzung und Redaktionstechnik hat natürlich ihre kirchenrechtliche Tradition; vgl. zuletzt Gerbard Schmitz, Ansegis und Regino. Die Rezeption der Kapitularien in den Libri duo de synodalisbus causis, in: ZRG KA 105 (1988) 95-132.

${ }_{228}$ Rudolf Kötzschke (Hg.), Die Urbare der Abtei Werden vom 9.-13.Jahrhundert (Rheinische Urbare 2 = Publikationen der Gesellschaft für Rheinische Geschichtskunde XX, Bonn 1906); vorausgegangen waren seine Studien zur Verwaltungsgeschichte der Großgrundherrschaft Werden an der Ruhr (Leipzig 1901).

229 Zuletzt: Hägermann (wie Anm. 16) 69-72; Hans-Werner Goetz, Die Grundherrschaft des Klosters Werden und die Siedlungsstrukturen im Ruhrgebiet im frühen und hohen Mittelalter, in: Ferdinand Seibt u. a. (Hg.), Vergessene Zeiten. Mittelalter im Ruhrgebiet, 2 (Essen 1990) 80-88; Hedwig Röckelein, Frauen auf dem Land im frühen und hohen Mittelalter im Spiegel der Grundherrschaften Werden a.d. Ruhr und Essen. Eine Fallstudie, in: Bea Lundt $(\mathrm{Hg}$.$) , Vergessene Frauen an der Ruhr. Von Herrscherinnen und Hörigen, Hausfrauen und$ Hexen 800-1800 (Köln/Weimar/Wien 1992) 18-50.

230 HStA Düsseldorf, Werden IXa 1 a; Beschreibung bei Kötzschke (wie Anm. 228) CIXCXXII; Text: 4-87. 
24), westfälische Heberegister (A3: $\$ \$ 25-37$ ) und Heberegister für Westfalen und Niederland (A4: $\$ \$ 38-43$ ). Alle Gruppen sind Neuschriften, die, zum Zweck übersichtlicherer Güter- und Einkünfteregie erstellt, aus verschiedenen Vorlagen (Einzelurkunden, Traditionsnotizen, Aufstellungen über Güter und Rechte, Heberollen) mit unterschiedlichem Zeit- und Ortsbezug stammen. Sie entstanden sukzessive: zuerst das Grundbuch (A1), wahrscheinlich nach 890 im Fahrwasser einer allgemeinen Reorganisation in Werden - Königsschutz, Abtwahl, Sicherung der Stellung durch weitere königliche und päpstliche Privilegien sind die Zeichen $^{231}$ - unter Abt Hembil. Es vereint - in der ursprünglichen Anlage - ohne erkennbare Ordnungskriterien eine Schenkungsurkunde von 855 in vollem Wortlaut, die bekannte descriptio der ehemals königlichen Villikation Friemersheim, fünf auf westfälische Bezirke (ministeria) bezogene Abgabenverzeichnisse, kurze Notizen über lokale Leistungen und Einkünfte sowie Traditionsnotizen (ab 890). In viele der absichtlich freigelassenen Schriftblock-Spatien sind Traditions-, Besitz- oder Abgabenotizen nachgetragen, zehn aus dem 10. und drei aus dem 11. bzw. 12.Jahrhundert. Die beiden folgenden Gruppen (A2-3) entstanden wohl nach dem Grundbuch, jedoch in engem zeitlichen Zusammenhang mit ihm. Sie sind als regionale und sachliche Ergänzungen zu verstehen. Urbar A2 enthält Güter- und Zinsverzeichnisse vorwiegend an der unteren Ems, die in Traditionsnotizen übergehen, Urbar A3 Gleiches über vorwiegend westfälische Güter, aber aus den Jahren vor 890. Spätere Zusätze sind selten. Sie fehlen ebenso in Urbar A4, das etwas später - im 2. Drittel des 10. Jahrhunderts - geschrieben sein dürfte; inhaltlich ergänzt es die voraufgehenden Gruppen und ersetzt Teile des Grundbuchs. Die Handschrift ist also in einem über Jahrzehnte, gestreckten ' Vorgang entstanden und ergänzt worden, eng den klosterinternen Orientierungserfordernissen angepaßt.

Dies wird auch ein Grund dafür sein, warum dem Kodex - wann im 10.Jahrhundert die Teile zusammengefügt wurden, ist unbekannt - praefatio, explizite Datierungen, Gesamt- bzw. Teiltitel, überleitende Sätz ${ }^{232}$ und interne Verweise fehlen. Das soll aber nicht heißen, daß ihm jede Ordination abginge. Im Gegenteil. Dies zeigt nicht nur die großzügige, auf Nachträge an den Rändern neben dem vorliniierten Schriftblock oder zwischen den Abschnitten angelegte Einrichtung der Seiten. Auffällig ist auch, wie stark viele Hände, zu klarer Minuskel und auf Worttrennung hin erzogen, die graphische Distinktion selbständiger Sachaussagen beachteten: dies führt vom über mehrere Seiten durchgeschriebenen Urkundenwortlaut über ortsbezogene mehrzeilige Abschnitte, halbzeilige Namenseinträge mit Geldzinssoll bis zu auffälligen Spatien innerhalb der Zeilen zwischen einzelnen ,Posten' (auch mit Trennzeichen). ${ }^{233}$ Der Abschnittsverdeutlichung die-

231 Kötzschke (wie Anm. 228) CXXI.

232 Abgesehen von wenigen Incipit- und Finit-Sätzen im Grundbuch: Kötschke (wie Anm. 228) 21, 25, 27, 53; dazu das ankündigende: de ministerio/de officio: 28, 36, 45, 57 u.ö. in A3-4.

${ }^{233}$ Dies ist der systematisch treffende Ausdruck von Kötzschke. Begriffen dieser Art (Eintrag, Posten u. a.) fehlt aber noch ihre Geschichte. 
nen häufig auch links ausgestellte Initialen; versalisierte Erstsätze, geplante (bzw. in Zeilenspatien nachgetragene) Zwischentitel und Trennungsstriche sind eher selten. ${ }^{234}$ Dazu kommen zweimal Ansätze zur Kolumnierung satzloser Einträge. ${ }^{235}$ Einmal verfährt Hand I sogar graphisch analog heutiger wissenschaftlicher Fußnotentechnik, wenn sie die summae zu zwei Abschnitten im ersten westfälischen Abgabenverzeichnis (Grundbuch $\$ 4$ ) zwischen bzw. sogar unter den liniierten Schriftblöcken - und durch einen Trennungsstrich abgesetzt! - notiert. ${ }^{236}$

In diesem wohl am besten ordinierten Abschnitt der ganzen Handschrift kann man noch drei weitere nachgeordnete Schrifthandlungen ausmachen. Zum einen sind häufig die Namen der Zinspflichtigen interlinear nachgetragen. Zweitens hat man in zwei Fällen - auch interlinear - Zinshöhen verbessert. Und drittens findet sich, zeilenbezogen an den äußeren Rand geschrieben, immer wieder ein , $\mathrm{r}^{\mathrm{r}}$, das Kötzschke plausibel als zeitgenössischen, requirendum'-Vermerk gedeutet hat. Diese Marginalien, mit denen auch andere Abschnitte im Grundbuch versehen sind, bezeugen dessen Gebrauch zur Kontrolle der konkreten jährlichen Einnahmen. Versuchte man im Prümer Urbar domaniales Soll zu regionalen Einkunftserwartungen zu schürzen, so wird hier das Soll-Buch um auf den Einzelfall bezogene Vermerke für interne Fehler oder Prestationsausfälle vor Ort ergänzt. Allerdings nicht um errechnete, numerisch ausgedrückte. Die nachgeordneten Schriftreflexe zum Verhältnis des Solls zum Entrichten und Haben zielen auf Präzisierungen der Ansprüche und verbleiben im Bereich eines Handlungsgebots, das nicht in terminierte Forderungen (restat), d.h. gestundete ,Rechnung' umgesetzt ist. $^{237}$ Dennoch bleibt die appropriationspraktische Nutzung mindestens des Grundbuchs offenkundig.

Damit bin ich längst übergegangen zu inhaltlichen Gesichtspunkten des Ordnungsverhaltens. Was ist im Werdener Kodex am Deskriptionsstil weiter auffällig?

Zum einen: Die Hebeverzeichnisse haben nur Variationen im Hinblick auf lokale und namentliche Genauigkeit sowie sachliche Ausführlichkeit zu bieten. Auffällig ist der vorherrschende Namensbezug der Pflichten. Dies wirkt - einmal abgesehen von der Frage, ob die Werdener Güter in Westfalen und Friesland bis gegen Ende des 9. Jahrhunderts nicht verhuft oder die Herrschaftsbeziehungen vorwiegend in den Familialen verankert waren - in der Sache schlicht, kaum an die oben untersuchten Polyptycha heranreichend, und im Stil entstehungsnah. Auch das Deskriptionsvokabular, die Benutzung lateinischer Wörter in Sonderbedeu-

\footnotetext{
234 Versalisiert sind eine Urkundeninvocatio (in der Hs.Bl. 1), die descriptio von Friemersheim (Bll. 4 ff.: CENSUS DE SINGULIS MANSIS, DE SERVICIO, MANCIPIA); das eine oder andere Erstwort (Bll. 7 b, 29 b, 31 b); Trennungsstriche z. B. auf Bl. 28 a, 31 b. Kötzschke (wie Anm. 228) 9, 16-19, 21, 60, 67.

${ }_{235}$ Bl. 9b, eine summa betreffend; Bl. 10 b, ordinal reihend; Kötzschke (wie Anm. 228) 25, 27.

$236 \mathrm{Bl}$. 7b-8b; Kötzschke (wie Anm. 228) $21 \mathrm{ff}$.

237 Auch die Tatsache, daß Inhaber- und Abgabenvermerke der früheren Verzeichnisse, die durch die späteren, ersetzt' werden, nicht durchgestrichen oder anderweitig ent-wertet sind, deutet auf andere Einstellungen zur, Geltung' verschrifteter grundherrlicher Rechte.
} 
tungen (z. B. scara, siclus, rus, pes) und die Häufigkeit von mundartlich-altsächsischen Nomina, die zum Teil sicher Rechtswortcharakter haben (heriscilling, herimalder, tuedihoua, holtmarca, land, uurd u.a.), in den ohnehin schon mit kaum noch latinisierten Orts- und Familiarennamen aufgeladenen Einzelangaben unterstreicht diesen Eindruck. Der nominale Mischmasch in den lateinisch gedachten Sätzen schlägt bisweilen sogar in mundartlich bestimmte Syntax um, sei es im explikativen Nebensatz oder durch Verwendung einer altsächsischen Verbform. ${ }^{238}$ Damit aber nicht genug. Ein zeitgenössischer Nachtrag in A3 (westliches Friesland) ist nahezu durchgehend altsächsisch gefaßt. Er beginnt: An Naruthi thiu kirica endi kiric land ... ${ }^{239}$ Dies enge Verhältnis zur Mundart im Rahmen des grundherrlichen Schriftgebarens ist durchaus zeit- und regionaltypisch zu nennen. Denn nicht nur die älteste urbariale Aufzeichnung aus dem Stift Essen, die sogenannte Essener Heberolle aus der ersten Hälfte des 10.Jahrhunderts, ist altsächsisch abgefaßt ${ }^{240}$, sondern auch das ,Heberegister ' des Stifts Freckenhorst, das, auf rotuli des 10.Jahrhunderts zurückgehend, in einer ansatzweise latinisierten Neuschrift aus der ersten Hälfte des 11.Jahrhunderts vorliegt. ${ }^{241}$ Auf diese Neigung zur mundartlichen Aufzeichnung kann ich hier nur hinweisen. ${ }^{242}$

Zum anderen: Die descriptio der Villikation Friemersheim ${ }^{243}$ bezeugt ein hohes Niveau sprachlich geformter und implizit divisionsgeleiteter Beschreibungstechnik. Schon die Gliederung des Ganzen ist auf geordnete Stufung abgestellt: zuerst das Friemersheimer Dominikalland in lokaler Verteilung (19 Ortsnamen), dann die mansus-Pflichten, klar geteilt in census und servitium, die Wiederholung dieses Dreischritts für die Neben-Villikation Hoch-Emmerich (mit Verweisen auf

${ }^{238}$ Kötzschke (wie Anm. 228) 40 Z. 15: "libram lini bene purgati id est ihekilod"; 40 Z. 2: "Selihoua ... altero anno ... malterot."

${ }^{239}$ A.a.O. 73 Z. $20 \mathrm{ff}$.

240 Druck: Theodor J. Lacomblet, Heberolle, in: Archiv f. d. Gesch. d. Niederrheins 1 (1832) 12f.; Ruth Schmidt-Wiegand, Essener Heberolle, in: VL (2. Aufl.) 2 (1980) $634 \mathrm{f}$.; zur Sache zuletzt Thomas Schilp, Die Grundherrschaftsorganisation des hochadligen Damenstifts Essen, in: Seibt (wie Anm. 229) 89-92.

${ }^{241}$ Ernst Friedlaender (Hg.), Die Heberegister des Klosters Freckenhorst nebst Stiftungsurkunde, Pfründeordnung und Hofrecht (Codex Traditionum Westfalicarum I, Münster 1872/ ND 1956), Edition: 25-59, zur Überlieferung: 13-24, sowie Ruth Schmidt-Wiegand in: VL (2.Aufl.) 2 (1980) 885-887. Zur Stiftsgeschichte Wilhelm Kobl, Das (freiweltliche) Damenstift Freckenhorst (Germania Sacra NF 10, Berlin/New York 1975); zur Grundherrschaft Werner Rösener, Grundherrschaft und Bauerntum im hochmittelalterlichen Westfalen, in: Westfälische Zeitschrift 139 (1989) 9-41, hier: $16 \mathrm{f}$.

242 Damit muß offenbleiben, ob solche altsächsische „Rechtsprosa“, so Dieter Kartschoke, Geschichte der deutschen Literatur im frühen Mittelalter (München 1990) 266-269, sich mehr der mündlich bestimmten Erfragungssituation oder bewußt altsächsisch-sprachlichem Verschriftungswillen verdankt. Metz (wie Anm. 63) $193 \mathrm{f}$. weist auf enge Beziehungen zur angelsächsischen Bezeichnungspraxis hin, die im Zusammenhang mit der Mission steht.

${ }_{243}$ Kötscbke (wie Anm. 228) 16-19; zur Villikation Friemersheim vgl. Erich Wisplinghoff, Bäuerliches Leben am Niederrhein im Rahmen der benediktinischen Grundherrschaft, in: Walter Janssen/Dietrich Lobrmann (Hg.), Villa - Curtis - Grangia. Landwirtschaft zwischen Loire und Rhein von der Römerzeit zum Hochmittelalter (Beih. d. FRANCIA 11, München 1983) 149-163. 
Friemersheim), die Kopfzinsordnung für die mancipia, schließlich Streu-mansi mit Sonderstatus. Die Ordnung ist ganz vom Verlaufsprotokollarischen gelöst. Man hebt aufs Durchschnittliche, auf die lokalen consuetudines ab. Konsequenterweise fehlen Einzelhufendetails und Familiaren-Namen - außer in den Nachträgen. Innerhalb der Teile sind Ordnungsgesichtspunkte verschiedenster Art am Werk. Die Aufstellung der Salländereien wird mit einer Bemerkung über die Herkunft (kaiserliche Schenkung an Bischof Hildgrim, Übertragung an St.-Liudger) abgeschlossen. Die Sinneinheiten in den beiden Zinsabschnitten sind konsequent auf Entrichtungstermine ausgerichtet. Die Dienstordnung ist bestechend klar aufgebaut und aspektreich detailliert, übertrifft an Ausführlichkeit zu einzelnen Tätigkeitsketten alles Frühere und zeugt von einer fast durchgehend explikativen Haltung zu Sache und Wort.

Genauer gesagt: Die Unterscheidung zwischen Zeit- und Stückdiensten liefert die Grunddivision dieses Abschnitts. Die drei jahreszeitlich oder monatlich fixierten Zeitdienstblöcke zu je zwei Wochen (anderweitig als noctes bezeichnet ${ }^{244}$ ) stehen damit am Anfang, gleich gefolgt von der ersten Erläuterung: In singulis ebdomadibus V quinque ${ }^{245}$ dies - eine einmalige Präzisierung des zeitlichen Frondienstaufwandes. Die Stückdienste sind klar nach ihrer landwirtschaftlichen Bedeutung gestuft: Getreidebau, Heumahd, Zäunung, Weiterverarbeitung des Getreides, Schweinemast und -hut, Gartenbeetbestellung, Flachsernte. Jeder Stückdienstbereich wird nach eigenen Erfordernissen subdividiert bzw. spezifiziert. Der wichtigste Bereich, die Getreidebaufronden, wird zuerst nach Größe und Verbindlichkeit (iugum, iornalis petitorius) unterteilt; darauf wird nach Winterund Sommersaat (qualitas) geschieden, dann folgt die Handlungskette: (aufbrechen,) pflügen, (säen,) eggen, reinigen, (schneiden, aufhocken,) einfahren; schließlich die Zuschreibung bestimmter Teilaufgaben an Mann und Frau und die Beköstigung und Zuteilung von Ertragsanteilen. Im Zuge dieser Detaillierungen werden Maße erläutert ( 1 iugum $=2$ iornales), lateinische Verben altsächsisch glossiert (z. B. proscindere, id est gibrakon ${ }^{246}$ ), Vollzugsbedingungen (si non ... tunc; ita ... ut) und Abfolgen (dehinc, tunc, rursum) von Teilakten präzisiert. Ähnliches gilt auch für die folgenden Stückdienste. Ich zitiere zum Beleg nur den Abschnitt über die Zäunung: Rursum ad curtem dominicam debet palos triginta deferre, quoties necesse est ad sepem innouandam. Veteres palos et uirgas in usus suos adsumere. In agro oportet iugalem sepem quod dicitur iucfac ita procurare, ut iumentum uel pecus in segetes non irrumpat. Quodsi irruperit, ipse debet. Ipsae iugalis sepes debet longitudinis esse ad quinque iugales uirgas. Quem sepem cum inueterauerit sibi assumat et faciat nouum. ${ }^{247}$

244 Zur Sache vgl. Kuchenbuch (wie Anm. 112) 126-128.

245 Was eine Gewohnheit wie die doppelte Schreibung von Zahlen als Ziffer und Wort anzeigt, ist hier nicht zu untersuchen.

246 Weitere altsächsische Wörter, die glossiert werden: giekkan, iucfac, iukruoda, aranfimba; ohne Übersetzungsgleichung: gimeltan, ketile gibreuan, afterbier, seliland.

${ }^{247}$ Kötzschke (wie Anm. 228) 17 Z.27-18 Z.5. 
Aber nicht nur die Detaillierung, auch die Verknüpfung bezeugt den Ordnungswillen. Im ganzen Abschnitt sucht man den Beginn einer neuen Sachaussage über eine Stückdienstspezies dadurch zu markieren, daß man auf den Zeitbezug (annis singulis) rekurriert oder adverbial anschließend einsetzt (item, rursum). ${ }^{248}$ Der Wille, den - im Kodex übrigens graphisch geschlossenen - Abschnitt sprachlich so zu gestalten, daß Verknüpfung und Distinktion der Genauigkeit und dem Verständnis der Sache dienen, ist unübersehbar. Ich kenne keinen Abschnitt in den karolingischen Polyptycha, der so allgemeinverbindlich, vollzugsdetailliert, verknüpfungslogisch und explikativ stilisiert ist.

Im Werdener Kodex sind also weit entwickelte formale und inhaltliche Ordnungstechniken zu erkennen. Doch finden sie nur in Teilen ${ }^{249} \mathrm{zu}$ Geschlossenheit und Konsequenz. Auch wenn der Kodex insgesamt bedacht kompiliert, für Ergänzungen vorbereitet und lange benutzt wurde, so bleibt er gerade auf der Ebene der in sich abgeschlossenen Teile nahezu stumm.

Dies gilt - mein letzter Punkt - besonders für die inkorporierten Urkunden und Traditionsnotizen. ${ }^{250} \mathrm{Hier}$ wird das Ordnungsniveau, von dem bereits die ältesten Traditionsnotizen - Notitia Arnonis (788-790), Breves Notitiae (798-800) ${ }^{251}$ - genauso zeugen wie die frühen Kartulare des 9.Jahrhunderts - seien sie nun primär um der besseren Güteraufsicht (wie im Falle Weißenburgs, Fuldas, Mondsees u. a.) oder um der Stiftermemoria willen (z. B. Cozrohs Zusammenstellung der frühen Freisinger Traditionen) erstell ${ }^{252}$-, nicht erreicht. Es fehlt den Einträgen jegliche zeitliche bzw. räumliche Ordnung (etwa nach Äbten oder/und Gauen), ebenso Überschrift und Durchgliederung. Gleich den beiden Fassungen des Liber Traditionum aus der Abtei St.-Pieter/Gent (10. und 11.Jahrhundert) fehlt im Werdener Kodex eine explizite Teil- und Gesamtordination. Aber man sollte nicht vergessen, daß in Werden ein Kartular existierte, das die Urkunden über die im Grundbuch fehlenden Besitzungen aus den Jahren 793-848 enthielt. ${ }^{253}$

248 Besonders dem item, das sich in den Verzeichnissen der Karolingerzeit erst sehr vereinzelt zur Einleitung eines weiteren ,Eintrags in gleicher Sache' findet - wenn, dann meist als später anschließender Ordnungsakt erkennbar -, wird ja eine grandiose Zukunft im Rechtsund Wirtschaftsschrifttum beschieden sein.

${ }^{249}$ Wichtig ist hier die Vermutung von Metz (wie Anm. 75) $71 \mathrm{f}$., daß die descriptio der Villikation Friemersheim auf Zeiten zurückgehen könnte, als die Domäne noch in Königsbesitz war.

${ }^{250}$ Kötzschke (wie Anm. 228), Urbar A1 $\$ \$ 1,6,8-11,16,19 ;$ Urbar A2 $\$ 21$.

251 Zuletzt (mit aller Literatur) Fritz Losek, Notitia Arnonis und Breves Notitiae. Die Salzburger Güterverzeichnisse aus der Zeit um 800: Sprachlich-historische Einleitung, Text und Übersetzung, in: Mitteilungen der Gesellschaft für Salzburger Landeskunde 130 (1990) 5-193.

252 Hierzu jetzt ausführlich Geary (wie Anm.18) $93 \mathrm{ff}$.

253 Beschreibung bei Kötzschke (wie Anm. 228) CVI-CIX, der dafür plädiert, daß das Kartular nicht nur zeitlich parallel zum Grundbuch, sondern auch komplementär zu ihm (nämlich die Güter betreffend, die im Grundbuch fehlen) angelegt worden ist. Dem Kartular, dem eine zeitliche oder räumliche Ordnung der einzelnen, im übrigen durchgezählten Urkunden fehlt, ist jedoch ein Verzeichnis vorangestellt. Neueste Edition und Forschungsstand (Datierung etwas später: in die erste Hälfte des 10. Jahrhunderts): Dirk Peter Blok, De oudste particuliere oorkonden van het klooster Werden (Assen 1960). 
Beide Kodizes können also als funktionaler Verbund gelten, beide dienten nebeneinander der Güter- und Einkünfteaufsicht - eine günstige Überlieferungssituation, die ahnen läßt, was in den Abteien dieser Zeit an grundherrlichem Schriftgut zuhanden gewesen sein dürfte.

\section{Zwischenergebnisse}

Damit möchte ich die Überlieferung des 9.Jahrhunderts verlassen. Bevor ich ins 12. springe, ist aber noch kurz zu resümieren, was nun in Erinnerung an die Orientierungen, die die kurze Betrachtung einiger ausgewählter Zeugnisse des 11.Jahrhunderts bieten konnte, gewonnen ist. Zunächst einmal konnte gezeigt werden, wie viel dem äußerlich so anspruchslosen grundherrlichen Schriftgut der Karolingerzeit zum Thema abzugewinnen ist. Dabei wird schriftgeschichtlichen Kennern nahezu all das, was zur Schreibweise und Ordination beigebracht wurde, bekannt, ja banal erschienen sein. Aber darauf kam es teilweise ja auch an; nämlich auszuweisen, daß das härene Gewand der Polyptycha und Urbare mit gleichem Kettfaden und nach dem gleichen Muster gewebt ist wie die Memorial-, Rechtsund Artesschriften, die theologischen Traktate bis hin auch zu den aufwendig illuminierten Liturgica. Daß die schriftkulturellen Werkzeuge, denen, zum System geschlossen, seit dem 12.Jahrhundert so weitreichende Wirkung zugesprochen wird, im 9.Jahrhundert zu wichtigen Anteilen längst bereitstanden und Anwendung fanden, ist ja durchaus Gemeinplatz der Forschung. ${ }^{254}$ Hier kann nun auch das grundherrliche Schriftgut verortet werden, auch wenn die Anbindung der Einzelbeobachtungen an die Schul-, Schreib- und Bibliothekssituation in den betreffenden Abteien sehr locker bleiben mußte. An den verschiedenen Stadien fortschreitender Verschriftlichung - von der Rolle aus St.-Victor über den Pariser und Helmstedter bis zum Werdener Kodex - konnte ein Ensemble skripturaler und ordinativer Regeln und Mittel nachgewiesen werden, mittels dessen nicht nur die einzelne pagina, sondern auch größere Sinneinheiten in Heft, Rolle und Kodex gestaltet wurden. Nicht nur die Durchgliederung (Absatzbildung und -markierung, Durchzählung usf.) des scriptum, sondern auch seine begriffliche Kennzeichnung (Titel) und der Rekurs auf Anfang und Ende sowie seine Teile (Incipit-Finit; Rück-, selten Vorverweise) zählen dazu. Nicht nur die Schrift-, sondern auch die Schriftlichkeitsreformen der Karolingerzeit trugen also auch in diesem Ordnungsbereich deutlich Früchte. Wie weitreichend die Erfolge waren, ist sicher noch nicht befriedigend ausgelotet. Trotz aller beobachteten punktuellen Ordnungsgewinne innerhalb der Verzeichnisse und in ihrer zeitlichen Folge: verglichen mit den einführend herangezogenen Zeugnissen aus dem 11.Jahrhundert fehlt eine konsequente Ordination des grundherrlichen Schriftstücks insgesamt, 
fehlen ebenso treffende Gesamttitel. Das schriftpraktische Formbewußtsein wirkt sich noch nicht auf das ,Ganze' aus.

Weiter scheinen mir - im Felde sachlicher Distinktion und inhaltlicher Reflexivität - Wirkungen der trivialen Schulung auf die grundherrliche Schriftpraxis unabweisbar, und zwar mit progressiver Tendenz. Dies gilt sowohl für die eröffnenden (proprietären bzw. appropriativen) als auch für die ausmündenden (dispensativen) Schriftakte.

Die Untersuchung der Verzeichnisse hatte zum Ergebnis, daß die Deskriptionstechniken nicht nur implizit von trivialdialektischen Divisionen (mit durchaus regelhaft wechselnden, ja stufungsbewußten Ausgangs- bzw. Fortsetzungskriterien, d.h. Subdivisionen) bestimmt sind, sondern im Laufe des 9.Jahrhunderts auch klar an lokaler, zeitlicher und sachlicher Genauigkeit gewinnen. Die Detaillierung erstreckt sich mehr in die dingliche und familiale Breite, geht mehr in die funktionale Tiefe und wird flexibler im Umgang mit den sprachlichen, begrifflichen und sequenziellen Vorgaben (Mundart, Vokabular, Fragenkatalog) bis hin zur Verzeichnung des Fehlenden (nullum), zur Sacherläuterung (id est) und zur Verhaltensanordnung. Logische und situative Entfaltungen geben sich die Hand. Warum das jeweils geschieht, wird aber nicht ausgedrückt, der rahmende, einordnende Bedacht und dessen Vokabular fehlen.

Auch die nachgeordneten Konzentrationen des Entfalteten zum rechtlich Allgemeinen oder zur Sachsumme sind vielfältig. Man verdichtet etwa die Pflichten ausgehend vom Inhaber oder von der Hufe über Exemplifizierung bis zum umfassenden de-servitio-Abschnitt. Man aggregiert rechtlich qualifizierte und einzeln enumerierte mansi bis zur attributslosen Hufengesamtzahl (pro Domäne oder gar Herrschaft). In der Praxis der Abgabenaddierung konnten neben der Bildung zusätzlicher Abstraktionen (capita von verschiedenen Vieharten, Silber-summae diverser Münzzinsarten) wichtige Verschiebungen vom debitum zum redditus, ja auch ansatzweise zum receptum ausgemacht werden: es wird also nicht nur unbeholfen zusammengezählt, sondern hier und da findet konkretes Ertragskalkül zu Wort und Ziffer. Aber auch dabei bleiben Grenzen gesetzt. Die beiden Ziele der herrschaftsinternen Aggregationen, mittels derer ja Entscheidendes zur Distanzierung vom ortsgemäß erhobenen und protokollierten Wissen erreicht wird: der Überblick nämlich über die dauerhafte Habe und über das zählbare Einkommen, werden zwar kenntlich, ihr Wortlaut in den summae bleibt aber in vielem unbeholfen, weil die Konkretisierung des Zwecks fehlt.

Adalhards Statuta als kostbares Faustpfand dispensativer Praxis bezeugen nun nicht nur divisionsgeleitetes Vorgehen, wobei jeder Ordnungsaufgabe die ihr eigene Lösung (ratio) zusteht, sondern auch expliziten Umgang mit dialektischen Schulbegriffen (genus, species, numerus, tempus usf.). Aber auch diesen so beeindruckenden Brevia fehlt die gezielte Reflexion auf die Aufgabe als ganze und vorbehaltlich dessen, was die gestörte Überlieferung zu vermuten erlaubt - die umfassende Ordination. Das systematische Denken meistert die Einzelfragen, dient aber kaum der Situierung im weiteren Zusammenhang.

Insgesamt ergibt sich also das Bild einer Vielfalt, die sich - man erinnere sich an 
die Trias seponere-distinguere-ordinare des quid-vel-quantum im Capitulare de villis - auf alle Dimensionen des Ordnungsverhaltens bei der Erstellung, der Bewahrung und der Benutzung des Schriftguts bezieht - und auf die Schriftguttypen selbst: eine breite Palette von der entstehungsnahen Rolle über vorgeplante Reinschriften in Heft und Kodex, sukzessive erstellte Kompilationen, ergänzende Nachträge, begleitende Sacherläuterungen, Korrekturen, schematische summae über Habe und Soll, konkretere über erwartete Einkünfte, Kontrollvermerke, präzise Aufstellungen über Ertragszuweisungen ${ }^{255}$, bis hin zu den distinctiones bzw. rationes für die klosterinternen Victus-Aufteilungen - und nicht zu vergessen schließlich das flankierende Kleinschriftgut (kurzlebige Einzelpergamente, sicher auch Wachstafeln und Kerbhölzer), die weitgehend verlorenen Briefe, Listen und Rechnungslegungen also, von denen Einhard, Adalhard und vielleicht das Prümer Urbar zeugen. Dennoch fehlt dieser Vielfalt der Zug zur autonomen, reflexiven Vollschriftlichkeit. Das zeigt sich auch daran, daß die Stücke kaum in externen Verweisungszusammenhängen stehen; ihnen fehlen weitgehend Hinweise auf ergänzendes schriftliches oder mündliches Wissen. Dort, wo dies - wie bei Adalhard - geschieht, blitzt die Dominanz des mündlichen usus cotidianus über das Geschriebene auf. ${ }^{256}$ Dieses Schriftgut ist nahezu anonym, kaum datiert, und nur in Ansätzen wird der gleitende Charakter der Unterhaltswirklichkeit, die Verschiebung des Überkommenen zum Jetzigen, artikuliert. Überall schimmert hindurch, daß man mit diesen Schriftstücken in Verständigungskreisen umging, wo nur ein Minimum dessen aufgeschrieben und formuliert sein mußte, was ihren sinnvollen Gebrauch gewährleistete. Das grundherrliche Schriftgut, so vielgestaltig es sich darstellt und so weit es auch zu seinen Entstehungszusammenhängen auf Distanz gebracht und auf die interne administrative Situation zugerichtet wurde, war unselbständig, blieb mnemopraktisches Hilfsmittel für einen Alltag, der bestimmt war von eingeweihter, situations- und sachkundiger Mündlichkeit.

\section{Jahrhundert}

Wie angekündigt, sollen meine Bemerkungen zum 12.Jahrhundert nicht in der Detaillierung ausfallen, wie dies für das 9.Jahrhundert geschah. Viel mehr als einige aufs Neuartige zielende Andeutungen sind nicht beabsichtigt. Die Beschränkung gründet jedoch nicht allein darin, diesen Aufsatz nicht noch mehr ausufern $\mathrm{zu}$ lassen, sondern auch in einem wesentlich schlechteren Stand der Überlieferungskritik. Das grundherrliche Schriftgut vermehrt, verdichtet und verzweigt

$255 \mathrm{Vgl}$. die hier nicht behandelte Aufstellung über Zuweisungen an die Konventualen in der Abtei St.-Denis (832), als Einzelpergament überliefert: Léon Levillain, Un état de redevances dues à la mense conventuelle de Saint-Denis, in: Bulletin de la Société de l'Histoire de Paris et de l'Ile de France 36 (1909) 79-90; zur Deutung dieses Stücks als „internes Arbeitsinstrument" vgl. Hägermann (wie Anm.6) $379 \mathrm{f}$.

256 Siehe oben (zu Anm. 102). 
sich seit den letzten Jahrzehnten des 11. und während des 12.Jahrhunderts enorm. Das liegt nicht nur an den sich beschleunigenden Ausbreitungswellen reformmonastischer Lebensformen, den funktionalen Differenzierungen amtskirchlicher und weltlicher Herrschaften, der Aufkunft und Durchsetzung neuer Sozialstrukturen, sondern auch an fortschreitenden Binnengliederungen der Institutionen man denke nur an die Trennung der Mensen, die Verselbständigung der Kloster-, Kapitel-, Hof-Ämter bis hin zu Einzelpfründe, Burglehen, Grangie und Meierei. Und eben überall in diesem nach außen wie nach innen wachsenden Bestand von Einrichtungen wurde zunehmend geschrieben. Zunehmend heißt hier wiederum: durch häufigere, ebenso initiative wie repetitive Schriftakte und im Zusammenhang mit neuen Aufgaben und verfeinerten Sinnbezügen. Im Rahmen der seigneurialen Überlieferung nehmen also nicht nur die herkömmlichen Beurkundungsakte und Besitz- bzw. Einkünftebeschreibungen zu, vermehren sich nicht nur die proto-archivischen Kompilationen (insbesondere die Kartulare), die memorialkodifikativen Fundationshistorien und die administrativ orientierten Abts- bzw. Bischofsgesta (mit urkundlichen und urbarialen Einschlägen), die domanialen bzw. dörflichen Chartecensiers, sondern neben ihnen kommen auch neue Sorten von scripta auf: orts- oder artbezogene Zinslisten, in Urkunden inserierte umfassende Güteraufzählungen, Servitien-Einträge in Memorialkalendern, orts- bzw. herrschaftsgültige Hofrechte, dörfliche Freiungen und Lokationen, Weistümer (Offnungen), Servitien- und Pfründenordnungen, Ordens- und Ämterstatute. ${ }^{257}$

257 Die beste Orientierung zur sich entfaltenden Überlieferung bieten eben nicht die gattungsspezifischen Einführungen (z.B. Fossier (wie Anm.16) über die Urbare und Zinsverzeichnisse), sondern umfassend überlieferungsgeschichtlich ansetzende Arbeiten, allen voran natürlich Clanchy (wie Anm. 9) 81-114, in der deutschen Forschung Keller (wie Anm.7) sowie (fürs spätere Mittelalter) Richter (wie Anm.16) und Hans Patze, Neue Typen des Geschäftsschriftgutes im 14. Jahrhundert, in: Der deutsche Territorialstaat im 14. Jahrhundert I, hg. v. Hans Patze (VuF XIII, Sigmaringen 1970) 9-65. Auch regionalgeschichtliche Untersuchungen können gut dazu beitragen. Beeindruckend ist hier immer noch Karl Lamprecht, Deutsches Wirtschaftsleben im Mittelalter. Untersuchungen über die Entwicklung der materiellen Kultur des platten Landes auf Grund zunächst des Mosellandes, Bd.2 (1885/6, ND Aalen 1960) Teil II (Quellenkunde). Kurze Überblicke zum bayerischen, niedersächsischen und südwestdeutschen Raum bieten Philippe Dollinger, Der bayerische Bauernstand vom 9. bis zum 13. Jahrhundert (München 1982; frz. Paris 1949) 20-38, Martin Last, Villikationen geistlicher Grundherren in Norddeutschland in der Zeit vom 12. bis zum 14.Jahrhundert (Diözesen Osnabrück, Bremen, Verden, Minden, Hildesheim), in: Die Grundherrschaft im späten Mittelalter I, hg. v. Hans Patze (VuF XXVII, Sigmaringen 1983) 383 ff., 444-450, Rösener (wie Anm. 17) 62-69. Nicht zu vergessen die französischen Regionalstudien aus der zweiten Annalesgeneration (Duby: Macon; Fossier: Picardie u. a.). Zu neuen Schriftgutsorten seien weiter einige Einzelstudien genannt: Werner Rösener, Frühe Hofrechte und Weistümer im Hochmittelalter, in: Probleme der Agrargeschichte des Feudalismus und des Kapitalismus 23 (Rostock 1990) 12-29; Dietrich Lobrmann, Formen der Enumeratio bonorum in Bischofs-, Papst- und Herrscherurkunden (9.-12. Jahrhundert), in: Archiv f. Diplomatik 26 (1980) 281-311; Franz Staab, Aspekte der Grundherrschaftsentwicklung von Lorsch vornehmlich aufgrund der Urbare des Codex Laureshamensis, in: Rösener (Hg.) (wie Anm. 16) 285-305; Charles-Edmond Perrin, Chartes de franchise et Rapports de droits en Lorraine, in: LMA 52 (1946) 11-42; J. J. Menzel, Die schlesischen Lokationsurkunden des 13. Jahrhunderts (1977). Am aufschlußreichsten im Spiegel einzelherrschaftlicher Überlieferung ist der 
Dieses sich vermehrende, verzweigende und verdichtende Schriftgut ist von der Forschung bislang weder systematisch erfaßt, noch auf seine inneren Bezüge hin untersucht worden. Meine Beobachtungen basieren deshalb auf kursorischer Lektüre von Überlieferung ${ }^{258}$ aus gut dreißig Herrschaften im Reich und im angrenzenden Frankreich. Am plausibelsten erschien mir eine Gruppierung der ausgewählten Lesefrüchte nach drei jeweils besonders auffälligen Gesichtspunkten: der deskriptiven Konkretion, der begrifflichen und ordinativen Systematik sowie der domanialen Rechenhaftigkeit. ${ }^{259}$

\section{Deskriptive Konkretion ${ }^{260}$}

Im ,Histoire-Polyptyque ' der flandrischen Abtei Marchiennes, das sein jüngster Herausgeber auf die Jahre $1116 / 1121$ datiert ${ }^{261}$, ist der anonyme Verfasser, der im Auftrag seines Abtes schrieb, wesentlich weiter gekommen in der Aufgabe, Habe und Soll möglichst detailliert zu beschreiben.

grandiose Bestand der Abtei Werden: vgl. Kötzschke (wie Anm. 228) bes. Nr. VI-VIII, XIII. Ich nenne zur Ergänzung noch: Herbert Klein, Die ältesten urbarialen Aufzeichnungen des Erzstifts Salzburg, in: Mitteilungen der Gesellschaft für Salzburger Landeskunde LXXIII (1933) 133-200: regionale officia-Verfassung; Urbare und Wirtschaftsordnungen des Domstifts zu Bamberg I. Teil, bearb. von Erich Freiberr von Guttenberg, aus dem Nachlaß hg. v. Alfred Wendehorst (Veröff. d. Gesellschaft für Fränkische Geschichte X,7, Würzburg 1969): frühe Servitien- und Pfründenordnungen; Enno Bünz, Das älteste Güterverzeichnis des Augustiner-Chorherrenstiftes Neumünster. Untersuchungen zur Grundherrschaft am Ende des 12. Jahrhunderts, in: Zeitschrift d. Gesellschaft für Schleswig-Holsteinische Geschichte 112 (1987) 27-122: Ineinander von Traditions- und Urbarialnotizen; Elisabeth Noichl (Hg.), Codex Falkensteinensis. Die Rechtsaufzeichnungen der Grafen von Falkenstein (Quellen u. Erörterungen zur Bayerischen Geschichte N.F. XXIX, München 1978): gemischte adnotationes; Hartmut Hoffmann, Bücher und Urkunden aus Helmarshausen und Corvey (MGH Studien u. Texte 4, Hannover 1992): Traditionsnotizen und Einkünfteverzeichnis mit Empfängerunterscheidungen.

258 Soweit im betreffenden Fall Faksimiles beigegeben sind, habe ich sie im Blick auf die Seiten-Ordination berücksichtigt.

${ }^{259} \mathrm{Da}$ jedes berücksichtigte Schriftstück natürlich alle drei Gesichtspunkte in verschiedener Gewichtung bezeugt, hat die Herausstellung nur eines von ihnen etwas Willkürliches. Soweit mit der Darstellung verträglich, wird anderes eher beiläufig notiert. Ganz verzichtet werden mußte auf die Anbindung der jeweiligen Stücke an die örtliche schriftkulturelle Situation.

260 Erste Erwägungen hierzu in meinem Aufsatz "Lavoro“ e „società “ dal tardo X secolo al primo XII. Note basate prevalentemente sulla tradizione urbariale a nord delle Alpi, in: Il secolo XI: una svolta? Hg. v. Cinzio Violante und Johannes Fried (Annali dell'Istituto storico italogermanico 35, Bologna 1993) 205-235, hier $224 \mathrm{ff}$.

${ }^{261}$ Bernard Delmaire, L'Histoire-Polyptyque de l'Abbaye de Marchiennes (1116/1121). Etude Critique et Edition (Louvain-La-Neuve 1985), Text: 65-95 (\$\$1-53). Er besteht aus der Fundationsgeschichte mit ausdrücklicher Benutzung von Annalen, Chroniken, Gesta und Augen- bzw. Ohrenzeugen ( $\$ 1$ ), dem Poleticum und nahezu zeitgleichen Zusätzen zu letzterem. Anlaß dürften laikale Gefährdungen der Güter und Rechte gewesen sein. Ich zitiere nach Delmaires Durchzählung in $\$ \$$. 
Schon der erste Satz des Poleticums $(\$ \$ 16-40)^{262}$ zeigt dies: In primis est situs ejusdem loci cum habitationibus et mansionibus suis regularibus et ecclesiasticis, arboretum proximum pomorum, pirorum et aliorum fructuum, hortus amplissimus ad quecumque volueris ad legumina colenda et plurimorum holerum diversa genera, ecclesia foris sine altario, camba cum utensilibus suis, totius ville cultilia cum domibus et reditibus suis $\mathrm{L}$ et dimidium $(\$ 16)$. Die klösterliche Habe am locus Marchiennes ist hier nicht nur - in bekannter dialektischer Rangierung - als von innen nach außen gegliederter situs aufgeführt, sondern auch jede Teileinheit hat ihre räumlich, sachlich oder rechtlich spezifizierten Attribute. In den folgenden, gut zwanzig Abschnitten verflicht der Anonymus urbariale Vorlagen mit Bibel- und Urkundenzitaten $(\$ 17,20)$, bringt geschichtliches Allgemeinwissen ins Spiel $(\$ 31)$, beruft sich darauf, was er fideli narratione gehört hat $(\$ 28)$, dürfte aber ebenso Gesta und Annalen benachbarter Abteien benutzt haben ( $\$ 39)$, kommentiert mittels etymologischer Exkurse $(\$ \$ 19,20,21)$ Fluß- und Ortsnamen (Scarpe) sowie Rechtsbegriffe (ad-vocatus), steigert schließlich seine, den Leser immer wieder ausdrücklich ansprechende Darlegung bis zur wörtlichen Rede historischer Zeugen $(\$ 30)$. All das dient der Erläuterung der gegenwärtigen $\mathrm{Zu}$ stände vor Ort; die erklärte Orientierung ist der utilis profectus administrationis (\$20). Man fühlt sich der Darstellungshaltung nach sehr an Paulus von St.-Père erinnert - auch wenn eine vergleichbar detaillierte formale Durchgliederung des Ganzen in Teile und Abschnitte fehlt. Es gibt darüberhinaus aber anderes Bemerkenswerte im Poleticum. Besonders auffällig ist die Konkretisierung des Verhältnisses zwischen den namhaften loca und deren situs. Man sieht jemanden am Werke, der ständig Erstreckungen, Umgegenden, Grenzen, Nähe und Ferne, Nachbarschaft usf. benennt, um die einzelne Habe genauer zu verorten und ihren räumlichen Zusammenhang mit anderen Gütern herzustellen. ${ }^{263}$ Was in der späten Karolingerzeit punktuell auftauchte, hat sich hier zum anhaltenden Blick auf verortete ,Lagen' entwickelt. Aber nicht nur das. Mehrfach geht der Anonymus noch weiter: er schildert den Flußverlauf der Scarpe in bezug auf Fischrecht, Wiesen-, Weide- und Sumpfnutzung $(\$ 17)$. Er geht auf die besondere Fruchtbarkeit örtlicher Böden ein $(\mathbb{\$} 19,40)$, auch auf wunderbare Besserung eines Flurstücks $(\$ 40)$. Er notiert interessiert eine Stelle, wo man Reste antiker Terra sigillata u.a. findet $(\$ 25)$. Diese räumlich einordnende, neugierige und utilitäre Aufmerksamkeit für die Lage der Güter und die Eigenschaften der Gegend (natura ${ }^{264}$ ) ist durchflochten von mehrschichtigem Zeitbewußtsein. Viel von der Darstellung ist, wie angedeutet, auf den aktuellen Zustand des Besitzes im Vergleich zur Vergan-

262 Die zeitgenössischen urbarialen Nachträge $(\$ \$ 41-53)$ lasse ich hier beiseite.

263 Ein paar Beispiele: omnis circumjacens terra $(\$ 17)$, vicus in proximo, ... in cujus extrema parte, non longe in quodam recessu circunfluentis aque (19), usque ad extremum confinium (21), trans fluvium (22), non longe autem ab eodem oppido (27), juxta confinium ville hujus (32) u. a.m.

264 In $\$ 22$ heißt es: "Non solum hunc viculum (Alne), sed et Marceniensem et Amagiensem situm sic natura protulit ut in circuitu eorum undam superfluam pariter gigneret et lutosum bitumen." Ähnlich auch die natura proferans in $\$ 40$. 
genheit zugeschnitten. Dazu kommt die Ausrichtung der Zinse auf die Abgabetermine; sie werden nicht nur als einzelne benannt (ad festum sancti Johannis unum denarium ad falcem: $\$ 19$ ), sondern auch abstrahierend zusammengefaßt (in anno per terminos tres: $\$ 26)$. Zugrunde liegt hier der circulus anni (\$22) mit seinen vielfachen Arbeits-, Abgabe-, Markt- und Gerichtsterminen - derlei ist in den karolingischen Verzeichnissen nicht präsent. Auch die präzisierenden Maßangaben sollten nicht übergangen werden; sie beziehen sich auf Haferzinse $(\$ \$ 19,22$, 36). Überhaupt wird der Bezug auf die konkrete Handlung gesucht. Man kann hier die in der Karolingerzeit so unscharfen, Glieder', Handlungen und Spannungen zwischen der Zentrale und den Besitzungen draußen deutlicher sehen: die Pflichten der Vögte werden angesprochen ( $\$ 20$ u. ö.); die Kompetenzen des Kellners werden erläutert und von denen des vilicus abgegrenzt ( $\$ 17 \mathrm{f}$.); Lohnabsprachen mit Handwerkern und Hirten, Regelungen (conditio) über Waldnutzung bis hin zum Recht an umgestürzten und liegengebliebenen Bäumen -, über Rodung, Transport, Weide; schließlich Abmachungen (constitutio) der Meier mit den agricolae selbst über Acker- bzw. Erntefronden (und den Freikauf von ihnen: $\$ \$ 26,38$ ).

Damit sind sicher noch nicht alle Felder sondiert, wo deskriptive Genauigkeit im Poleticum von Marchiennes auffällt. Doch auch die viel bekanntere Aufstellung der Rechte des dem Marienkloster in Ettenheimmünster gehörenden Hofes in Münchweier ( $\mathrm{Kr}$. Lahr) von ca. 1150 lohnt ein kurzes Eingehen. ${ }^{265}$ Das Hofrecht, in leider nur später Abschrift überliefert, versteht sich seiner einleitenden Sätze entsprechend - Ettenheimmünster war bischöfliches Eigenkloster - als straßburgische Konfirmation alter, von nobiles und populares beeideter Rechte eines Ortes, wo so ungewöhnlich viel gedient werden muß, daß dieser Fall zum Exempel taugt: sic statuta est, ut habeat omnia iura sicut quaelibet curia Argentinensis ecclesia habens omnia iura ( $\$ 1 \mathrm{f}$.). Das kurze Stück, dem die Promulgation fehlt, das aber an jedem Dingtag ,rezitiert' werden soll $(\$ 15)$, ist nahezu rechtswörtlich stilisiert. ${ }^{266}$ Weiter ist die sprachliche Verdeutlichung der rechtlichen Sachverhalte auffällig, denn in so gut wie keinem Abschnitt fehlt, entweder in glossatorischer Manier oder direkt eingefügt, das einschlägige mundartliche Sach-

${ }^{265}$ Beste Edition dieses, ältesten (grundherrlichen) Weistums': Hermann Bloch/Werner Wittich, Die Jura curiae in Munwilare, in: Zeitschrift f. d. Gesch. d. Oberrheins NF XV (1900) 391-431 (Untersuchung zur Überlieferung, Zeitstellung, Inhalt, Glossen; Text: 422-425); ich zitiere nach der dortigen Numerierung; zur Datierung und Einordnung zuletzt Rösener (wie Anm. 257) $19 \mathrm{ff}$.

266 Man hat nicht mehr die unscharfen, für das Frühmittelalter so charakteristischen Rechtswortkonglomerate vor sich - man denke hier an die einleitend zitierte Urkunde Abt Poppos für die Weinbauern von Wasserbillig -, sondern eine die ganze Aufstellung durchflechtende ius/iura-Terminologie, deren Attribute ebenso auf die Findung (quaerere, invenire), Setzung (statuere) und Befestigung (iuramenta) zielen wie auf die Tradition (recitare) und Anwendung (ex iure, ut perficiantur iura statuta, iudicare secundum legem statutam, secumdum iura statuta). Daraus ergibt sich die Vorstellung vom ,Ganzen' des Rechts oder der Rechte (omni iure, omnia iura). Dennoch war das Weistum natürlich nicht der Ort für Rechtssystematik. Allein das formal Subsumtive soll hier herausgestellt werden. 
bzw. Rechtswort. ${ }^{267}$ Solche terminologische Zweischichtigkeit des Ganzen - sie geht weit über das in der späten Karolingerzeit Gefundene hinaus - ist sicher auch Ausdruck von mehr Praxisnähe. Die Artikulation ist gewissermaßen janusköpfig gefaßt, weist in zwei soziale Richtungen: das Lateinische ins Kloster, das Deutsche zu den Dinghofpflichtigen.

Nun zu den sachlichen Konkretisierungen. Mit neuartiger Ausführlichkeit werden die Gerichtskompetenzen über allmendliche Nutzungen von Weiden, Saatfeldern, Weingärten, Wiesen, Weg und Steg präzisiert $(\mathbb{S} 4-5)$, genauso die Behandlung von Dieben im örtlichen ,Stock' $(\$ \$ 6-8)$ - hier bis hin zur Form ihrer Übergabe an den Mann des Vogtes am Hoftor des Fronhofs. Bei der Ausstattung von Leibeigenen des Klosters mit Saatgut, Land und Vieh (Anstiftung) dringt man bis zur Verwendung des Unrats vor der Tür vor (\$\$11-13). Schließlich wird die Begutachtung des am Andreastag fälligen Zinsschweins der Hufner mit dem Satz beschrieben: hic accipiendus est cum iuramento coci et villici et hominum caenobii, qui visu et auditu perceperunt quantitatem et precium eius et sciunt, quantus et quanti debeat esse ( $\$ 17)$. Solche Sätze aus dem Feld der Abgabenkontrolle kenne ich aus dem 9.-11.Jahrhundert nicht.

Auch die sogenannten Acta Murensia, wohl gegen 1160 anonym entstandene Aufzeichnungen aus der schwäbischen Reformabtei Muri ${ }^{268}$, sind in diesem $\mathrm{Zu}-$ sammenhang der Erwähnung wert. Nicht nur als Kompilator ${ }^{269}$, sondern auch als Kommentator erinnert auch der Anonymus aus Muri durchaus an Paulus von St.-

267 Ich habe weit über zwanzig solcher Ausdrücke gezählt; z. B. gerwange (Speerschwingen als Geste der Investitur), ebirweide, widerhore, fravile, stoc, scopoza, gewerland, hobswin, maiecins, tagewane, husrochi u. a.m.

268 Edition: Martin Kiem (Hg.), Das Kloster Muri im Kanton Aargau (Quellen zur Schweizer Geschichte, Bd.3, 2. Abt., Basel 1883) 3-102. Zum Stand der Überlieferungskritik vgl. Rösener (wie Anm. 17) 300-303. Welche Anteile des gesamten Wortlauts auf obiges Datum zurückgehen, ist sicher noch nicht gültig geklärt. Dazu wäre eine genaue Untersuchung der Handschrift nötig. Ich verdanke Thomas Hildbrandt (Zürich) diesen Hinweis.

269 Rösener (wie Anm. 17) 310 ordnet die Acta - im Anschluß an die Forschungen Hans Hirschs, Hermann Jakobs' u.a. - der Art von Aufzeichnungen zu, die für die schwäbischen Reformklöster (St. Georgen, Allerheiligen u. a.) typisch sind (Gründungsgeschichte und Güterbeschreibung). Sie erinnern - aus gleichem Grunde - aber ebenso an das Genter Kartular, den Vetus Aganon und den Kodex aus Marchiennes. Zur Einordnung vgl. J. Kastner, Historiae fundationum monasteriorum. Frühformen monastischer Institutionsgeschichtsschreibung im Mittelalter (Münchener Beiträge z. Mediävistik u. Renaissance-Forschung 18, München 1974). Wenn man Teil I (eine vieldiskutierte Habsburger-Genealogie) übergeht, ergibt sich: Gründungsgeschichte mit erster Gütersumma (1027-1065) (II); weitere Entwicklungen (besonders die Reihe der Vögte) bis zur Privilegierung durch Kaiser und Papst (1065-1114) (III); Beschreibung der substantiae der Abtei (substantia interior: Reliquien, Liturgica, Bücher der Abteikirche; substantia exterior: Ausstattung weiterer Kirchen, Rechte der Nebenklöster, der Klosterdiener, Hofrecht von Muri, Erwerbs-, Güter- und Urbarialnotizen, grob regional geordnet; darunter die bekannte Geschichte Wohlens) (IV). Die Gliederung des Herausgebers (4 Teile, 33 Abschnitte) deckt sich leider nicht mit dem der Handschrift nachgestellten Inhaltsverzeichnis (101f.). Bezeichnenderweise hat der Schreiber die für uns bedeutsamsten Abschnitte (19-33) unter Titel wie: De substantia huius cenobii (XXIII) und De augmentatione possessionum (XXVI) gefaßt. Ich zitiere deshalb im Text nach der Seitenzahl der Edition. 
Père. Er leitet ein, bezeichnet Übergänge in der Darstellung (S.30, 46f., 50, 55), verweist auf Früheres oder noch Kommendes. Er beruft sich auf mündliche Aussagen von Gewährsleuten, zitiert verschiedenerlei Schriftstücke (scripturae, pactum, carta ${ }^{270}$ ), fordert zur Lektüre von ausführlicherem einschlägigem Schriftgut auf, erklärt sich über die Grenzen seines Wissens und seines Vorhabens, faßt Dargelegtes zusammen (besonders prägnant: 45) und - ein Novum - fordert Nachfolgende zur Fortsetzung auf: Nunc ergo, sicut nos substantiam istius sancte ecclesie, que vel ante nos vel nostris temporibus huc collata est, descripsimus, sic faciant et illi, qui post nos veniant (96).

So, wie im Hofrecht von Münchweier das Ganze und seine Teile ins Wortlicht der iura gezogen sind, hat der Anonymus von Muri konsequent auf den Terminus constitutio für die verschiedensten Rechtsverhältnisse abgestellt. ${ }^{271}$ In den Acta insgesamt ist also ein ,juristischer' Subsumtionswille, ein rechtsrhetorischer Stil erkennbar ${ }^{272}$, der auch hochinteressante Aspekte des Rechtewandels (Anstiftung, Veralten bzw. Abgang) aufweist. ${ }^{273}$ Ähnlich wird auch der Terminus substantia für alle ,Dinge' gebraucht, in gleich welchem Deskriptionszusammenhang sie auftauchen $(46,50,55,67,70)$.

Die sachliche Detaillierung, um die es hier primär geht, erstreckt sich auf recht verschiedene Bereiche. Da ist zum einen die Genauigkeit bei den rationes mensurae - sie beziehen sich auf Hohl- und Flächenmaße sowie Streckenbemessungen $(62,70,83)$ : präzisiert wird nicht nur sprachlich durch Hinweis auf den oberdeutschen Lokal-Ausdruck (fronemez, sistir, imi, manwerc, skaza), sondern auch durch genaue Relationen zu regional bzw. örtlich gebräuchlichen (Norm-)Maßen und Meßverfahren. ${ }^{274}$ Zum anderen werden Spezialkulturen - man denke an den Salzstandort Prüms in Vic-sur-Seille - mit beeindruckender Genauigkeit vorgeführt: der Fischfang (78f.), die Schweigenwirtschaft (armentarii) (83f.) und der cultus vitium (90-95). Die Ausstattung von Familiaren mit Gerät, Vieh, Saatgut, Haus und Holz zu Hufnern geschieht - in deutlicher Parallele zum Hofrecht von Münchweier - mit klar geordnetem und detailreichen Bedacht - alle nötigen genera rerum, meist attributiv präzisiert, sind aufgeführt. ${ }^{275}$

270 Einmal wird die Übernahme eines Diploms Heinrichs V. mit dem Satz eingeleitet: Cuius carte textus se ita habet (40).

271 Kiem (wie Anm. 268): Hofrecht insgesamt (constitutio rusticorum): 46f., 61, 64, 65, 70, 80/84 (Almbauern), $91 \mathrm{f}$. (Weinbauern); Mühlenrecht: 72; die villici/magistri betreffend: 73, 93, 80; Zinsbestimmungen: 75, 98 f.; Maßbestimmungen: 83, 93.

${ }^{272}$ Wie der ,Brauch' (consuetudo: 60, 80) und andere sporadisch verwendete Recht-Begriffe in den Acta sich systematisch zur constitutio verhalten, wäre gesondert zu untersuchen.

${ }^{273}$ Zur Anstiftung von Hufnern: 61. Einmal (81) heißt es: "In ipsa adhuc curte fuerunt multa constituta, que, quia non potuerunt perdurare, ideo non scribimus in ea." Vgl. auch 64.

274 Auffällig ist nur der Gebrauch von computare für die Präzisierung von Landsortenquanta: ager und vinea werden in Anzahl iugera (65, 72, 94), pratum in Anzahl diurnales (82), predium in Anzahl mansi, taxiert".

${ }^{275}$ Kiem (wie Anm. 268) $61 \mathrm{f}$.: "Ubicunque vel quandocunque hic in terra nostra potestate aliquis ab initio faciendus ac constituendus vel justificandus est, illuc debet dari aratrum cum ferramentis et plaustrum cum quatuor bobus, sacofa pregnans cum duobus porculis anniculis, gallus cum duabus gallinais, quos ipse, qui accipit, debet ipso anno nutrire et reddere, 
Nicht zuletzt ist die ins Einzelne gehende Darstellung der drei traditionellen Hol- und Kontrolltermine des Propstes in den Schweigen am Fuß des Rigi (Immensee, Küßnacht, Weggis, Gersau) zu erwähnen (80f.). In den Verben accipere bzw. educere und providere bzw. ordinare wird die praktische Einheit der appropriativen und regulativen Handlungen deutlich - Verknüpfungen, die man im 9. Jahrhundert noch kaum findet. Auffällig - damit sollen diese knappen Beobachtungen beschlossen werden - ist noch, wie häufig der Anonymus von der utilitas bestimmter Güter oder Zustände spricht.

Schließlich sollen einige Details aus dem Abschnitt De possessionibus ecclesie des heute verschollenen Liber Theoderici aeditui ${ }^{276}$, einer hochinteressanten Sammelhandschrift, die Theoderich, Küster der Abtei Deutz, unter den Äbten Gerlach und Hartpern (1146-1169) anfertigte ${ }^{277}$, das bisher gewonnene Bild ergänzen. Theoderich beginnt die Güter und Einkünftebeschreibung mit einer, Vergangenheit und Gegenwart bemerkenswert verschränkenden Feststellung: De iure curtium ad hanc ecclesiam pertinentium scribere uolentes quodam errore prepedimur quia multo plura antiquis quam modernis temporibus secundum tenorem testamentorum nostrorum persoluebant, scilicet quia plura ex eis bona inbeneficiata sunt, et tam propter terre sterilitatem quam propter aduocatorum uiolentiam et etiam propter frequenter aquarum inundantiam deuastata sunt. Tamen quod nostris temporibus scilicet Gerlaci abbatis uel eius predecessoris Rudolfi tempore uillicos earum soluere uidimus futuris pro sui utilitate et pro nostra fide insinuare curamus. ${ }^{278}$ Eine so klare Artikulation der Ursachen und des Aufgaben-

quando et alii dant. Debent etiam dare falx, securis, dolabra et omnia ferramenta, que sunt necessaria et semen omnium generum, id est spelte, avene, lini, rafei, pistarum, milii ceterarumque rerum, et domus et ligna et omnia alia, que sunt necessaria. Boves autem vel sus, si ipso anno moriuntur, alii debent dari." Zur Rodung in diesen Gegenden im 12.Jahrhundert vgl. Rösener (wie Anm.17) 327f.

276 Teiledition: J. Theodor Lacomblet, Die Benedictiner-Abtei zu Deutz. Ihre Stiftung und ersten Wohltäter, ihre Äbte, Besitzungen und Reliquien, in: Archiv für die Geschichte des Niederrheins 5 (1866) 265-322. Zur Geschichte der Abtei überblickend Joseph Milz, Deutz, in: Germania Benedictina 8 (1980) 293-313; zur Grundherrschaft: ders., Studien zur mittelalterlichen Wirtschafts- und Verfassungsgeschichte der Abtei Deutz (Veröffentlichungen des Kölner Geschichtsvereins 30, Köln 1970).

277 Der Codex (neueste Beschreibung und Deutung bei Monika Sinderhauf, Die Abtei Deutz und ihre innere Erneuerung. Die Geschichte des Klosters im Spiegel des verschollenen Codex Thioderici (Vierow 1996)) wird mit vier Illuminationen (Hl. Heribert, Maria, Trinität, Himmel und Hölle) eingeleitet. Es folgen Nekrolog, Verbrüderungskolumnen, frühe Schenkungen und Memorien (267-270), die Abtsgesta (299-322), ein Verzeichnis zinspflichtiger Pfarrkirchen (289-291), das eigentliche, hier einzig herangezogene Güter- und Einkünfteverzeichnis (270-289), liturgische Ordnungen und Bräuche, das Verzeichnis der Namen und Inschriften der 1155 nach Deutz transferierten Gebeine der 11000 Jungfrauen und ihrer Begleiter (292-299). Die, soweit aus der entstellten Edition erkennbar, wenig ordinierte Kompilation bezeugt das Neben- und Ineinander diversester Materien, die allein der (kom)memorative Gesamtsinn vereint.

${ }_{278}$ Lacomblet (wie Anm. 276) 270. Nicht nur dieser Satz belegt, wie die beiden Äbte um den Zustand von Besitz und Einkommen bemüht waren. Auch Theoderich kommentiert mehr- 
verständnisses ist neu. Dazu kommt, wie auch schon in den vorigen Fällen, mehr Genauigkeit bei der Eintreibung von Abgaben und der Durchsetzung von Diensten. Allein schon die Belege zur Anbindung der Einzelpflichten an Festtags-, jahreszeitliche oder örtlich abgemachte Termine (tempore vindemie, tempore statuto) sind abundant. Sachlich kommt weiteres hinzu. Im ersten Pflichtenkatalog des Verzeichnisses, neun Hufen in Windesheim betreffend, wird nicht nur, dem Zuge der Zeit zur Monetisierung entsprechend, die Möglichkeit der Ablösung durch ein Geldquantum (redimere), sondern auch die Buße für verschiedene Fälle der Verweigerung (negligentia) aufgeführt (S.271). Beides, Kommutation und Buße, sind Zeichen für die genauere Fassung des Spielraums im appropriativen Alltag. Weiter stößt man regelmäßig auf die nuntii abbatis, die gezielt vor Ort nach dem Rechten sehen. Noch plastischer wird dieser Aspekt - eingesprengt in die Reihe der ortsbezogenen Beschreibungen und deutlich per Überschrift herausgehoben - in dem Abschnitt über die jährlich im Umkreis des St. Bartholomäustags fällige Visitationsreise des Abtes rheinabwärts über mehrere Stationen bis nach Arnhem: alle Modalitäten der Reise des Abts mit seinem Gefolge zu Pferd und Schiff (Übernachtung, Gastung, Gepäck, Verantwortlichkeiten der örtlichen Verwalter und Familiaren, Gericht, Rentenkollektion) sind bedacht. ${ }^{279}$ Schließlich ist die ,Zellteilung' der Empfängerseite in den Aufstellungen omnipräsent. Sogar das Beschreibungsformular für die örtlichen Aufstellungen ist auf die Sonderung verschiedener Rentenbezieher innerhalb der Abtei abgestellt: man trifft nicht nur regelmäßig auf Abt, Kellner, Kämmerer, Konvent und Vogt als Direktempfänger von census und servitia, sondern auch auf verschiedene ihrer $\mathrm{Kü}$ chen. Neben diesem Reflex der sich stabilisierenden Sondervermögen der Klosterämter und Dienstbereiche ${ }^{280}$ ist auch eine lakonische Aufstellung der villikalen Servitien pro Monat im Jahreslauf in das Verzeichnis aufgenommen. ${ }^{281}$ Die Aufstellungen münden schließlich in separate Einkommens- und Austeilungsstatute (procuratio, obedientia) für den Kellner, den Kämmerer, den Kustos, den Elemo-

fach den aktuellen Zustand von Gütern, auch im Blick zurück: 275, 280. Vgl. dazu Milz, Studien (wie Anm. 276).

279 Lacomblet (wie Anm. 276) 278f.; zur Sache Milz, Studien (wie Anm. 276) 67-70.

280 Die Formierung der Ämter spiegelt sich - über Empfängerangaben - noch klarer im urbarialen und administrativen Schriftgut der Stifte. Hier nur zwei Hinweise. Im Güterverzeichnis des St.-Kastor-Stifts Karden/Mosel (Edition: Heinrich Beyer (Bearb.), Urkundenbuch zur Geschichte der mittelrheinischen Territorien 1 (Koblenz 1860/ND Aalen 1974) Nr. 400, 455-457) von ca. 1100 werden Propst, Kellner, Kustos, Scholaster, die Kanoniker selbst und die örtlichen Priester als Empfänger genannt. Zur Sache Ferdinand Pauly, Das Stift St. Kastor an der Mosel (Germania Sacra NF 19,3, Berlin/New York 1986) 233-297 pass. Ein nach Villikationen geordnetes Urbar der Präbendalgüter für die Kanoniker des Bamberger Domstifts, von Dompropst Eberhard ca. 1120-1124 erstellt, bildet den Auftakt der hochinteressanten Bamberger Überlieferung (mit frühen, für diverse Empfänger bestimmten Servitienordnungen). Vgl. von Guttenberg/Wendeborst (wie Anm. 257) 103-114 (Texte), 21-32 (Kommentar).

281 Lacomblet (wie Anm. 276) 284f.; zur Sache Milz, Studien (wie Anm. 276) 44ff., $80 \mathrm{ff}$. 
sinar und Infirmarius. ${ }^{282}$ Solche zu eigenen Sektionen geformte Bestimmungen sind es, die nun den Platz einzunehmen und zum speziellen Überlieferungsfeld auszuweiten beginnen, den Adalhards singuläre Statuta im 9. Jahrhundert hatten.

Ergeben hat sich anhand dieser wenigen Hinweise: Der natürliche und wirtschaftliche situs wird genauer gefaßt. Gegenwart und Vergangenheit werden zum Eindruck einer (meist schlechten, verbesserungsbedürftigen) ,Situation ' aufeinander bezogen - der Zeitfluß ist präsent. Man versucht, die vielen Rechte unter einen Terminus zu subsumieren und gleichzeitig den mundartlichen Eigenheiten gerecht zu werden - rechtssprachlich also ein Nebeneinander von formaler Abstraktion und funktionaler Konkretion; sprachpraktisch eine bilinguale Lage. Die Maßverhältnisse werden situiert - damit gewinnt die Verschriftung der Mengen und Werte an Präzision. Die örtliche grundherrliche Szene wird viel konkreter ins Spiel gebracht - Abgabenkontrolle, ad-hoc-Vereinbarungen, Vergehensahndungen usf. Entsprechend kommen die Verbindungen zum Zentrum zum Vorscheindas praktische Hin und Her nimmt Gestalt an. Umgekehrt schlagen die internen Sonderungen und Aufgabenstellungen am Besitzort durch. Alles ist mehr im Sinnbereich einkommensorientierter und lagebewußter Notwendigkeiten plaziert - dies im Gegensatz zu der weitgehend statuarisch wirkenden Überlieferung der Karolingerzeit. Schließlich findet man das kompilative und redaktionelle Niveau wieder, für das bisher allein Paulus von St.-Père Pate stand. Daran ist nun genauer anzuschließen.

\section{Begriffliche und ordinative Systematik}

Die Aufzeichnungen, die Abt Meinhard ${ }^{283}$ von Marmoutier/Elsaß zwischen 1137 und 1146 im Zuge seiner grundherrlichen Reformpolitik veranlaßt und promulgiert hat ${ }^{284}$, sind zweifach interessant für unser Thema. Zum einen lohnt ein Blick

282 Lacomblet (wie Anm. 278) 285-289; nähere Deutung von Milz, Studien (wie Anm. 276) $76 \mathrm{ff}$.

283 Edition: Johann Daniel Schöpflin, Alsatia aevi Merovingici, Carolini, Saxonici, Salici, Suevici diplomatica I (Mannheim 1772) Nr.275, 225-230. Zum Herausgeber: Jürgen Voss, Universität, Geschichtswissenschaft und Diplomatie im Zeitalter der Aufklärung: Johann Daniel Schöpflin (1694-1171) (1979).

284 Zur Überlieferung und Kritik: Charles Edmond Perrin, Essai sur la fortune immobilière de l'abbaye alsacienne de Marmoutier aux $\mathrm{X}^{\mathrm{e}}$ et $\mathrm{XI}^{\mathrm{e}}$ siècles (Collection d'études sur l'histoire du droit et des institutions de l'Alsace X, Strasbourg 1935) $17 \mathrm{f}$. Perrin nennt die Aufzeichnungen, die sonst als ,Hofrecht ${ }^{c}$ gelten, vorsichtig "une sorte de coutumier seigneurial“ (116ff.). Das Stück, ohne Eingangsprotokoll, schließt mit dem umfassend funktionsbewußten Satz: "Haec ergo MEYNHARDUS Dei gratia abbas Maurimonasterii hominibus ecclesiae nostrae notissima, et usu cottidiana trita, memorie ac firmitatis gratia, quia labilis est hominum memoria et sine litteris ad omnia facilis irrepit oblivio, coram consociis, coram scabionibus, coram ministerialibus, coram universa familia, coram simul toto placitali populo feci renovari, cunctorum testimoniis confirmari, litteris mandari, scriptis presentibus perpetuari, sigilli quoque nostri subter impressione a generatione in generationem perpetua robo- 
auf den Aufbau der Aufzeichnungen insgesamt, auch wenn dem Ganzen die formale Durchgliederung fehlt. ${ }^{285}$ Der Löwenanteil der Bestimmungen gilt den Rechten des Abtes und seiner Diener (S.225-228): Zuerst werden seine iustitiae et satisfactiones an der ,Mark', dem territorialisierten Nahbereich ums Kloster, abgehandelt ${ }^{286}$, gefolgt von den Gaben an den Metzer Bischof, der Regelung der bäuerlichen Fuhrdienstverpflichtungen für die profectio regis - ob über die Alpen oder nach Sachsen -, dem Hufenstatut, den Bestimmungen über die tria placita (Termine, Vogtgastung aus Mitteln des Abts, Besuchspflicht der Familiaren, Standort und Bewachung des Stocks). Danach geht es um die Aufgaben und Einkünfte der höchsten Diener seines, Hauses': des Schultheißen, des Stallmeisters und des Kämmerers. Dann folgen Bestimmungen über Ausstattung, Rechte und Pflichten der villici und der Waldhüter (228-230). Dem Ganzen ist also - dies im Vergleich nicht nur zum Capitulare de villis, sondern auch zu anderen frühen ,Hofrechten', auch dem von Münchweier - der Wille zum systematischen Vorgehen anzusehen: Ämtererneuerung, monetäre und agrikole Nutzung des Nahbereichs (Mark), Außenpflichten (Bischof, König), Rechtsprechung, Dienerschaft, Verwaltung vor Ort (Domänen, Forsten). Die Ordnung der Gesichtspunkte folgt Prinzipien wie: von innen nach außen und von oben nach unten - auch Ansätze zu einheitlicher Rechtssprache (jus, justitia) sind erkennbar. In der Fassung des $\mathrm{Hu}-$ fenstatuts ${ }^{287}$ ist - unser zweiter Punkt - dialektische Schulung unübersehbar. Es beginnt - implizit am genus orientiert - grundsätzlich: Tres sane mansorum sunt differentiae; ingenui, serviles, proprii. Dann folgt eine präzise, detailreiche Erörterung der Unterschiede zwischen den drei species, die sich mehrerer Prinzipien bedient. Die Kennzeichnung der freien Hufen lautet: Ingenui seu liberi dicuntur baronibus inbeneficiati, neque censum solventes neque triduana servitia facientes, cum caballis serviunt vel ipsi cum abbate, si voluerit, equitando, vel sibi, si forte petierit, prestando. Es wird also nicht nur die rechtliche qualitas (Lehnsgut) herangezogen, sondern auch der Handlungstyp gekennzeichnet; und zwar zweifach, absetzend und setzend (mit der weiteren Distinktion zwischen Abtswille und Abtsbitte). Ähnliches geschieht mit den mansi serviles. Auf die pauschale Nennung der Abgaben- und Dienstpflichten folgt - in mehreren sachbezogenen Schüben (Kornernte, Weinlese, Heumahd, Holzwirtschaft, Stallreinigung) - eine aus-

rari (ff. Segenswunsch) (230)." Zur Situation in Marmoutier und zur Reform- und Rekuperationspolitik Meinhards: Rösener (wie Anm.17) 387-399.

${ }^{285}$ Die Abschnitte und Titel der Schöpflinschen Edition gehören, wie Perrin (wie Anm. 284) $117 \mathrm{~m}$. Anm. 74 überzeugend nachweist, nicht zur ersten Fassung. Läßt man sie weg, dann ergibt sich ein viel klarerer Aufbau.

286 Schöpflin (wie Anm. 283) 225f. Man beginnt mit der Erneuerung der Ämtervergabe beim Abtswechsel, dann folgen die Zoll- und Bannweineinkünfte, die Wiesen- und Holzungsrechte, die Acker- und Erntefronden, das Erbrecht, Gefälle aus Bagatelldelikten und Kopfzinse, die Stellung der barones seu casati milites in der Mark.

287 Schöpflin (wie Anm. 283) 227. Der exkursartig anmutende Abschnitt ergibt sich meines Erachtens konsequent aus dem Vorangehenden. Dort werden die unterschiedlichen Beteiligungen von Mansusbauern am Troßdienst zur profectio regis erörtert. Im Anschluß daran waren dann die Mansusdifferenzen grundsätzlich anzusprechen. 
führliche Reihung aller möglichen Dienste unter dem Gesichtspunkt, ob sie von den mansi serviles zu leisten sind oder eben nicht. Der durch die peniblen Ausschließungen definierte Bestand von minima justitiola ist dann der Ausgangspunkt für die positive Kennzeichnung der mansi proprii. Aber selbst ihr Status (isti ergo dicuntur proprii, eo quod possesores eorum ad omnia ac si proprii subiciantur servi) läßt noch eine Abgrenzung zu. Die lange Reihe ihrer Fronden (bis zur Kloakenreinigung) schließt mit der Bemerkung: comedunt sufficienter ac bibunt, nihil aliud mercedis accipiunt.

Gründliche Planung und konsequente Verschriftung kennzeichnet ein von $\mathrm{Ru}-$ dolf Kötzschke ,Urbar D' genanntes Gesamtverzeichnis der Güter und Rechte der Werdener Filialabtei in Helmstedt. ${ }^{288}$ Es wurde, kurz nach seiner Entstehung, gegen 1150 reinschriftlich in den Liber privilegiorum maior monasterii Werdinense aufgenommen. ${ }^{289}$ Dem Stück fehlen zwar Titel und weitere explikative Bemerkungen zu Entstehung, Geltungsweise, Aufbau und Ausdrucksweise. Trotzdem spiegelt es - verglichen mit dem urbarialen Schriftgut Werdens aus dem 9./ 10. Jahrhundert - implizit den Fortgang der Ordinationspraxis. Alle größeren Abschnitte sind nicht nur auf der Seite klar voneinander abgesetzt (regelmäßige 4-6zeilige Spatien) und abschnittsintern, wenn auch nicht mit letzter Konsequenz, durch Zeilenneubeginn mit ausgestellter Initiale, also posten- bzw. eintragsartig gegliedert, sondern auch durch versalisierte Überschriften zusätzlich qualifiziert. ${ }^{290}$ Der inhaltliche Aufbau insgesamt entspricht dem graphischen Willen zur Übersichtlichkeit: Man beginnt mit den wichtigsten nutzbaren Gütern für Abt und Brüder (Villikationen), dann folgen das Dienstrecht für alle Hufner, die Sondergüter (Kirchen, Ämter, Lehen), schließlich die (wohl regional bedingte) Fortsetzung der Villikationen und ihrer Abgaben bzw. Servitien bis hin zum Streubesitz. ${ }^{291}$ Standardisierung regiert innerhalb der Abschnitte. Die Beschreibungen der Fronhofsbezirke (territorium) sind streng nach dem gleichen Formular aufgebaut und stilisiert: Ausstattung und Abgaben des subvillicus, Zahl und Zinse der Hufen am Zentralort, Zahl und Zinse der zugeordneten Hufen anderswo. Details

288 HStA Düsseldorf, Werden B 59 1/2, Bll. 41b-48a; Kritische Edition: Kötzschke (wie Anm. 228) 167-185. Ich zitiere nach Kötzschkes Einteilung in \$\$.

289 Beschreibung der Hs. bei Kötzschke (wie Anm. 228) CXXXIII-CXVII. Der Kodex besteht aus einem Kartular und zwei grundherrlichen Verzeichnissen (Helmstedter und Werdener Güter betreffend); Deutung der o. g. Verzeichnisse als grundherrliche Dokumente: $R u$ dolf Kötzscbke, Die Urbare der Abtei Werden a.d. Ruhr. Einleitung und Register (Rheinische Urbare 4, Bonn 1958) CCCLXXXII-VI.

290 Im unmittelbaren Vergleich mit dem Schrift- und Seitenbild der Werdener Mischhandschrift vom Ende des 9. Jahrhunderts fällt der Ordnungsgewinn insgesamt sofort ins Auge. $\mathrm{Daß}$ sich jedoch keine neuen Elemente finden, bestätigt den auch sonst gewonnenen Eindruck von der Entwicklung.

291 Genauer gesagt: zuerst sind die wichtigsten Fronhöfe, zu Villikationen gruppiert ( $\$ S 1-4)$, aufgeführt, dann der nordöstliche Hufen-Streubesitz (5), eine allgemeine Frondienstordnung (6), der Hufenbesitz zur Abtei gehöriger Kirchen (7), der Zinshufenbesitz von Küsterei, Brüder-Reichnissen, Hospiz und Siechenhaus (8), die an die Ministerialen verlehnten Güter (9), die speziellen Leistungen des Helmstedter villicus (10), zwei weitere Villikationen und die Leistungen ihrer Leiter (11-14, 15), schließlich westlicher Streubesitz (15-18). 
des Formulars sind stereotyp wiederholt - darunter die bezeichnende Formel: quicquid utilitatis evenerit. Ähnlich steht es mit der Stilisierung der Aussageeinheiten anderer Abschnitte. Die Einträge etwa im Abschnitt über den Kirchenbesitz oder über die ministerialischen Lehen gleichen einander bis auf Name und Zahl. Schließlich geben autonome ${ }^{292}$ Überschriften den Abschnitten ihren klaren Sinn: De villicatione in Ingereslove, in Karlesthorpe, in Sumeresthorpe etwa sind die großen Abschnitte überschrieben, ohne daß das Wort villicatio in ihnen selbst fällt. Aus Abfolge und Zwischenbetitelung ergibt sich, daß das (titellose) Ganze bereits als aus seinen besonderen Teilen bestehend gedacht wird - ein deutliches Zeichen bewußterer Fassung im Vergleich zu vielen Verzeichnissen des 9.Jahrhunderts. Summatives Ertragskalkül aber fehlt, man war auf die Sicherung der Titel und Ansprüche, nicht auf deren Umsetzung in Ertrag aus. Dies paßt auch zu Inhalt und Bestimmung des ganzen Kodex, eben repräsentativ-memorialer Fond der , Güter und Rechte', nicht Manuale für laufende Alltagsadministration zu sein.

Für mehr ordinative Ausdrücklichkeit und explizite Abschrifts-Methodik stehen die folgenden beiden Zeugnisse. Der den Diplomatikern so bekannte Eberhard beginnt seine Kodifikation der Fuldaer urkundlichen und urbarialen Überlieferung, die in die Jahre zwischen 1150 und 1165 fällt, mit den Sätzen: In nomine patris et filii. et spiritus sancti. incipit liber descriptus in honore sancti martyris Bonifacii. patroni nostri. continens privilegia apostolicorum. precepta regum et imperatorum. oblationes fidelium. concambia quoque quorundam prediorum. nec non etiam tradiciones familiarum huius monasterii Fuldensis. Quae omnia diuisa sunt in quasque partes. ita ut singulae quaeque habeant suas distinctiones. et sua capitula. ut melius ac leuius possint inueniri. quae a legentibus inquiruntur. et a querentibus inuestigantur. Notare debent legentes. ne scriptori culpam inponant. eo quod non est hoc opus ordinatum secundum uices personarum. et secundum ordinem temporum. Singulas enim scedulas accepimus a librario. sicut poterant inueniri. Quibus redditis. alias accepimus. Nec poterat quaeque scedula leuiter legi prae nimia uetustate et inexperientia scoticae scripturae. et apicum uilitate. Hoc tamen prae omnibus oramus ut considerent fratres quanto labore singula collecta sint et inuenta. atque transcripta. et ubi opus fuit correcta. Nam de scripturae exilitate. et membranae qualitate nihil ad rem. cum possit melius adhuc scribi. ${ }^{293}$

Diese Darlegung wurde bislang noch nicht ausreichend gewürdigt. ${ }^{294}$ Eberhard

292 Autonom hier in dem Sinne, daß sie nicht aus der Beschreibung herausgewachsene und um Unwichtiges gekürzte Anfangssätze sind (vgl. dazu die Ausführungen oben zu den Zwischen-'Titeln" einiger Brevia des Polyptychums von St.-Germain), sondern bedachte ,Über"Schriften. Ausnahmen $(\$ 6,10)$ bestätigen die Regel.

${ }^{293}$ Ernst F. J. Dronke (Hg.) Traditiones et antiquitates Fuldenses (Fulda 1844, ND Osnabrück 1966) V.

${ }^{294}$ Zum Codex Eberhardi noch immer grundlegend: Otto Konrad Roller, Eberhard von Fulda und seine Urkundenkopien (Marburg 1901); dazu Edmund E. Stengel (Hg.), Urkundenbuch des Klosters Fulda 1 (Marburg 1958) XXVIII-XXXV; jüngste Studien: Franz Staab, Echte Termineiurkunden aus dem frühen Mittelalter und Fälschungen Eberhards von Fulda, in: Fälschungen im Mittelalter, Teil III (MGH-Schrr. 33,III, Hannover 1988) 283-314; Her- 
gibt hier über mehrerlei Auskunft. Ausgehend von der Vorstellung eines hergestellten Gesamt (liber scriptus) erläutert er dessen Ordnung, d.h. Gliederung (divisio) in Teile (partes): er hat sich - da sichert er sich gegen abweichende Vorstellungen $\mathrm{ab}$ - nicht von Kriterien wie den vices personarum oder dem ordo temporum $^{295}$ leiten lassen, sondern ordnet die Stücke primär ,typologisch', hierin zeitgenössischen Gewohnheiten folgend ${ }^{296}$, nach dem Status und Ziel der Aussteller. So entsteht eine erste Ebene ranggestufter Zuordnung der scripta. ${ }^{297}$ Weiter soll jede pars ihre eigenen Untergliederungen haben (distinctiones et capitula). Eberhard hat sich durchaus konsequent an dieses mehrfach gestufte Ordinationsprogramm gehalten, an das er in den Prologen zu den einzelnen Büchern sowie in verschiedenen Überleitungssätzen in Abwandlungen immer wieder erinnert. ${ }^{298}$ Das weisen nicht nur chronologische und regionale Binnengliederungen, sondern auch Überschriften sowie Durchzählungen der Stücke am Seitenrand aus, die in geplanten, d.h. später erstellten und dann den Teilen vorangestellten Inhaltsverzeichnissen ausgewiesen sind. ${ }^{299}$ Als Zweck dieser Bemühungen gilt Eberhard das ,bessere und leichtere Auffinden'. Er weist natürlich auf die Mühsal der Entzifferung der alten Vorlagen aus dem Armarium hin und entschuldigt sich bei den Lesern und Benutzern. Und ihm fällt zur Kennzeichnung seines Tuns und seiner Verfahren (scribere, colligere, conscribere, summatim ac nominatim ex ordine describere) einmal das Verb texere ein. ${ }^{300}$

Auch wenn Eberhard damals für seine Brüder, Abt Markward und den Patron Bonifatius in viele - nicht alle! - Segmente der urkundlichen Überlieferung nicht

mann Jakobs, Zu den Fuldaer Papsturkunden des Frühmittelalters, in: Blätter f. dte. Landesgeschichte 128 (1992) 31-84, bes. $49 \mathrm{ff}$.

295 Ich vermute, daß Eberhard hier auch auf die Ordnungsweise für seine Arbeit wichtiger Vorlagen anspielt, einerseits auf die Deponie-Weise der Einzelurkunden (scedula), andererseits auf die 8 regional und nach Abtszeiten gegliederten Kartulare, die im 9. Jahrhundert unter Hraban entstanden waren. Siehe seinen eigenen Hinweis: Dronke (wie Anm. 293) 144. Zur Restüberlieferung der alten Kartulare vgl. (mit der älteren Literatur) Walter Heinemeyer, Ein Fragment der verschollenen karolingischen Cartulare der Abtei Fulda, in: Archiv f. Diplomatik 17 (1971) 126-135 (m. Faks.).

296 Dazu Bresslau (wie Anm. 4) I, 63 (Unterscheidung von privilegia und precepta).

$297 \mathrm{Daß}$ aus seinem Schema die Materialien herausfielen, die mit den Einkünften (redditus) zu tun hatten, merkt er indirekt an anderer Stelle an, wo er noch bündiger formuliert (Dronke, (wie Anm. 293) V): “privilegia apostolicorum, precepta regum, tradiciones fidelium, oblaciones fratrum ceteraque alia. Bemerkenswert in diesem Zusammenhang der Übergangssatz: Determinatis atque congestis prediis que vel traditionibus seu oblationibus vel concambiis collata sunt, nunc de reditibus eorum prediorum, que abbati et fratribus serviunt, pertractemus (115)."

${ }^{298}$ Eberhards Prologe hat Dronke (wie Anm. 293) V-IX versammelt.

299 Welche Wirrnisse und Korrekturen Eberhard sich dadurch eingehandelt hat, daß er die anfängliche Bandplanung revidierte und auch vieles nachtrug, ist hier nicht zu schildern. Vgl. dazu Roller (wie Anm. 294) 8-18.

${ }^{300}$ Dronke (wie Anm. 293) VI: "Quia uero quaedam sunt intermissa quae postmodum in armario invenimus. placuit ut iterum a primordio incipiamus. et ea quae pretermissa sunt a uetustissimis et iam pene deficientibus scedulis colligentes. alteram distinctionem texentes usque ad tempora nostra perstringamus." 
nur redaktionell, sondern auktorial eingriff und heute dieser gezielten WortlautUntreue gemäß als Fälscher gilt - er hat versucht, seiner schwierigen Aufgabe durch eine nahezu umfassende und in vielem konsequente Ordination gerecht zu werden; und er hat diese Ordination nicht nur vollzogen, sondern sich auch dazu erklärt. Beides fehlt - eine grundlegende Differenz - in den Fuldaer Kartularen aus der Zeit Hrabans. ${ }^{301}$ Zur Angabe der formalen Kriterien der Wissensordnung und ihrer ausführlichen Begründung fühlte man sich damals noch kaum veranlaßt. 302

Es bietet sich an, hier noch einige Hinweise auf das Ordnungsverhalten im ersten Teil des sogenannten Codex Laureshamensis ${ }^{303}$, der in den Jahren 1170-1175 entstandenen, Chronik ${ }^{\varsigma}$ der Lorscher Abte ${ }^{304}$, anzufügen. Der anlegenden Hand A wird gleiche Beeinflussung aus Schwaben zugesprochen wie Eberhard ${ }^{305}$, und sie liefert in ihren Kommentaren zu Form und Verfahren gute Ergänzungen zum Fuldaer Schreiber und Kompilator. Die Chronik nennt man besser eine ,urkundliche Klostergeschichte' (Glöckner). Geboten wird die chronologisch geordnete Reihe der laureshamensis ecclesie priuilegia tam apostolica quam imperatoria, ipsorumque largitiones, seu cetereas fidelium dei donationes (I, 265). Jedes Stück ist überschriftlich abgesetzt. Viele von ihnen sind durch Berichte (annotationes) über Kirchen- und Reichsereignisse, Klostergeschichten, Abtstaten usf. eingeleitet oder miteinander verbunden, doch bleibt der Wille deutlich, vorrangig die transscriptio der Urkunden zu bieten. Im Rahmen dieser Verbindungssätze trifft man immer wieder auf Äußerungen zur Art seines Verfahrens als transscriptor. Auf sie allein will ich mich hier beschränken. Zuerst sollte angemerkt sein, wie der Anonymus sich ausdrückt, wenn er den Inhalt, den Wortlaut, die Geltung, die Machart eines von ihm übernommenen Schriftstücks ankündigt: traditionis continentia talis est, quorum tenor talis est, auctoritas hec est, quod tale est, donatio hunc modum continet, hoc modo - das sind seine Formulierungen; das Wort textus benutzt er, so weit ich beobachten konnte, nicht. ${ }^{306}$ Wie er es mit dem überlieferten Wortlaut hält, geht weiter aus einer ausführlichen Annotation über den Stil und die Fehlerhaftigkeit seiner Vorlagen (originalia) sowie deren zeitgenössischen Grund hervor. Sie gelte es ihres ehrwürdigen Alters wegen zu respektieren, auch wenn die klassisch orientierten Lateinkundigen seiner Zeit sich an dem alten Sprachmischmasch

\section{Vgl. Anm. 295.}

302 Dazu Geary (wie Anm. 18) 84 ff.

303 Hervorragende Edition: Karl Glöckner (Bearb. u. Hg.), Codex Laureshamensis I-III (Arbeiten d. Hist. Komm. f. d. Volksstaat Hessen, Darmstadt 1929-1936, ND mit Nachträgen von Friedrich Knöpp (1963). Der Codex hieß im 15. Jahrhundert Liber Privilegiorum Sancti Nazarii in Laurissa. Umfassende Beschreibung der Hs., ihr Entstehung, der Schreiber und ihrer Quellenbenutzung bei Glöckner I, 1-57; Staab (wie Anm. 257) 285-302 hat - über Glöckner hinaus - unser Wissen um weitere wichtige Vorlagen ergänzt, sodaß sein Urteil gilt, "daß der Codex Laureshamensis nur als der Überrest einer ehemals sehr viel reicheren Überlieferung anzusehen ist" (302).

304 Glöckner (wie Anm. 303) I, 265-452.

305 Glöckner (wie Anm. 303) I, 19.

306 Glöckner (wie Anm. 303) I, 267, 273, 285, 302, 305, 310, 315 u. ö. 
stießen und angemessenen Stil wünschten. ${ }^{307}$ Doch dieser hohe Treuegrad gegenüber Graphie, Idiom und Stil der originalia war angesichts vieler obsoleter Inhalte nicht durchzuhalten. An anderer Stelle erklärt der Lorscher Anonymus sich befugt, die fremdartigen und weitschweifigen Zeugennamen aus Schenkungsurkunden wegzulassen, dies mit dem Hinweis, sie seien ja in den originalia erhalten (I, 268). Aber er geht noch weiter und äußert sich generell zum Verhältnis von Formelgut und spezifischem Gehalt von Schenkungsurkunden: Exordia finesque singularum donationum, formas quoque precariarum omnes transcribere, mancipiorum nichilominus et testium nomina seriatim ponere, et longum est et non necessarium; maxime, cum exceptis personarum locorumque uocabulis ac temporum designationibus, aut eundem aut non multum disparem modum habeant et continentiam. Sufficiat igitur, si salua rerum ueritate, quando, ubi, qualiter, quid, a quibusque collatum sit nichil pretermittamus (I, 294; ähnlich II, 5). Hier ist Bedeutendes beisammen, was methodisch geleiteten abschriftlichen Umgang mit Schriftstücken ausmacht: die Unterscheidung von Inhalt (continentia) und Form (forma, modus), von Anfang und Ende, Name und Bezeichnung, Unverzichtbarem und Kontingentem, damit auch die Vorstellung vom sachlich Wesentlichen, Wahren und seiner - dialektisch verstandenen - kategorialen Formelemente. Wie die historische Kritik zur Lorscher Überlieferung bestätigt, haben sich der Schreiber A und seine Nachfolger, anders als Eberhard, an diese Maximen kategoriengeleiteter Regestierung salva rerum veritate gehalten.

Im zweiten Drittel des 12. Jahrhunderts, das zeigt die Auswahl, verfügen die (in ihrer Rolle als Veranlasser, Schreiber sich auch namhaft machenden) Äbte und Mönche in Marmoutier, Werden/Helmstedt, Fulda und Lorsch, sowohl bei der Erstellung neuen grundherrlichen Schriftguts wie bei der Abschrift, Kompilation und Kommentierung von überkommenem über ihre skripturalen, ordinativen und begrifflichen Werkzeuge in einer Weise, die sich deutlich als, verbessert' von dem im 9. Jahrhundert Beobachteten abhebt. Aber nicht die Aufkunft neuer Ordnungsmittel ist das Bezeichnende, sondern die Ausdrücklichkeit und Konsequenz im Umgang mit den längst bekannten. Dies zeigt sich erstens bei begrifflichen Operationen. Das Divisionsgebaren gewinnt an Stringenz, indem nun sowohl ausschließend (negativ) als auch setzend (positiv) definiert wird. Weiter wird der relative Wert zeitspezifischer Ausdrucksweisen erkannt und anerkannt. Neben die id-est-Haltung tritt die Reflexion über die Spannungen zwischen überlieferter

307 Glöckner (wie Anm. 303) I, 273: "Si quis in hac priuilegiorum transcriptione barbarismos siue solecismos legens reprehenderit, non nobis imputet, sed recurrens ad originalia, multo plura in eis uerborum dumtaxat vicia, non sensuum reperiet, que nos omnia corrigere pro ipsa antiquitatis reuerentia nec uolumus, nec debemus. Quod utrum ex notariorum imperitia prouenerit, aut scribendarum legum talis tunc calamus et usus exstiterit, aut certe Francorum lingue que tum maxime uiguit, huiusmodi fuerit ydioma, non satis constat. Adtestantur his Salicorum Ribuariorumque leges, que ita ex latino teutonicoque et quibusdam insolitis permixte surt, et dictionibus intercisis siue intricatis, casibusque amfractuosis uel preposteratis descripte, ut uix ab studiosis earum legi dinoscique ualeant. Sed nos utinam politiores loquendi amamus munditias, tam ornatui studeremus morum quam verborum, et ut ait Macrobius (Sat. I,5,2), uiueremus preteritis moribus, et presentibus uerbis loqueremur." 
und eigener Sprache (Wortschatz, Stil). Auch im Aufbau, im Nacheinander der Sachen, ist mehr Bedacht im Blick auf ein Ziel bzw. auf das Ganze am Werk. Dazu dient auch die formalbegriffliche Durchflechtung der scripta: von durch Kategorien bestimmten ,Unterschieden' her werden nicht nur Sachgesichtspunkte wie etwa Rechtsdifferenzen, sondern auch vorliegende Schriftstücke erfaßt, eingeordnet und erschließbar gemacht (durch Überschrift und Zählung; durch gesondertes Verzeichnis der so identifizierten Stücke). Schließlich ist auch der Umgang mit ihnen distanzierter und kontrollierter: sie gelten als Originale mit Form und Inhalt, Anfang und Ende, innerhalb derer das Gültige bzw. Bleibende vom Repetitiven und Veralteten getrennt werden kann (Regest). Eine methodisch bewußte, auf begriffliche Klarheit und sachliche Folgerichtigkeit abzielende Verschriftung und Verschriftlichung tritt hier also entgegen ${ }^{308}$ - durchaus mit dem Niveau der Leistung von Paulus von St.-Père in Chartres vergleichbar. Inwieweit die Gestaltung von Zeile, Abschnitt, Seite, Lage und Kodex diesen progressiven Befund spiegelt, muß, obwohl am Fall des Helmstedter Urbars erwiesen, insgesamt offen bleiben.

\section{Domaniale Rechenhaftigkeit}

Im Jahre 1145, im dreiundzwanzigsten Jahr seines Abbatiats (1122-1151), wurde Suger von St.-Denis auf einer Kapitelsitzung über weltliche Geschäfte von seinen Mitbürgern bekniet, einen schriftlichen Bericht über die ,mühselig erworbenen Früchte' seiner bisherigen administratio zu erstatten, damit sie im Gedächtnis der Nachwelt blieben. Er tat dies in den anschließenden Jahren mit seinem Liber de rebus in administratione sua gestis. ${ }^{309}$ Dieser Bericht gilt, zusammen mit seinem. Libellus de consecratione ecclesiae Sancti Dionysii ${ }^{310}$, als Kronzeugnis neuartigen Denkens und Handelns. Dies nicht nur im Sinne von Sugers berühmter Bildung der, Gotik' bei Umbau und Neuausstattung der Abteikirche ${ }^{311}$, sondern auch als Ausdruck umfassender altbenediktinischer renovatio in einer Zeit höchst verschiedener geistiger, sozialer und wirtschaftlicher Herausforderungen. ${ }^{312}$

308 Dies allerdings mit dem Vorbehalt, daß die Form des Abschlusses - man denke an den Anonymus von Muri, der zur Fortsetzung aufforderte, und an die Umdeutung des Codex Laurehamensis dadurch, daß Hand L die Chronik zum Kopialbuch umdeutet (Glöckner (wie Anm.303) 18f.) - nicht nur die Art des Bestandes, sondern auch die Durchführungsweise maßgeblich modifizieren kann.

309 Ich benutze die Edition von $A$. Lecoy de la Marche ( $\mathrm{Hg}$.), Suger. Oeuvres complètes (Paris 1867 ND Hildesheim/New York 1979) 155-209.

310 Lecoy (wie Anm. 309) 213-238.

311 Erwin Panofsky (Hg.), Abbot Suger on the Abbey Church of Saint-Denis and Its Art Treasures (Princeton 1946/1979); Georges Duby, Die Zeit der Kathedralen. Kunst und Gesellschaft 980-1420 (Frankfurt/M. 1980) 159f., 170-204.

312 Vgl. die Beiträge im Tagungsband zum 900jährigen Geburtsjahr Sugers: Paula Lieber Gerson (Hg.), Abbot Suger and Saint-Denis. A Symposium (New York 1986) sowie Philippe Verdier, La politique financière de Suger dans la reconstruction de Saint-Denis et l'enrichis- 
Im folgenden geht es nur um sehr begrenzte Fragen. Nicht einmal die nach Sugers konkreten Methoden und Erfolgen als Administrator von Abtei und Grundherrschaft (Verdreifachung der Einkünfte) steht in Rede; sie ist im wirtschaftlichen Detail und als Zusammenhang aller betreffenden Handlungen gut beantwortet. ${ }^{313}$ Ich will nur den die grundherrlichen Handlungen betreffenden Teil von Sugers Bericht (Kap. I-XXIII ${ }^{314}$ daraufhin untersuchen, wie er ordnend und denkend verfährt.

Er beginnt mit einer recht klaren Exposition. Nach dem Bericht über den Anlaß der Schrift wird der Auftrag formuliert. Zu handeln ist über die incrementa, tam in novarum acquisitione quam in amissarum recuperatione, emendatarum etiam possessionum multiplicatione, aedificiorum constitutione, auri, argenti, et pretiosissimarum gemmarum, necnon et palliarum repositione (I, 155). ${ }^{315}$ Drei Bereiche des Erfolgshandelns sind zu erkennen: die possessiones, die aedificia und der thesaurus. Dieser Teilung grob entsprechend hat Suger seinen Gesamtbericht aufgebaut. Was dann im ersten Teil folgt, sind über zwanzig locus-orientierte, sehr verschieden ausführliche Geschichten, die - Suger deutet dies selber an $(I, 156)$-, ausgehend von Gütern in der Umgebung der Abtei, in ihrer Abfolge insgesamt eine nach Süden (Orléans) ausgreifende und dann zum Kloster zurückführende Schleife bilden. Dieser als Itinerar imaginierten Ordnung des possessionesStoffs ${ }^{316}$ geben gelegentliche Vor- und Rückbezüge (XI, 169, XII-XIII) und Übergangsformulierungen (XXIV) weitere Kontur. Suger hat viel vom Ganzen vor dem inneren Auge, auch wenn er die Sequenz der Ortsgeschichten nicht zum Traktat ausformt. Auch die Außenbezüge der Geschichten bezeugen Schriftorientierung. Sugers Taten beziehen sich deutlich stärker auf Schriftstücke, vor allem Urkunden, als auf mündliche Traditionen. Auf die cartae antiquae im armarium wird bei der Rekuperation anbahnend zurückgegriffen, und neue privilegia werden an höchsten Stellen flankierend erbeten. Vieles Erreichte - ob es auf Rodung,

sement du trésor, in: Xavier Barral i Altet (Hg.), Artistes, Artisans et Production Artistique au Moyen Age. Bd. II (Paris 1987) 167-182.

313 Georges Duby ist im Anschluß an Beobachtungen in seinem Buch L'économie rurale et la vie des campagnes dans l'Occident médiéval (Paris 1962) 150, 244, 392, 419 immer wieder auf Suger zurückgekommen; besonders im bekannten Essay Guerriers et paysans VII-XII ${ }^{\mathrm{e}}$ siècle. Premier essor de l'économie européenne (Paris 1973) 227, 240-246 pass.; geschlossener ist die kurze Untersuchung von Charles Higounet, L'abate Suger e le campagne francesi, in: Aldo Ferrabino (Hg.), Le Bonefica benedettina (Rom 1963) 121-126; zur Güterverwaltung Sugers vgl. die beeindruckende, weitgreifende (vor allem unter Einbeziehung der urkundlichen Überlieferung) Studie von Giles Constable, Suger's Monastic Administration, in: Gerson (wie Anm. 312) 17-32.

314 Lecoy (wie Anm. 309) 155-185. Die Kapitelgliederung samt der Titel (De Trembliaco usf.) ist nicht immer konsequent. Lecoy (a.a.O.) IX-XI datiert sie nicht.

315 Über den zweiten Teil (Kap. XXIV-XXXIV), also die aedificiorum institutio und die thesaurorum augmentatio (I, 156), handle ich nicht.

316 Andere Gütererwerbs- und -verwaltungsgesta des 12. Jahrhunderts sind - wie etwa die Chronik des Klosters Petershausen (hg. v. Otto Feger, Konstanz 1956) - grob chronologisch oder - wie etwa die Vita Meinwerks von Paderborn (hg. v. Franz Tenckboff, MGH SSrG 59, Hannover 1921) - nach Schenkern geordnet. 
Flurbereinigung, Hofausbau, Kauf, Pfand- oder Steuerauslösung zurückgeht wird, bis hinunter zum jährlich fälligen Pachtvertrag, abschließend beurkundet. 317

Eine rege und kontinuierliche rechtsschriftliche Praxis zeichnet sich also ab. Sie bezieht sich auch auf dispensative Regelungen. Suger weist mehrfach darauf hin, daß seine Besserungsbemühungen besonderen Empfängergruppen oder Verbrauchsbereichen im Kloster zugekommen sind, und auch das wird urkundlich festgehalten. ${ }^{318}$

Wichtiger als diese ordinativen und dispensativen Gesichtspunkte scheint mir etwas anderes zu sein. In nahezu allen Geschichten hat Suger die Zeiten polarisiert: früher lagen die Äcker wüst, erpreßten die benachbarten Burgherren ungerechtfertigte Abgaben, blieben die Bauern Zinse schuldig, waren Besitztitel in Vergessenheit geraten - nun aber stehen die Felder in Blüte, hält der Adel freigiebige und friedliche Nachbarschaft, reißen sich die Bauern um jeden Hof, jede Pacht, sind alte Rechte ertragreich reaktiviert. Zu diesen Konversionen der Lage haben ganz maßgeblich weitsichtige Aufwendungen beigetragen. Immer wieder fallen die Wörter sumptus und expensa. ${ }^{319}$ Ohne den ständigen Griff ins klösterliche marsupium (II, 159) waren für Suger Neuerwerb, Wiedererwerb und Verbesserung der Güter nicht mehr möglich. Das Bewußtsein tritt hier zutage, daß ohne vorherige ,Kosten' kaum Fortschritte zu machen, Verbesserungen zu erwarten sind.

Wie nun artikuliert und verortet Suger diese Erfolge in seinem Bericht? Ich meine drei Divisionen erkennen zu können, die vor allem von den beiden Verben meliorare und emendare sowie von den Nomina augmentatio und incrementum ausgehen. ${ }^{320}$ Erstens: in den wenigen verbalen Wendungen bezieht Suger sich ausschließlich auf Verbesserungen der Böden vor Ort (terra, carucca: XI, 169f., XVI, 176). Es geht um qualitative Entwicklungen der örtlichen Anbauverhältnisse. ${ }^{321}$ Die deutlich vorherrschenden nominalen Bezüge in den Berichten belegen, worum es Suger vorrangig geht: um quantitates. Mittels einer zweiten Division scheidet Suger die Güter von den Einkünften. Dies kommt besonders im Vorwort zum Ausdruck. Hatte er zu dessen Beginn, wie oben zitiert, sein Verständnis der ihm gestellten Aufgabe an den incrementa possessionum festgemacht, so wechselt er gegen Ende die Aussagerichtung zur reddituum augmentatio (I, 156; ergänzend: XXIV, 185). Aus dieser Unterscheidung folgt eine dritte, meines Erachtens

317 Lecoy (wie Anm. 309) III, 160; X, 167; XI, 168, 170; XII, 172; XIV, 174; XVII, 177; XX, 181; XXI, 831. Wie hoch und erfolgreich, Suger dabei oft ,pokert' (Papst, König), stellt Constable (wie Anm. 313) $22 \mathrm{f}$. klar.

318 Lecoy (wie Anm. 309): Hospital (157, 164, 166); Refektorium (162, 185); Armenfürsorge

(174); Kirchenbau (185). Vgl. auch Constable (wie Anm. 313) $25 \mathrm{f}$.

319 Lecoy (wie Anm. 303) 156, 158, 159, 165, 167, 173, 174.

320 An Verben wie amplificare (XII, 172) und adquirere (VII, 164) gebundene Aussagen, die ich beiseite lasse, ließe sich zeigen, daß das semantische Feld der Erfolgssprache Sugers mit meinen Bemerkungen längst nicht systematisch $-d$.h. textlinguistisch - abgegrast ist.

${ }^{321}$ Hierzu wären viele weitere Details im Ausdrucksverhalten Sugers beizubringen (replantari, rehospitari usf.), auf die ich hier verzichte. Vgl. die vorige Anm. 
die bestimmende Division. Vierzehn seiner Berichte eröffnet, durchsetzt oder meistens - beschließt Suger mit Feststellungen folgender Art: incrementum census octo librarum; cum prius haberemus duodecim libras, modo viginti. De annona decem aut duodecim modios habebamus, nunc decem et octo (V, 163). Suger teilt also wie selbstverständlich die Erträge (census, redditus, consuetudo) in Pfennigoder Pfund-, Korn- und auch Weinmengen. Ansätze zu solchen Bündelungen des Solls der Hufen zum domanialen oder gar regionalen Jahresertrag hatten sich bereits bei urbarialen Summierungen im 9.Jahrhundert, besonders in zwei zusätzlichen summae zum Prümer Urbar, gefunden. Was bei Suger als neuartig auffällt, ist der systematisch quantitative Vergleich verschiedener Einkommenszustände, der Ertragskontrast der Zeiten. Dazu brauchte es nicht nur der Kette ständiger Aufrechnungen des konkret Erhaltenen (I, 158: computatio), sondern auch eines weiteren abstraktiven Schritts, der Fassung dieser Ertragserfahrungen in numerisch ausgedrückte Durchschnitte. Was Sugers estimativen Polarisierungen vorausliegt, sind also pauschalierte Ertragserfahrungen. Diese Erfahrungen drückt er immer wieder als, Wert'-sein aus (valere: 156, 169, 172, 176).

Hier liegt der Angelpunkt eines durchaus neuartigen Schreibens über grundherrliche Praxis. Aus den census-Katalogen der mansi des 9. Jahrhunderts sind ja Unmengen partikularer valente-Angaben (insbesondere für Viehzinse), aus den Leges seit.ihrem Aufkommen differenzierte Münzäquivalente für Güterbußtarife bekannt. Dazu kommen in grundherrlichen ,Kauf'-Urkunden breit gestreute Belege für Münzmengen, zu denen Güter der verschiedensten Art den Besitzer wechselten. Dazu kommen schließlich, besonders in Notzeiten, herrscherliche „Höchstpreis'-Edikte für Brotgetreide. Längst also führen Denare, Rechengeld und Silbermengen ihr Valenzen und Äquivalenzen stiftendes Schriftdasein im grundherrlichen und bußrechtlichen Taxier- und Abgabewesen sowie bei Tausch und Kauf. Suger schreibt nun aber auch über Gesamterträge, die vor allem Domänen, aber auch Bauerngüter, Marktgebühren usf. oder Konglomerate derselben jährlich abwerfen. Neben das Gesamt der Habe (Villa-, Hufenzahlen u. a.) und das jährliche Soll der Pflichtigen ist nun der errechnete Ertrag getreten, mit dem man rechnen können will, der die Orientierung in den Zeitläuften ermöglicht.

Eine weitere Zuspitzung schließlich: Obwohl die wichtigsten Ertragsarten nebeneinander stehen, erkennt man beim näheren Hinsehen, daß der Geldausdruck der lokalen Jahreseinkommen das Übergewicht hat. Die große Mehrheit von Sugers ,Bilanz'-Sätzen handelt über das incrementum denariorum. ${ }^{322}$ Im Ertragsdenken Sugers hat das, Geld' den ersten Platz eingenommen.

Sugers Erfolgsbericht über seine grundherrliche Administration, so läßt sich zusammenfassen, läuft zielstrebig auf errechnete Zuwächse an Getreide-, vor allem aber Münzquanta pro Ort und Jahr hinaus. Er läßt keinen Zweifel daran, daß diese Zuwächse nicht allein aus geschicktem Umgang mit Freunden, Gegnern und Familiaren resultieren, sondern es ebenso vorausschauender (investiver) Aus-

322 In den dreizehn Belegen verteilen sich die Bezüge auf Korn, Wein und Münze wie folgt: nur Wein:1; nur Korn:1; Korn und Münze:4; nur Münze:7. 
gaben und begleitender Aufrechnungen bedurfte. Die ausschlaggebenden Instrumente des Erfolges sind der vermehrte Gebrauch der Schrift und der kontinuierliche Umgang mit dem Münzgeld. Dies zeigen Sugers Darstellungsweise und Ausdrucksrichtungen unmißverständlich. Während im Süden von Paris im Augustinerchorherrenstift St.-Victor der Mönch und Lehrer Hugo bei seiner Auslegung der drei wichtigsten Umstände des Handelns vom Ordnungsbild des Münzbeutels ausgeht, der in mehrere cellae für die verschiedenen Währungen unterteilt ist $^{323}$, benutzt Suger in St.-Denis im Norden der aufstrebenden Stadt vorwiegend den Pfennig- bzw. Pfundindex, um die lokalen Einkommensteigerungen während seiner Amtsjahre auf den Punkt zu bringen. Dennoch bleibt seine administrative providentia ${ }^{324}$, vielleicht auftragsbestimmt, Stückwerk, denn er faßt seine Erfolge nicht zum Ganzen, zur summa summarum incrementorum zusammen. Und sein Trachten nach Vermehrung der Erträge, dem man schon einen Gutteil aus Knappheit geborener, Wirtschaftlichkeit' zubilligen möchte, bleibt vor allem ausgerichtet auf ein sakrales Verausgabungsziel: den Umbau und die Neuausstattung der Klosterkirche. 325

Auch um die Vermehrung der Einkünfte, nun aber eher als Reform des laufenden Unterhalts, geht es im letzten hier behandelten Fall. Chronische, aus neuartigen Kaufkraftverlusten der regional umlaufenden Münzen resultierende Versorgungsengpässe der Mönchsgemeinschaft von Cluny ${ }^{326}$ dürften es gewesen sein, die Abt Petrus Venerabilis veranlaßten, eine ausführliche Beschreibung der wichtigsten Klosterbesitzungen im weiteren Umkreis der Abtei erstellen zu lassen. Dies von einem ehemaligen Mönch, nun aber im englischen Normannenreich administrativ erfahrenen Gönner Clunys, Bischof Heinrich von Winchester, bei einem seiner Besuche dort (1149 bzw. 1155/6). ${ }^{327}$

Das Stück ist nur abschriftlich am Ende eines der Kartulare Clunys (13.Jahrhundert), ohne erkennbaren Grund abrupt abbrechend, überliefert. Es beginnt mit knappen Bestimmungen über die Brotgewichte und -rationen für die Mönche,

323 William M. Green, Hugo of St Victor. De tribus maximis circumstantiis gestorum, in: Speculum 18 (1943) 484-493, hier: 488.

${ }_{324}$ Einmal $(I V, 163)$ geißelt Suger die improvidentia derjenigen, die den Preisauftrieb des Getreides gegen Jahresende nicht bedenken.

${ }_{325}$ Hierzu neben den in Anm. 312 und 313 genannten Arbeiten auch: Martin Warnke, Bau und Überbau. Soziologie der mittelalterlichen Architektur nach den Schriftquellen (Frankfurt/M. 1976) Kap. II, $63 \mathrm{ff}$.

326 Duby, Guerriers (wie Anm. 313) $242 \mathrm{ff}$.

327 Edition: Auguste Bernard/Alexandre Bruel (Hg.), Recueil des chartes de l'abbaye de Cluny, Bd.V (Paris 1894) Nr. 4143, 490-505. Ich zitiere nach Abschnitt (nicht zeitgenössisch) und Seitenzahl. Nach den Studien Georges Dubys von 1952 und 1956 zu diesem Stück (wie Anm.8) 61-82, 87-101 bietet nun die ausführliche Untersuchung von Alain Guerreau, Douze doyennés clunisiens au milieu du XII ${ }^{\mathrm{e}}$ siècle, in: Annales de Bourgogne LII (1980) 83128 das Einschlägige zur Überlieferung, Quellenkritik und Wirtschaftsgeschichte (mittels faktorenanalytischer Untersuchung). Den letzten Stand der Forschung nimmt auf: Maria Hillebrandt, Berzé-la-Ville. La création d'une dépendance clunisienne, in: Le gouvernement d'Hugues de Semur à Cluny. Actes du Colloque scientifique international. Cluny, Septembre 1988 (Cluny 1990) 199-229. 
die familia und das Hospiz im Verhältnis zu den Getreidemengen, die zum Verbacken nötig sind (I, 490f.). Dann folgen ausführliche Beschreibungen von $12 \mathrm{De}-$ kanien (II-XIII, 491-505). Beide Teile, das betonen Duby und Guerreau, gehören zusammen. Im ersten ist errechnet, was man täglich im Zentrum braucht. Im zweiten sind diverse Einkünfte aufgeführt und Möglichkeiten bedacht, die solchen Bedarf decken helfen sollen. Auch wenn dieser Zusammenhang von Heinrich nicht benannt, geschweige denn erläutert wird - schon die allein förmliche Kombination dispensativer und approppriativer Abschnitte in einem Schriftstück macht es prominent für unser Thema. Jedoch auch im Detail sind viele neue Töne zu hören.

Vorweg aber: Trotz seines ja abschriftlichen Status ist das Stück nicht systematisch ordiniert. Es fehlt ein treffender Gesamttitel. Der Einleitungssatz zum ersten Teil - hec est constitucio expense Cluniaci per manum donni Henrici, episcopi Wintoniensis - ist sachlich treffend, zugleich begrifflich unabhängig vom dann Folgenden formuliert. Denn was im Einleitungssatz als Ausgabe (expensa) gilt, heißt dann Versorgung (procuratio), wird zugeteilt, gegeben, soll genügen (tribuere, dare, sufficere). Dem zweiten Teil fehlen Einleitungssatz und Überschrift, aber jedes der 12 Kapitel ist nach dem gleichen Muster eingeleitet (Decania de Bello Monte usf.). Decania heißen administrative Zentren, denen rententragende Besitzungen in bis zu 11 Ortschaften ringsum zugeordnet sind. Diese Besitzungen werden bisweilen als membrum (bzw. prepositura) bezeichnet. Eine mehrstufige administrative Gliederung zeichnet sich also ab. Die Reihenfolge der Dekanie-Kapitel ergibt allerdings keine Gesamtordnung nach einem Kriterium (Zentrum-Peripherie, Größe, Alter, Ordinalzahlen, Alphabet o. ä.). Doch bilden zwei Kapitelgruppen (II-VI; VII-XI) Teilitinerare zuerst nördlich, dann südlich von Cluny. ${ }^{328}$ Die überlieferte Anordnung bezeugt also Entstehungsnähe. Auch Spuren des Erhebungsvorgangs, präzisierende Aussagen Ortskundiger im Rahmen des Befragungsschemas, haben sich erhalten. ${ }^{329}$

Mit nur einer Ausnahme (Kap.VI: Cluny selbst) folgen alle Dekaniebeschreibungen einem im groben gleichen Schema, dessen Verfestigung zum Formular deutlich anklingt ${ }^{330}$, das aber nicht intern ordiniert ist. Es besteht aus folgenden Abschnitten: (1) pauschalierte Natural- und Geldabgaben pro Ortschaft; (2) pauschalierte kirchliche Einkünfte (Zehnte, Oblationen u.a.); (3) Angaben zur domanialen Ausstattung (Mühlen, Backhäuser, Weingut, Wiesen, Zug- und anderes Vieh, ausgesätes und bereitgehaltenes Saatgut, Ernte, Gebäude, Fronden der Familiaren); (4) Sonderservitien an Empfänger in Cluny; (5) Gesamtsummen; (6) nicht unter (5) subsumierte Erträge aus Mühlen, Kirchen, besonders aber aus dem dominium, den Domanialländereien (Getreide, Wein). Der Descriptiotyp ist also weitgehend auf die Aufführung bereits aggregierter, vom einzelnen Hebungsindex

328 Vgl. Guerreau (wie Anm. 327) 126 (Karte).

329 Bernard/Bruel (wie Anm. 327) 500f.: dicunt, quod ...

330 Guerreau (wie Anm. 327) 86f. Meines Erachtens ist auch Kap. II nach diesem Schema erstellt. Regelmäßig sich wiederholende Sätze: Summa omnium hec est; hec omnia absque luccracione dominii; in instauramento sunt. 
(Hufe, Haus, Boden, Kopf usw.) abgelöster Jahreserträge zugeschnitten (1, 2, 6). Regelmäßig werden diese lokalen Erträge dann, soweit möglich, zur ,dekanialen Gesamtsumme addiert (5). Schließlich werden Anteile für direkte Servitien in der Zentrale (in Küche, Keller, Siechenhaus usf.) reserviert (4). Auch in Cluny sind also, wie oben bereits mehrfach registriert, in die örtlichen Beschreibungen zweckgenaue Verbrauchsbestimmungen für besondere Einrichtungen bzw. Empfänger in der Zentrale eingebaut.

Diese kurze Charakterisierung von Aufbau und Zweckausrichtungen der Aufstellungen darf aber nicht darüber hinwegtäuschen, daß innerhalb des Schemas ausgesprochen variabel und situationsnah operiert wird. Man wechselt z.B. in den Orts- und Kirchenzinsabschnitten die Reihenfolge der Geld- bzw. Naturalabgaben oder bindet Einzelformen an genaue Entrichtungstermine (Festtage). Man verortet besondere Grundstücke präziser, beschreibt deren aktuellen Zustand, vermerkt Neuerungen. Man notiert, wie regionale Getreidemaße auf das in Cluny geltende zu verrechnen sind. Man zieht kleinere $Z$ wischensummen oder verweist darauf, daß der gerade aufgeführte Posten bereits in einer vorher genannten Summe enthalten ist. Man erwähnt besondere Rentenformen (Teilbau, Halbierung/Drittelung von Parrochialeinkünften), Abgabenanteile, die an andere Empfänger (Adel) gehen, und Inhaberrechte (Leihedauer, Verpfändung). Man hält Einzelheiten zur Abtsgastung fest, ebenso Kommutationsmöglichkeiten von Diensten in Geldzinse, Transportausgaben und Frondienstpräbenden, auch bislang nicht entrichtete Zinsanteile. Man bestimmt Verfahren der Zehntkollektion.

Diese Tendenz zur detaillierten und situationsangemessenen Aufnahme des Vorgefundenen, zu Erwartenden und Möglichen kulminiert in den Abschnitten zur domanialen Ausstattung (3). Ein Beispiel: Apud Bellum Montem (Beaumont) sunt VIIII boves, et adhuc addi possunt ibi $\mathrm{X}$ boves, quia sufficit terra ad lucrandum. ... Si bene vinee colantur, possunt ibi colligi VI carrate vini. ... IIII molendina, si bonum tempus fuerit, sufficiunt ad procuracionem minoris familie (III, 492). Jeder der drei Sätze hat es in sich. Im dritten kommt eine seit dem 11.Jahrhundert im grundherrlichen Schriftgut etablierte Grunderfahrung zum Ausdruck: die Ungewißheit der Zeiten, der Wechsel der guten und schlechten, d.h. ertragreichen und ertragarmen Jahre. Aber diese Erfahrung wird hier ins Kalkül gewendet, wenn man weitere Belege hinzuzieht ${ }^{331}$ : das Auf und Ab der Erträge wird nicht nur als fataler Vorgang hingenommen, sondern man bedenkt ihn, indem man die Marge zwischen den kargen und reichlichen Zeiten ausmacht und festhält. Sätze wie der erste im Zitat - sie gehören zum Deskriptionsschema - bezeugen den systematischen Willen, am Ort den Bestand des vorhandenen Viehs, besonders aber

331 Bernard/Bruel (wie Anm. 327) V, 494f.: "Debentur ibi XVIII sext. annone de decima et de tascha ad mensuram Clun., sed hoc in tempore sterili. Quando vero tempus melioratur, augebitur numerus sext." Eine Bemerkung wie: "De vineis dominicis possunt colligi $\mathrm{X}$ carrate vini, et, si bonum tempus fuerit, XX" (IX, 498; ebenso: XI, 502) verweist noch genauer auf das Wissen um die Bandbreite der möglichen Erträge. Im Weinbau konnte man in guten Jahren mit dem doppelten Normalertrag rechnen. Weitere Bezugnahmen auf die wechselnden Ertragsqualitäten der Zeiten/Jahre ließen sich häufen. 
des Zugviehs und der wichtigen agrikolen Geräte ${ }^{332}$ ins ausgewogene Verhältnis zu den domanialen Äckern, Wiesen und Wäldern zu bringen. Ausschlaggebende dingliche Voraussetzungen domanialen Wirtschaftens (Zugvieh-Pflug-Ackerland-Relationen) werden von Ort zu Ort aufs Optimale hin kontrolliert. Schließlich - wie hier im zweiten Satz - fehlt auch Kalkül zu den Kosten und der Qualität der ,Arbeit' nicht. Im Weinbau trifft man immer wieder aufs bene colere, oft ergänzt um den Münzaufwand, der den, guten Anbau' garantieren soll. ${ }^{333}$ Sogar das lokale Frondienstpotential wird auf Stimmigkeit durchdacht: Sunt ibi CCL operarii ad prata falcanda, sed CL sufficiunt ad eandem operacionem et $\mathrm{C}$ reliqui ununsquisque dat II den. pro operacione sua, si tamen dominus voluerit (XIII, 503).

Heinrich, dafür sprechen die vorgeführten Details zur Genüge, suchte sein Ziel, die Hebung und Stabilisierung des victus für die Zentrale, dadurch zu erreichen, $\mathrm{da} ß$ er den Besitz und die Einkünfte nicht nur in statuarischer Anordnung von Sachen und Rechten erheben ließ, sondern als den wechselnden Zeitläuften unterworfene und für Gestaltungsmöglichkeiten offene Ensembles konzipierte. Dem entspricht die klare, Spaltung' der Einkünfte in all die Zinse, die aus den Bauerngütern und Kirchenrechten der zur Dekanie gehörenden Ortschaften zu erwarten sind - Abschnitte 1, 2 und 5 des Formulars -, und die Erträge aus den Einrichtungen des dominium in den Abschnitten 3 und 6. Gerade auf die dominium-Erträge - über sie schweigen die Verzeichnisse des 9. Jahrhunderts nahezu völlig - dürfte es angekommen sein. ${ }^{334}$ Sie konnten aber nur als realistische Größen fürs Zentrum gelten, wenn ins Kalkül auch der Aufwand einging, mit dem sie erwirtschaftet wurden. Derlei Aufwendungen gehören teilweise zum Formular, drängen sich aber auch als Detail immer wieder zwischen die üblichen Posten. ${ }^{335} \mathrm{~W}$ ie bei Suger spielt also auch hier das Wissen um die Abhängigkeit des Ertrags von den Ausgaben mit. Und schließlich verraten die Worte, die man zur Nutzung des dominium und seiner Erträge einsetzt, das Wesentliche: lucrare terram, lucrum totius anni, lucracio dominii. Jede Summierung der Zinse (Abschnitt 5) schließt mit dem Formularsatz: Hec omnia redduntur absque (his que colligunter de) lucracione dominii. Aber: das (vielfach im folgenden Abschnitt aufgeführte) lucrum besteht in Fuder Wein und Heu, Scheffel bzw. Sester Korn, nicht in Münzquanta.

Was für die Ertragsperspektive des dominium die lucracio, das dürfte für die der Abgaben der ,Wert' sein. Schon bei Suger war ab und zu in seinen Bilanzen über die örtliche Ertragssteigerung zu beobachten, was in den 12 Dekanieaufstellungen

332 Andere Aufstellungen mit gleichem Sinn gehen nicht vom Zugvieh, sondern von den carrucae aus (Bernard/Bruel (wie Anm. 327) 495, 496).

${ }^{333}$ Bernard/Bruel (wie Anm. 327) 494, 496, 498; der wechselnden Situation angepaßte Aufwendungen bezeugen Sätze wie: "Vinea que est in dominico bene potest coli hoc anno pro XXX sol., et sequentibus annis pro XX solidis (499)."

${ }_{334}$ Duby (wie Anm. 8) $94 \mathrm{f} ., 98 \mathrm{ff}$.

335 Bestandteile dieser Aufwendungen sind: Saatgut (Formular), ,Versorgungen (procuraciones) der Familiaren, Ackerdienste der villani (Formular), ,Löhne', d. h. Münzmengen zur Bestellung von Weingütern und zur Bezahlung von Transportleistungen der villani. 
in deutlich mehr Details präsent ist - die Projektion konkreter Abgabemengen auf ihre Gültigkeit, ihr ,Wert-sein'. Es geht um eine bedeutsame Verschiebung der Ausdrucksweise im Blick auf den redditus. Bei Heinrich ist der Übergang vom Rentenbrauch (consuetudo) über den gewohnten Ertrag (de qua solent colligere, accipere o. ̈.) und das jährlich Zusammengerechnete (per annum computatur) zur numerisch ausgedrückten, Valenz' (valere per annum) vielfach gleitend. Die zur Formel verfestigten Belege darüber, daß Einkünfte ihren in Pfennig und Scheffel gezählten ,Erfahrungswert' haben, sind zwar in den Abschnitten über die kirchlichen Einkünfte konzentriert. ${ }^{336}$ Aber die neue val(u)ierende Ausdrucksweise man könnte von einer Verschiebung vom substantiellen Wie-viel zum relationalen Wie-viel-wert ${ }^{337}$ sprechen - bezieht sich nicht nur auf die gewohnten, geltenden Abgaben. Sie erfaßt auch - sporadisch - Möglichkeiten, Chancen, schlägt sozusagen von der Erfahrung in Erwartungen um. Dies im Blick auf verbessertes Wirtschaften unter günstigen Umständen ${ }^{338}$ ebenso wie auf Verkaufserlöse (precium) anstelle von Naturalabgaben. ${ }^{339}$

Auch wenn die beiden Ertragssektoren, der, lukrative‘ Eigenbau und die,werten' Zinse, distinkte Bereiche bleiben, im Vokabular, das alle Teile von Heinrichs Aufstellungen durchzieht, haben Termini des Messens, des vergleichenden $\mathrm{Zu}$ ordnens und Rechnens einen hohen Stellenwert. Da sind zum einen die regionalen Währungen (moneta) ${ }^{340}$ und die regionalen, immer wieder auf die Normen in Cluny umgerechneten Getreide- und Weinmaße ${ }^{341}$, zum anderen die formalen Termini wie numerus, quantitas, magnitudo, totum, medietas, tertia, quarta und decima pars. Schließlich: es wird nicht nur ständig aufgeteilt, zusammengezählt, hinzugerechnet, ausgenommen und rückverwiesen, sondern diese Operationen werden auch als solche bezeichnet: per annum computantur, computati sunt; summa redditus, summa omnium, in summam redactus; que non sunt (ad plenum) annumerata; sed superius numerata sunt usf. - hierin kommt regelhaft ein Bewußtsein vom rechenhaften Operieren zum Ausdruck, auf das man im grundherrlichen Schriftgut des 9.Jahrhunderts nur ansatzweise trifft. Diesen Artikulationen fehlt aber noch der Bezug auf die wichtigsten Instrumente pragmatischer Schriftlichkeit, mit denen Heinrich, aber nicht nur er, natürlich vertraut war: Wachstafel und Abrechnungszettel, Kerbholz und Abakus. ${ }^{342}$

336 Bernard/Bruel (wie Anm. 327) III, 492f., VIII/IX, 497 ff., XI, $501 \mathrm{f}$.

337 In den späteren oberdeutschen Urbaren kommt dies im Wort, Gült ${ }^{\varsigma}$ zum Tragen.

338 Bernard/Bruel (wie Anm. 327) XII, 502: "Novem molendina sunt ibi, et si bene facta essent, et bonum esset tempus, valerent per annum LII sext. annone, sed modo ex parte vastata sunt."

339 Bernard/Bruel (wie Anm. 327) III, 491 f.: "In Augusto debentur ibi XVI sext. vini vel precium vini quantum tunc venditur."

340 In zwei Kapiteln (II, III) sind neben der moneta Cluniacensis andere Prägungen erwähnt. Aus der jeweiligen nachfolgenden summa omnium erhellt, daß letztere ersterer gleich gelten (entsprechend der Relation: 1 lib. $=20$ sol. $=240$ den.).

341 Vgl. hierzu Guerrean (wie Anm. 327) 90 ff.

342 Selbst in dem klaren Gebot zur mindestens monatlichen Abrechnung sowohl des Kloster-Kellners vor dem Abt als auch der grangiarii vor dem Kellner, das 1152 in die Zisterzien- 
Schließlich: die Operationen münden nicht in Gesamterträge auf dekanialer Ebene oder gar in eine schriftliche summa summarum fürs Zentrum. Jede der 12 summae omnium (Abschnitt 5 im Schema) bezieht sich nur auf die Abgaben der Dörfler und Kirchen. Die Erträge des dominum am Ort gehen nicht in sie ein. Dies gründet sicher im Auftrag, den Petrus Venerabilis Heinrich erteilte. Nicht der jährliche Gesamtertrag sollte ermittelt, sondern eine Krise überwunden werden. Dies ließ sich nur auf örtlicher Ebene machen. Die Errechnung gegebener Erträge und die Meliorierung der domanialen Anbauumstände - beide Handlungsarten bewahren ihren Ortsbezug, und es ist keine Verbindung zwischen dem ersten Teil über den täglichen Brotbedarf in Cluny und den folgenden dekanialen Aufstellungen formuliert.

Beide Zeugnisse, Sugers Rechenschaft und Heinrichs Bestandsaufnahme, belegen neuartige Haltungen in der grundherrlichen Praxis und ihrem schriftlichen Niederschlag (Vokabular, Gedankenfolge, Ausdrucksweise), die ich probeweise als domaniale Rechenhaftigkeit bezeichnen möchte. Ich meine damit Denk- und Verhaltensarten, die auf ertragssteigernde und vorteilsorientierte Sachwaltung in Approppriation, Dispensation und Landbau in Eigenregie zielen. Was sich schon in den Zeugnissen aus Marchiennes, Münchweier, Muri und Deutz an mehr Detailgenauigkeit, Zeitbewußtsein und Verbindung zwischen Besitzort und Zentrale zeigte, ist hier ertragsperspektivisch konturiert. Das zeigt sich an Münzvergleich und Maßverrechnung, an der Registrierung von Ausgaben als ,Kosten' (Kauf, Lohn u.a.), an optimierenden Abschätzungen von Land-Zugvieh-ArbeitsQuanta, am Vergleich der Zeiten, am Umgang mit verschiedenen Ertragsarten, d.h. an den Tendenzen zur Valuierung der konventionellen Zinse und zur Vermehrung der domanialen Erträge, schließlich an der bedeutenden Rolle des Münzgelds als Einkommensindex. Als Hypothese sei angeschlossen, daß in all diesen Erscheinungen mehr Relationalität, mehr wägendes, wertendes und errechnendes Verbinden und Vergleichen wirkt.

Aber beiden Zeugnissen fehlt - vor allem zweckbegründet - die Orientierung auf ein Wirtschaftsgesamt, obwohl zum einen - in beiden Zeugnissen - die Zuweisung lokaler Einnahmeanteile an genau bestimmte Empfänger und zum anderenin Cluny - die Verkoppelung des errechneten Brotbedarfs im Kloster mit den dekanialen Besitz- und Ertragsaufstellungen das Aneinanderrücken und Ineinandergreifen dispensativer und appropriativer Handlungsstränge im Schriftgut spiegelt.

serstatuten einging, sind weder der Schriftbezug noch die Werkzeuge der Rechnungslegung erwähnt. D. Joseph-Maria Canivez (Hg.), Statuta Capitulorum Generalium Ordinis Cisterciensis ab anno 1116 ad annum 1786, Bd. 1 (Louvain 1933) 45: "Quando vel quibus maior cellerarius computare debet? Maior cellerarius semel in mense, vel saepe si Abbas voluerit, de omnibus quae accepit vel expendit Abbati vel quibus iusserit computet. Alii autem sive grangiarii, sive qui aliquibus praesunt operariis, in praesentia cellerarii vel quibus cum eo iusserit Abbas, similiter faciant." Zum - deutlich schriftlichen! - Rechnungslegungsgebot der Prämonstratenser wenig später (1170) vgl. Dietrich Lobrmann, Die Wirtschaftshöfe der Prämonstratenser im hohen und schließlich späten Mittelalter, in: Patze, Grundherrschaft (wie Anm. 257) I 205-240, hier: 211. 


\section{Schlußbemerkungen}

Am Ende eines so überlangen Weges sollten nur noch knapp gehaltene Erwägungen stehen. Die Aufgabe, ausgewählte Schriftzeugnisse ruraler Einkommenssicherung im früheren Mittelalter auf ihre internen Ordnungserscheinungen hin zu untersuchen, wurde auch mit dem Ziel abgesteckt, zur Frage nach den Zusammenhängen von Schriftpraxis und Denkstil aus einem bislang wenig beachteten Überlieferungsbereich beizutragen. Verschrieb mir diese Aufgabe, wollte sie ernst genommen sein, ein schlichtes Vorrücken von Zeugnis zu Zeugnis, so war eine methodisch durchsichtige Orientierung an epochenimmanenten Deutungskriterien schon viel schwieriger. Meine Lösung bestand in einem Suchgang mit Hilfe von sechs Zeugnissen aus dem 11.Jahrhundert. Zwischen Beginn und Ende des gewählten Zeitraums wurde der Ausgangspunkt gewählt, damit dann zurück- und vorausgeschaut werden konnte. Ergeben hat sich der Grundbefund, daß jedes grundherrliche Schriftzeugnis, von der Erstellung über die Bearbeitung zur Benutzung und Bewahrung, vielfältigem Wandel ausgesetzt ist. Die systematischen Kriterien solchen Wandels: Schrift(bild), Ordination, Stil, Vokabular, Sprache, interne und externe Gattungs-, Sach- und Zeitbezüge. Sie dienten zum Leitfaden für die dann folgende Reihe von Einzelinterpretationen, die auf schriftstückinternen Wandel und schrittweise Fortschritte vom 9. zum 12.Jahrhundert abzielte.

Beides, auf einzelne Zeugnisse genauer einzugehen und sie als Glieder einer Kette von Fortschritten zu deuten, ergab Beschränkungen. Nur wenige Dokumente, nahezu alle aus Benediktinerklöstern, kamen zu Wort. Laikale und königliche Zeugnisse (bis auf Andeutungen zum Capitulare de villis) fehlen. ${ }^{33}$ Der Fortschrittsfolge mußte zum Opfer fallen, wie viel an Zuwachs und Fortschreibung von Gewohntem in der Überlieferung besonders seit dem 11.Jahrhundert steckt. Damit wurde auch das Bestandswachstum selbst nicht hinreichend als Entwicklungsindiz berücksichtigt. Und es wurden - über die Andeutungen zu Gent, Reims, Werden und Fulda hinaus - Chancen zum eingehenden Vergleich von Überlieferungsetappen innerhalb einer Grundherrschaft ausgelassen. ${ }^{344}$

Neben den Beschränkungen sind schwerwiegende Mankos zu nennen. Die

343 Deshalb steht die ganze Abhandlung sozusagen unter dem ,Vorbehalt ${ }^{c}$ des Domesday Book (s. Anm. 20) - nicht nur wegen seines Umfangs und seiner redaktionellen Vielfalt, sondern auch der Möglichkeit, die Verschriftung teilweise mit einem überlieferten Fragenschema (inquisitio Eliensis) zu vergleichen. Die frühesten mir bekannten adligen Register (Aufzeichnungen der Grafen von Falkenstein ab 1166: Noichl (wie Anm. 257); sowie F. Philippi/W. A. F. Bannier (Hg.), Das Güterverzeichnis Graf Heinrichs von Dale (1188), in: Bijdragen en Mededeelingen van het Historisch Genootschap (Utrecht) 25 (1904) 365-443 habe ich eingesehen. Bis auf die ausgeprägte Neigung, die adnotatio (Falkenstein) bzw. den item-Eintrag (Dale) als Ordnungsprinzipien zu nutzen, und bedeutsame Illuminationen (Falkenstein) bieten sie nur Bekanntes.

${ }^{344}$ Dies gilt besonders für die Corveyer Überlieferung. Vgl. Hans Heinrich Kaminski, Studien zur Reichsabtei Corvey in der Salierzeit (Veröff. d. Historischen Kommission Westfalens X, Köln/Graz 1972). Auch das Domstift Bamberg wäre in Frage gekommen. Vgl. von Guttenberg/Wendehorst (wie Anm. 257). 
Stücke wurden recht uneinheitlich interpretiert, was nicht nur an ihnen selbst lag, sondern auch am Aufbau und Gang der Abhandlung. Vor allem aber wurden sie nicht durchgehend und konsequent in ihre Überlieferungszusammenhänge (Codex, Mitüberlieferung, Bewahrorte) gestellt, nur auswahlsweise an die örtliche Schriftkultur zurückgebunden (Skriptorium, Bücherstube) und selten in ,trivialem' Klima situiert (Adalhard - Alkuin). Hier bleibt noch Wichtiges, fürs 12.Jahrhundert nahezu alles zu tun.

Eine ausführliche Darstellung der Ergebnisse ist hier nicht nötig - Teilresümees sind über die ganze Abhandlung verstreut. Es soll nur um einige weitertragende Erwägungen gehen. Im grundherrlichen Schriftgut des 9.Jahrhunderts sind bereits alle skripturalen und ordinativen Instrumente zuhanden, die auch im 12. regieren - nur fehlt dem schriftpraktischen Formbewußtsein der Karolingerzeit der Sinn für Konsequenz und Ganzheit. Gleiches gilt für sachliche Distinktionen sowie für reflexive und explikative Interventionen. Allem kann man Starres in der Methode, Statuiertes im Inhalt ablesen. Sowohl der Stil der kategorialen Entfaltungen der Sachen, Leute und Rechte pro villa als auch die Formen literarischer Distanzierung vom Erhobenen (Formular, Abschrift, Summenbildung) bezeugen diesen Eindruck. Das grundherrliche Schriftgut des 9.Jahrhunderts, so scheint mir, steht der grundherrlichen Alltagspraxis wie in teilweise aufwendigem Formalismus befangen gegenüber. Könnte dies ein Merkmal sein, das auch für andere Bereiche der Schriftpraxis und des Denkens im 9. Jahrhundert gilt? Kann man von einem ,ungelenken' Gebrauch des Lateins als Schrift, Sprache und Begriffsgefüge sprechen?

In den grundherrlichen Zeugnissen des späten 11. und 12.Jahrhunderts, mehr über sie verstreut als in ihnen einzeln konzentriert, ist vielerlei Steigerung und Entfaltung zu erkennen: mehr Deutlichkeit (Über-Sichtlichkeit) in Schriftbild und Ordination, genauere und sprachlich gewandtere Beschreibungen (der locus wird so zum situs), zunehmende Formstrenge und Folgerichtigkeit im Gebrauch von Ordnungsbegriffen, häufigere Reflexion und Explizitheit in der Haltung zur Sache und zum geschriebenen Ganzen sowie seinen Teilen, die bewußtere Verwendung mundartlicher Ausdrücke, der konsequentere Gebrauch von Abstrakta beim Verzeichnen und Ordnen von Schriftstücken, Rechtsformen, Rentenverhältnissen und Besitzstrukturen, schließlich zunehmend vergleichende, wertende und berechnende Ausdrucksweisen bis hin zur Subsumtion entscheidender Inhalte unter eine Ordnungskategorie, einen Index. Doch zögere ich, diese Gewinne beim retexere und intexere im Sinne von Adalbero und Paulus zu dramatisieren, zur Figur einer epochalen Wende oder eines Strukturumbruchs zu erklären; zu begrenzt ist auch der untersuchte Ausschnitt aus der Gesamtüberlieferung. Es ist, gerade im Rückblick auf zahlreiche progressive Einzelheiten aus dem 9. Jahrhundert, zu viel Allmählichkeit, auch zu wenig geballt Neues im Spiel. Deshalb neige ich zum Begriffspaar der Verdeutlichung und Elaborierung, um den Vorgang insgesamt zu charakterisieren. Damit soll nicht ausgeschlossen sein, daß das Tempo und die Verbreitung der Besserungen seit dem späten 11.Jahrhundert wächst und $\mathrm{da} ß$ die Vorgänge räumlich gestuft, ja gerichtet sind. Dafür könnten die Zeugnisse 
aus dem Westen stehen (Chartres, Marchiennes, St.-Denis und Cluny). ${ }^{345}$ Aber nicht nur sie, auch die anderen Stücke aus dem 12. Jahrhundert bezeugen ein hohes Maß an Elaboriertheit. Die grundherrliche Schriftpraxis ist sowohl im Erstellen wie im Fortschreiben von Schriftgut flexibler und differenzierter geworden: sprachlich, stilistisch, begrifflich. Sie drückt Agilität, Bedachtheit und Nähe zur Aufgabe, zur Sache und zur Lage aus. Versuchen sich die benediktinischen Mönche im 9.Jahrhundert gegenüber den mündlich vermittelten Gewohnheiten der Familialen durch schematisches Aufstellen zu behaupten, um dann schriftgestützte Distanz aufzubauen, so nutzen die des 12.Jahrhunderts ihr Schriftkönnen für vielfältigere $Z$ wecke - am auffälligsten sind die Annäherung an die Praxis und die Verbindungen, die sie herstellen, Verbindungen zwischen Einzelbrauch und Recht, zwischen Anspruch und Wirklichkeit, zwischen Vergangenheit, Gegenwart und auch Zukunft. Überlieferungstypologisch zugespitzt: der Deskriptionstyp hat sich allmählich vom schematisch geordneten Ergebnisprotokoll zum handlungsorientierten Rechts- und Administrationsdokument gewandelt.

All das muß man als Leistung benediktinsichen Mönchtums ansehen, und all das ist ohne die Wirkungen jahrhundertelanger trivialer Schulung kaum denkbar. Wenn ich im Laufe der Abhandlung auf Spuren vor allem dialektischen Vorgehens geachtet habe, so hat sich hoffentlich, parallel dazu, manches grammatische und rhetorische Detail eingefunden, das den Hauptbefund, den Zugewinn an dialektisch geschultem Operieren, ergänzt. Projiziert man diesen Gesamteindruck auf Kommendes, dann wird daraus eine Exposition. Das gilt für weitere Ordnungsgewinne im grundherrlichen Schriftwesen geistlicher Einrichtungen, etwa beim Kodifizieren von Ländereien, Rechten und Einkünften: treffende Gesamttitel, durchgehende Ordnung der Dokumente (nach Alter, Bedeutung, laufender Zahl oder gar Anfangsbuchstaben) samt Inhaltsverzeichnis, Trennung von überliefertem Wortlaut (textus) und modernem Kommentar (glosa). ${ }^{346}$ Mir scheint, daß den neuen, an den aufstrebenden hohen Schulen so aktiven Orden, auch den Zisterziensern, dabei eine besondere Rolle zukommt. ${ }^{347}$ Es muß eben nur die Verbin-

${ }^{345}$ Dies ist nur eine schwache Vermutung. Alles hierzu methodisch Nötige ist versammelt bei Johannes Fried, Deutsche Geschichte im früheren und hohen Mittelalter. Bemerkungen zu einigen neuen Gesamtdarstellungen, in: HZ 245 (1987) 625-659, hier: $640 \mathrm{ff}$.

${ }_{346}$ Man denke nur an grundherrliche Dokumentationen wie den Güter- und Einkünftekodex der Zisterzienserabtei Eberbach von 1211 mit dem sprechenden Gesamttitel Oculus memorie und seiner durchgehend übersichtlichen Einrichtung (Heinrich Meyer zu Ermgassen (Bearb.), Der Oculus Memorie, ein Güterverzeichnis von 1211 aus Kloster Eberbach im Rheingau (Veröff. d. Histor. Kommission f. Nassau XXXI, Wiesbaden 1981) 3 Bde.), an die Abschrift des Prümer Urbars durch Cesarius von Milendonk um 1222, hergestellt in der Zisterze Heisterbach, in der der textus von 893 und die glosa des Caesarius wie in einer scholastischen Studierhandschrift in Schriftgröße und Seiteneinrichtung geschieden und durch Zeichen aufeinander bezogen sind (Schwab (wie Anm.139) Faksimile im Anhang), oder der Kodex aus Tennenbach von 1317/1341, der nicht nur wegen seiner prominenten Mitüberlieferung (Freiburger Stadtrecht), sondern auch wegen seines Aufbaus secundum ordinem litterarum alfabeti Bedeutung hat (Johannes Zenlin/Max Weber (Bearb.), Das Tennenbacher Güterbuch (Stuttgart 1969) $2 \mathrm{f}$.).

${ }_{347}$ Rouse (Cistercian Aids (wie Anm.14) 131f.) stellt heraus, wie wichtig in den Jahren 
dung zwischen dem grundherrlichen und dem neuen doktrinalen Schriftgut hergestellt werden, um auf beider Gleichartigkeit aufmerksam zu werden. ${ }^{348}$

Ebenso wichtig ist das Erreichte im Licht neuer schriftpraktischer Werkzeuge wie dem Papier, der Kursive, dem Positionszahlensystem (mit arabischen Ziffern und indischer Null), der Pecia-Kopiertechnik, der Rastertabellierung, dem analytischen Register, dann im Blick auf den dramatischen Einbruch der alltagssprachlichen Mundarten ins Schriftwesen, angesichts neuer Schriftguttypen wie den Lehnsverzeichnissen, den Einnahme- und Ausgabenrechnungen, den Haushaltungstraktaten, den Weistümern, den Lagerbüchern, der Registerführung u.a.m., schließlich der Professionalisierung der grundherrlichen Schriftführung und Verwaltung selbst. Ohne die hier herausgestellten benediktinischen Leistungen ist der Durchbruch zu diesen neuen Techniken, Ausdrucksweisen und Schriftguttypen und ihre Verbreitung auch im grundherrlichen Handlungsfeld kaum denkbar. Die Initiative dazu kommt aber anderen sozialen Gruppen zu: den neuen Orden, den Studierten in herrschaftlichen Diensten, dem Handelspatriziat.

Schließlich drei Bemerkungen noch generellerer Art. Erstens: Im Blick auf wichtige neuere Forschungsleistungen zur Literalitätsentwicklung ergibt sich im Spiegel des grundherrlichen Schriftguts der Grundeindruck von einer ,gestreckteren ' Entwicklung: das Bild einer sich seit dem späten 11.Jahrhundert rasant entfaltenden, Schriftmentalität ${ }^{\circ}{ }^{349}$ bzw. ,Textualität ${ }^{350}$ ist aus der Sicht des hier untersuchten Schriftguts mindestens durch eine lang währende Anbahnung zu komplettieren, während derer der schriftkulturelle Nachlaß der Spätantike in den Klöstern nicht nur sorgsam gehütet und vervielfältigt, sondern auch umfassend elaboriert und immer bewußter gehandhabt wird. ${ }^{351}$ Zweitens: Was das grundherrliche Schriftgut seit dem ausgehenden 8. Jahrhundert an zunehmend begriffs-, mittelund formbewußter Handhabung von Schrift und Sprache bezeugt, sollte nicht vorschnell aufs Konto sich entfaltender ,Rationalität' oder ,Rationalisierung

1170-1250 Hilfsmittel wie die Wortkonkordanz, der Sachindex, die Alphabetisation, die arabischen Zahlen usf. auch für die Zisterzienser (neben den Dominikanern und Franziskanern) wurden, um für neue Aufgaben, insbesondere für die schriftbezogene Predigt, gerüstet zu sein. Ausführlicher und im breiteren Zusammenhang dazu Rouse/Rouse (wie Anm. 14).

${ }^{348} \mathrm{Zu}$ erinnern ist nur an Jordan von Sachsens Ableitung der forma tractandi und der forma tractatus aus der causa formalis (1220) (Anm. 19). Erinnern möchte ich hier an den glänzenden Ordinatio-Aufsatz von Parkes (wie Anm. 14). Ihm ein karolingerzeitliches Pendant zur Seite zu stellen, ist eine dringende Aufgabe.

${ }^{449}$ Clanchy (wie Anm. 9) Teil II (The Literate Mentality) $185 \mathrm{ff}$.

350 Stock (wie Anm. 5). Abgesehen davon, daß im grundherrlichen Schriftgut nur spät, und nach außen (auf andere, wortlautstabile Schriftstücke: Urkunden und Kodizes) weisend, der Terminus textus fällt - mein Hauptbedenken Stocks wichtiger Untersuchung gegenüber gründet in seinem linguistischen, nahezu unhistorischen Text-Begriff. Mehr Rücksicht auf das Materiale am Schriftstück und seiner situativen Verankerung ist meines Erachtens mindestens solange nötig, wie sich - historisch - der Text noch nicht von der Seite gelöst hat. Hierzu Illich (wie Anm. 14) 121-133.

351 Vgl. dazu - mit sakral-bibliogenem Ausgangspunkt - Keller, Vom , heiligen Buch' (wie Anm.7) $14 \mathrm{ff}$. sowie gegen Stocks zu späten Ansatz gerichtet, McKitterick, Uses (wie Anm. 11) $2 \mathrm{ff}$. 
überschrieben werden. So wichtig es ist, Max Webers These vom okzidentalen Rationalisierungsprozeß kommunikationstheoretisch zu ergänzen und historisch an die Eigentümlichkeiten des mittelalterlichen Schriftgebrauchs zu binden ${ }^{352}$, die prominente Geschichte der Begriffe Rationalität und Rationalisierung selbst ${ }^{353}$ reicht doch nicht nah genug ans Mittelalter heran, als daß man sicher sein könnte, Applikationen dieser Begriffsform wären beim jetzigen Forschungsstand heuristisch besonders fruchtbar. Was das Beleggut zu den Sinnfeldern von ratio und rationare, besonders vom 9. Jahrhundert an, zu bieten hat, muß erst noch zusammengebracht und gewichtet werden. ${ }^{354}$ Drittens: Konstruktivere Skepsis ist für den so wichtigen Aspekt, ökonomischen' Zweck- und Wirkungsdenkens angebracht. Wie tragfähig neuere Fragen nach der Aufkunft eines alteuropäischen ,Wirtschaftsrationalismus' während des früheren Mittelalters sind ${ }^{355}$, wird davon abhängen, wie genau man die kleinen Schritte im Übergang vom gift exchange zur profit economy ${ }^{356}$ und von distributiven zu produktiven Institutionen ${ }^{357}$ aufspüren kann, die das spätere geld- und marktorientierte, Wirtschaften' konditionieren. Das hier untersuchte grundherrliche Schriftgut gibt auf diese alte Frage Antworten, die neue Fragen möglich machen. Unübersehbar ist zum einen, daß die Bezeichnungskonventionen für das grundherrliche ,Einkommen' sich - fast unmerklich - verschieben bzw. differenzieren: es führen Wege, vom debitum ausgehend, über den redditus zum receptum. Was bedeutet diese Verlagerung von der Pflicht der Gebenden zum berechneten Einkommen der Empfangenden im Blick auf unsere eingespielten Vorstellungen von der grundherrlichen Approppriation? Ähnlich bedeutsam ist sicher auch, daß im 9.Jahrhundert der Gütererwerb (Urkunde), die Güter- und Einkünfteverzeichnung (Polyptychon), die Güterverteilung (Traktat Adalhards) und auch Aspekte der Güterherstellung (Capitulare de villis) je eigene Schriftgestaltung gewinnen - ohne daß Verflechtungen zwischen ihnen explizit werden, daß im 12.Jahrhundert sich aber die Belege für ein begründetes Nebeneinander, ja Zueinander innerhalb des gleichen Schriftstücks mehren. Die komplexe Habe, das zersplitterte Renteneinkommen, die einzelnen Empfänger und der lokal verteilte Eigenbau beginnen, sich von kaum verbundenen Teilen zu Dimensionen eines Handlungs- und Wirkungszusammenhangs zu wandeln,

352 Brian Stock, Schriftgebrauch und Rationalität im Mittelalter, in: Wolfgang Schluchter (Hg.), Max Webers Sicht des okzidentalen Christentums. Interpretation und Kritik (Frankfurt/M. 1988) 165-183 (engl. in: ders., Listening for the text: on the uses of the past (Baltimore/London 1990) 113-139).

${ }^{353}$ Lothar Rolke/Stefan Gosepath, Rationalität, Rationalisierung, in: Hist. Wb. d. Philosophie 8 (Darmstadt 1992) 52-66.

354 Stocks Belege setzen zu spät ein (wie Anm.5, s.v. ratio).

355 Fried, Vorbemerkungen (wie Anm. 6) 398-400; ders., Formierung (wie Anm. 5) 146. Der frühe Aufsatz von Alfons Dopsch, Wirtschaftsgeist und Individualismus im Frühmittelalter, in: Archiv f. Kulturgeschichte 19 (1929) 45-76 verdankt sich deutlich wirtschaftsliberaler Projektionen und lebt von ganz anderen Überlieferungsbezügen.

356 Little (wie Anm. 8) $3 \mathrm{ff}$. (dort der Titel: from gift economy to profit economy).

357 Karl Polanyi/Conrad M. Arenberg/Harry W. Pearson (Hg.), Trade and Market in Early Empires. Economics in History and Theory (New York/London 1957). 
mit dem Ziel eines utilis profectus administrationis. Ergänzend dazu macht sich die Beziehung auf Verbrauchs- und Geldvalenzen breit. Zeichnet sich hier die Aufkunft der Denkzusammenhänge ebenso wie die Schriftgestalt des aktiven ,Wirtschaftens' als funktionaler ,Einheit' von Herstellung, Verteilung, Austausch und Verbrauch ab? Nicht zuletzt sei in Erinnerung gebracht, daß Adalhard die Suffizienz zum Angelpunkt seiner Verteilungsregelungen machte. In den Zeugnissen des 11. und 12.Jahrhunderts mehren sich die Belege für die utilitas. Suger aber setzt alles daran, dem Neubau der Klosterkirche durch eine ebenso umsichtige wie rücksichtslose augmentatio reddituum zu dienen. Kann man diese Maximen als Indizien allmählicher Ausbildung von Texturen und Texten des, Wirtschaftens' begreifen? ${ }^{358}$

358 Nachzutragen sind hier einige thematisch einschlägige Neuerscheinungen. Zu Anm. 17: Thomas Hildebrand, Quellenkritik in der Zeitdimension - vom Umgang mit Schriftgut, Anmerkungen zur theoretischen Grundlegung einer Analyse von prozeßhaft bedeutungsvollem Schriftgut mit zwei Beispielen aus der mittelalterlichen Ostschweiz; in FmSt 29 (1995) 349389; zu Anm. 61: Michael Richter, The oral Tradition in the early Middle Ages (Typologie des Sources du Mogue Age Occidental 71, Turukout 1994; zu Anm 257: Enno Bünz, Probleme der hochmittelalterlichen Urbarüberlieferung, in: Werner Rösener $(\mathrm{Hg}$.$) , Grundherrschaft$ und bäuerliche Gesellschaft im Hochmittelalter (Veröff. d. Max-Planck-Instituts f. Geschichte 115, Göttingen 1995) 31-75; Thomas Hildebrand, Herrschaft, Schrift und Gedächtnis. Das Kloster Allerheiligen und sein Umgang mit Wissen in Wirtschaft, Recht und Archiv (11.-16. Jahrhundert) (Zürich 1996); zu Anm. 346: Ludolf Kuchenbuch, Die Achtung vor dem alten Buch und die Furcht vor dem neuen. Cesarius von Meilendonk erstellt 1222 eine Abschrift des Prümer Urbars von 893, in: Historische Anthropologie 3 (1995) 175-202. 